\title{
Social identity, rent-seeking, and redistribution
}

Citation for published version (APA):

Zaunbrecher, H. W. (2021). Social identity, rent-seeking, and redistribution: essays in experimental economics. [Doctoral Thesis, Maastricht University]. ProefschriftMaken. https://doi.org/10.26481/dis.20211028hz

Document status and date:

Published: 01/01/2021

DOI:

10.26481/dis.20211028hz

Document Version:

Publisher's PDF, also known as Version of record

\section{Please check the document version of this publication:}

- A submitted manuscript is the version of the article upon submission and before peer-review. There can be important differences between the submitted version and the official published version of record.

People interested in the research are advised to contact the author for the final version of the publication, or visit the DOI to the publisher's website.

- The final author version and the galley proof are versions of the publication after peer review.

- The final published version features the final layout of the paper including the volume, issue and page numbers.

Link to publication

\footnotetext{
General rights rights.

- You may freely distribute the URL identifying the publication in the public portal. please follow below link for the End User Agreement:

www.umlib.nl/taverne-license

Take down policy

If you believe that this document breaches copyright please contact us at:

repository@maastrichtuniversity.nl

providing details and we will investigate your claim.
}

Copyright and moral rights for the publications made accessible in the public portal are retained by the authors and/or other copyright owners and it is a condition of accessing publications that users recognise and abide by the legal requirements associated with these

- Users may download and print one copy of any publication from the public portal for the purpose of private study or research.

- You may not further distribute the material or use it for any profit-making activity or commercial gain

If the publication is distributed under the terms of Article $25 \mathrm{fa}$ of the Dutch Copyright Act, indicated by the "Taverne" license above, 
"There can be no peace until they renounce their Rabbit God and accept our Duck God." 

Doctoral thesis

\section{SOCIAL IDENTITY, RENT-SEEKING, AND REDISTRIBUTION}

Essays in Experimental Economics

Henrik W. Zaunbrecher 
(c) Henrik W. Zaunbrecher, Maastricht 2021.

All rights reserved. No part of this publication may be reproduced, stored in a retrieval system or transmitted in any form or by any means, electronic, mechanical, photocopying, recording or otherwise, without prior written permission of the author.

Cover and Quote Paul Noth/The New Yorker Collection/The Cartoon Bank Production ProefschriftMaken || Publisher www.proefschriftmaken.nl ISBN 978-94-6423-486-2 


\title{
SOCIAL IDENTITY, RENT-SEEKING, AND REDISTRIBUTION
}

\section{Essays in Experimental Economics}

\author{
Dissertation
}

To obtain the degree of Doctor at Maastricht University, on the authority of the Rector Magnificus, Prof. Dr. R.M. Letschert, in accordance with the decision of the Board of Deans, to be defended in public

on Thursday 28th of October 2021, at 12.00 hours

$$
\text { by }
$$

Henrik W. Zaunbrecher 


\section{Promotor}

Prof. Dr. Arno Riedl

\section{Co-supervisor}

Dr. Jona Linde

\section{Assessment Committee}

Prof. Dr. Alexander Brüggen (Chair)

Prof. Dr. Christine Harbring (RWTH Aachen)

Prof. Dr. Martin Sefton (University of Nottingham)

Dr. Dr. Hannes Rusch 


\section{Acknowledgments}

Doing a PhD is a peculiar task. You learn an incredible amount of new things but you also increasingly doubt that you know anything at all. And because you also pick up a thing or two about statistics, the stuff you actually do learn now comes with confidence intervals.

During my time in Maastricht, I crossed paths with a great number of people whom I owe thanks to. First of all I want to thank my supervisors Arno Riedl and Jona Linde. Arno, you took me on as a research assistant during my masters and were very patient in teaching me the ins and outs of doing research. I remember vividly one of our first meetings where I tried to convince you that developing an analytical solution to a model was pointless when I could just as well find the solution with Solver in Excel. I'm grateful for your very detailed and critical feedback at all stages of my projects. It was invaluable and made all of my projects better. We also often discussed university politics and while we disagreed on some issues, you were supportive of me getting involved in the PhD Committee and Central PhD Platform which is not always the case in other departments or faculties. Jona, you joined the supervision team when most of the projects were already up and running but your comments and fresh perspective helped to resolve some crucial gridlocks in my projects. You always had time to provide feedback, discuss BEElab problems, or just listen to me venting my frustration about teaching or other issues. I also want to thank Tony Williams for being on the supervision team at the beginning of the $\mathrm{PhD}$ and always having an open door to provide advise and feedback or listen to my rants.

I want to thank Alexander Brüggen, Christine Harbring, Martin Sefton, and Hannes Rusch for reading and assessing my thesis and for patiently answering the endless number of emails that it took to schedule the defence.

Special thanks to Johannes Abeler for giving me the opportunity to spent a semester at the University of Oxford. I tremendously enjoyed 
the chance to attend lectures, seminars, and meetings with so many brilliant people from all kinds of fields.

I'm grateful to all the members of the MPE department for providing a great environment to pursue a PhD. Firstly, Elke Lucas for all the support in dealing with the often opaque university administration but even more for the shared small talk and coffee breaks between teaching blocks. Sylvia Beenen, Clemens Kool, David Hoeksema for always trying to accommodate my teaching preferences and helping out with many administrative issues. Martin Strobel, for all the advice, help, and discussions over the years that made you a kind of "shadow supervisor" at times. I'm also grateful to Sasha Vostroknutov for all the advise and fun evenings especially during my research master. Christian Seel for getting me interested in contest games and for making a valiant effort (together with Thomas Demuynck) in getting Riccardo used to Belgian beers.

Thanks to Elias Tsakas for organising the job market training, discussions about basketball, and brainstorming how to teach proofs to psychology students. I'm also very grateful to Max Löffler, Matthias Wibral, Giannis Lois, for providing me with an (air-conditioned) office in the summer periods. As I taught quite a lot of courses I had the pleasure to teach alongside most of my colleagues at the MPE department and I want to give a special thanks to the course coordinators who made this easy, Elias Tsakas, Max Löffler, Peter Werner, Kristoff Bosmans, Dominik Karos, Christian Kerckhoffs, Matthias Wibral, Hannes Rusch, Stefan Terstiege, and Christina Rott. I also want to thank Andrew Mackenzie, Thomas Meissner, Arkadi Predtetchinski, Jean-Jacques Herings, Chris Woolnough, Tse-Ling Teh, Matthew Embrey, for being great colleagues to work with.

Special thanks to Christine Gutekunst, Diogo Geraldes, Mehmet Ismail, Pierrefrancesco Guarino, Fortuna Casoria, Aidas Masiliunas, Evi Nalmpanti, Péter Bayer, Eveline Vandewal, Toygar Kerman, Giang Tran, Fan Rao, Lars Wittrock, David Albrecht, Paul Bokern, Emre Ergin, Aline Meysonnat, Marcia Diaz Claudio, Leticia Rettore Micheli, Mike Langen, Adam Jassem, Elisa Voisin, Michael Grätz, Max Brüning, Olga Meshcheriakova, Mariana Tavares, Johannes Schuffels, Thomas Gemert, 
Alexander Dicks, Alexandra de Gendre, Stefan Dietrich for all the biertjes, coffees, discussions about research, and rants about teaching.

During my PhD I also greatly enjoyed being a member of the $\mathrm{PhD}$ Committee and Central PhD Platform. Thanks to Ulrike Thürheimer, Etienne Wijler, Ruud Wetzels, Jasper Brinkerink, Dinah Guthermuth, Steffi Kohl, Moritz Buchem, Lena Pieper, Samantha Crans, Per Bles, Nina Karthaus, Juan Palacios, Constantijn van Aartsen, Bart Kleine Deters, Angela Mengelers, Marith Dieker, Christine Resch, and Kim van Broekhoven for organising so many events and fighting the good fight! I'm also grateful to Carla Haelermans for improving conditions for the $\mathrm{PhD}$ students of SBE. I would also like to thank Martijn Stroom, who also served on the PhD committee and reminded me on a daily basis how long I've been around. But I mostly want to thank him separately here because he would be upset if he was just a name on a list ;)

I'm deeply thankful to Florian Heine for teaching me the essentials of programming experiments and being a great coauthor. Thanks to Lina Lozano for all the reggaeton parties and Marcello Negrini for teaching us what makes a good pizza. Sharing frustrations and many beers with you made the PhD life much easier. I'd also like to express my gratitude to Anastas Tenev and Jasmine Maes for being great office neighbours, always eager to discuss (and kill) research ideas, and the daily dose of dark humour you provided. I'm grateful to Maria Polipciuc for all the discussions about research, books, many shared beers, and letting me take over her apartment.

I'm deeply thankful to Nickolas Gagnon. You introduced me to the world of craft beers, maple syrup, and organised the social gatherings that glued our department's PhDs together. Your ability to manage an every growing number of projects, churn through new versions of your papers, and still find the time to organize beers or cooking evenings is something I deeply admire.

I could not have asked for a better office mate than the "Myopic Maestro", Riccardo Saulle. I still remember how we spent the whole first day in our (first) joint office discussing cameras and music. We shared many laughs and beers over the years. I don't know if it's a result of the 
reggae music but I envy you for your ability to approach most things in life with a easy-going attitude.

I'm also extremely grateful to have shared an office with Frauke Stehr. Thank you for all the laughs, walks, and discussions about research and German politics. Bantering with you between tutorials is one of the few things that kept me sane when having 8 hour teaching days, even though it was mostly me who got roasted. Your friendship made the lockdown and curfew periods much easier to endure.

I might not have even started the PhD if I had not met Rasmus Lönn during the Research Master. The first week of the Master started with Set Theory, Matrix Algebra, and the realisation for me that nearly everyone else in my cohort had a significant stronger math and statistics background than me. Luckily Rasmus and Peter Thesling took me under their wings and coached me trough the first months of foundational econometrics and math courses. Thanks you for all the drinks, trash-food binges, Media Markt adventures, discussions about politics, research, and life in general, and all your attempts to drag me to the gym at 8AM. People who know me will know that getting me out of bed voluntarily at that time is a rare feat. I' $m$ immensely grateful that you have been such a loyal friend over the last 8 years.

This dissertation would not have been possible without the encouragement and support of my parents Resi and Franz-Josef Zaunbrecher as well as my sister Barbara and her husband Christoph Zaunbrecher. You have been a rock to lean on and I'm eternally grateful to you. Finally, thanks to my partner Sarah for always being supportive of my endeavors and tolerating my often very late night/early morning writing sessions. Your love and support means the world to me.

Henrik W. Zaunbrecher Maastricht, September 2021 


\section{Contents}

Acknowledgments $\quad$ i

1 Introduction 1

2 Declining Wages And Redistribution 9

2.1 Experimental Design . . . . . . . . . . . . . . . . 15

2.2 Hypotheses . . . . . . . . . . . . . . . 20

2.3 Results . . . . . . . . . . . . . . . 22

2.4 Discussion . . . . . . . . . . . . . . . . . . . . . 29

Appendices 33

2.A Instructions . . . . . . . . . . . . . . 34

2.B Screenshots . . . . . . . . . . . . . . . . 41

2.C Random-Effects Tobit regressions . . . . . . . . . . 42

2.D Non-Selfish-individuals giving at least once . . . . 45

2.E Non-Altruists-individuals giving less than 9 Euro . . 47

3 Social Identity and Social Preferences in the Lab 51

3.1 Introduction . . . . . . . . . . . . . . 53

3.2 Experimental Methods . . . . . . . . . . . . . . . 57

3.3 Measurement Approaches and Econometrics . . . . . . 66

3.4 Results . . . . . . . . . . . . . . . 71

3.5 Discussion and Conclusion . . . . . . . . . . 86

$\begin{array}{ll}\text { Appendices } & 89\end{array}$

3.A Instructions . . . . . . . . . . . . . . . 89

3.B Randomization check . . . . . . . . . . . . . . . . 101

3.C Contest Contributions and In-Out Difference . . . . . . 104

3.D Order Effects by Treatment . . . . . . . . . . . . 105

4 Conflict and Migration 107

4.1 Introduction . . . . . . . . . . . . . . . . . . . . . 109

4.2 Experimental Design . . . . . . . . . . . . . . . . 113 
4.3 Theoretical Framework, Equilibrium Benchmark, and Predictions . . . . . . . . . . . . . . . 119

4.4 Results . . . . . . . . . . . . . . . . . . . . . 123

4.5 Discussion and Conclusion . . . . . . . . . . . . . 133

$\begin{array}{ll}\text { Appendices } & 137\end{array}$

4.A Instructions . . . . . . . . . . . . . . . 137

4.B Session overview . . . . . . . . . . . . . . . . . 148

4.C Equilibrium Strategies and Social Identity . . . . . . 148

4.D Equilibrium predictions with social preferences for ingroup and outgroup . . . . . . . . . . . . . . 153

4.E Marginal effect of migration treatments at different levels of migration . . . . . . . . . . . . . 158

4.F Comparing only the migration treatments . . . . . . 159

4.G What explains change in ingroup bias? . . . . . . . . 160

4.H The Role of Beliefs . . . . . . . . . . . . . . . . . . . 161

4.I Individual Regressions - Drivers of the Contribution Decision . . . . . . . . . . . . . . . . . 164

5 General Discussion 169

$\begin{array}{ll}\text { Bibliography } & 171\end{array}$

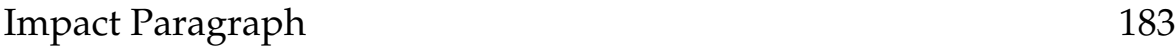

$\begin{array}{ll}\text { Summary } & 185\end{array}$

$\begin{array}{ll}\text { About the author } & 187\end{array}$ 




\section{1 \\ Introduction}

This thesis deals with social preferences, social identity, inequality, and contests. The common theme across the different chapters is that we explore situations in which people fight over, or have to propose how to distribute resources. When this process is not creating new wealth on its own and the parties fighting over the resources have to commit effort or funds to obtain the resources, this process is called rent-seeking. The most common example of rent-seeking behavior is lobbying. Companies lobby governments to grant subsidies, introduce licensing to make market entry for competitors more difficult, grant monopoly rights, or impose tariffs on foreign imports. The money spent on such lobbying activities is not productively used to create additional wealth but rather to obtain special privileges and to redistribute resources. This idea was first developed by Tullock (1967) and got its name "rent-seeking" in later work by Krueger (1974). When modelled as a game, it usually takes the form of a contest in which the participants compete by investing resources to secure a prize.

The reason that economists are concerned with such activities, is that these activities can be seen as a negative sum game, thus reducing the overall welfare in an economy. In his book "The Rise and Decline of Nations" Olson (1982) identifies rent-seeking activities as a key reason 
for differences in economic growth across countries. His thesis is that countries and states that have higher levels of rent-seeking suffer from lower economic growth because special interest groups that seek to maximise resources for their coalition represent frictions that limit the ability of resources to be allocated efficiently. These frictions can take the form of lobbying for barriers to entry, resistance to technological change that would diminish their rent, price controls, or other protectionist efforts.

In chapter 2 of this thesis, we look at the flip-side of Mancur Olson's argument. While Olson argues that distributional conflicts over resources reduce economic growth, we are interested how decreasing absolute and relative growth affects distributive preferences. In a lab experiment, we investigate the effect of absolute and relative wage decreases on individual preferences for redistribution. We find that absolute or relative wage decreases significantly reduce the willingness of people to share with others. Strikingly, this effect is especially pronounced for individuals who have an income that is overall higher compared to the person they are matched with.

While Chapter 2 looks at how two individuals decide to distribute resources, many conflicts over resources in the field, especially high-stake ones, are not decided by individuals but by groups of people such as corporations, political parties, or countries. Sherif et al. (1961) showed that putting children in groups and letting them compete over prizes generated hostility and aggression towards the outgroup. This phenomenon was further formalized by Tajfel and Turner $(1970,1979,1985)$ as social identity theory. They showed that rather minimal conditions, like randomly assigning people into groups based on a coin flip, are sufficient to create ingroup favoritism and outgroup hostility. This research found its way into the field of Economics with the work of Akerlof and Kranton (2000) who show that accounting for a person's social identity can substantially change the predictions of economic models. In the following years, economists have studied the effect of social identity on social preferences, coordination, public good provision, trust, cheating, and conflict (See e.g. Aksoy \& Palma, 2019; Bacine \& Eckel, 2020; Chen \& Chen, 2011; Chen \& Li, 2009; Chowdhury et al., 2016; Eckel \& Grossman, 2005). A popular way to get a clean estimate of the effect 
of social identity, is to create new social identities in the experimental laboratory. This avoids confounds that exist in the field such as self selection into specific groups or group specific characteristics. Both make it difficult to distinguish between the effect that being in "a" group has from the effect that selecting oneself and being into a specific group has and make it hard to generalise the results of field studies.

But to use social identity in the lab, it would be useful to know which methods are best suited to create social identity in the lab without introducing confounding factors and how to measure the strength of social identity. In Chapter 3 we address this by comparing different methods to induce social identity and different econometric approaches to measure its strength in the lab. We find that a one-shot group contest game is successful in inducing social identity as measured by social preferences towards the in- and outgroup irrespective of the measurement approach. However, when the strength of social identity is measured within-subject, all methods are successful in introducing an ingroup bias. Further analysis suggests that the within-subject measurement approach itself might have an effect on the strength of the induced social identity and thus could confound the measurement.

Interestingly, contests are not only a good way to induce social identity, but also likely to be consecutively influenced by the strength of social identity itself. The theoretical model used in chapter 4 predicts that social identity increases contributions in group contests and thus leads to an escalation of conflict. ${ }^{1}$ As these group contests are models of collective rent-seeking, any additional contribution to them leads to an overall welfare loss and is thus undesirable. If being in a group contest induces a social identity and a strong social identity results in higher contest contributions, we potentially have a vicious circle in which the high contributions in the contest game reinforce themselves. However, as the possibility of exclusion and clear group boundaries are

\footnotetext{
${ }^{1}$ The model is adapted from Zaunbrecher and Riedl (2016). The corresponding experiment found a large degree of overcontribution but no difference between the treatment in which we induce identity and the normal group contest. However, the evidence from Chapter 3 suggests that this might be a result of the group contest itself serving as a more powerful social identity induction than the task used in the social identity condition.
} 
an important element of social identity (see e.g. Haslam, 2004; Tajfel \& Turner, 1985), a potential remedy for this overcontribution is the change of the group composition. When the friend of today can be the enemy of tomorrow, and vice versa, people might be less inclined to adopt a strong identification with their group and thus contribute less to the contest. $^{2}$

In chapter 4 we test this by letting two groups compete against each other for a prize and by varying the degree to which migration happens between the groups. In the control treatment, groups are fixed and no changes to the group composition are made. In the endogenous treatment, we let participants decide to switch groups after each round of the contest and implement a subset of these decisions. In the exogenous treatment, we exogenously determine migrations between groups by implementing decisions from the endogenous treatment. We find that the endogenous migration treatment leads to a significant increase in contributions whereas the exogenous migration treatment only leads to a marginal decrease compared to the control treatment without migration. Surprisingly, the ingroup bias in social preference that participants show at the beginning of the experiment stays unchanged over the course of the experiment.

One feature all chapters in this thesis have in common is that they are lab experiments. Economists started to adopt this methodology from social psychologists, as it allows us to study causal effects in an environment in which we can rule out confounders that are usually found in the field or in observational data. A drawback that is often pointed out is that lab experiments lack external validity because students behave differently from other people or because the lab itself is a rather special environment and not comparable with situations in "real life". While there has been a long discussion around the generalizability from students to the general population, the most comprehensive study of different participant pools in the US by Snowberg and Yariv (2021) finds that comparative statics and correlations are very similar across pools. ${ }^{3}$

\footnotetext{
${ }^{2}$ In a related argument, Tajfel and Turner (1979) note that if groups are permeable, individuals from lower status groups will try to disassociate themselves from the group and pursue their own ends.

${ }^{3}$ The most prominent debate about the topic was sparked by a series of articles by
} 
Studies that compare or link experimental and field data also consistently find that experimental results generalize and explain behaviour in the field well across a wide range of domains. ${ }^{4}$

Another way of approaching the external validity issue is to ask if there are alternative methods that allow causal inference without the drawback that the results are potentially less externally valid. The "credibility revolution" in empirical economics popularized methods to perform causal inference on observational data and as a result, economists do not necessarily rely on students and lab experiment anymore to get causal estimates of treatment effects. Under the right circumstances, quasi experimental methods allow us to perform causal inference on observational data, mimicking the performance of an experiment without requiring random assignment of treatments by the experimenter. As the data comes from the field, it is often seen as more externally valid than lab experiments without compromising on internal validity. However, each of these quasi-experimental methods requires strong assumptions about the underlying data of which only some are testable.

Difference-in-Differences designs relies on the assumption of parallel trends. While it is possible to show good covariate balance and parallel trends in the pre-treatment period, we cannot test parallel trends for the counter-factual post-treatment periods in which the treatment did not take place. One could assume that parallel trends pre-treatment extrapolate to the counterfactual post-treatment period but it has been shown that this can be insufficient to recover treatment effects from policy experiments (e.g. Wichman \& Ferraro, 2017). Even when one is willing to make the assumption that trends are parallel, getting clean Difference-in-Differences estimates has been shown to be less straightforward than was assumed just a few years ago. E.g. recent work by

Levitt and List that questioned the generalizability of lab experiments (Levitt \& List, 2007a, 2007b, 2008) and resulted in a large number of critical responses (see e.g. Camerer, 2015; Falk \& Heckman, 2009; Kessler \& Vesterlund, 2015).

${ }^{4}$ See e.g. Riedl and Smeets, 2017 for the link between social preferences and social responsible investments, Potters and Stoop, 2016 for the link between cheating in the lab and the field, Herbst and Mas, 2015 for peer effects on work productivity in the lab and field (Herbst and Mas 2015), Alm et al., 2015 for tax compliance in the lab and field, Armantier and Boly, 2013 for corruption the lab and field. 
Goodman-Bacon (2021) showed that when treatment timing differs between units estimates of the average treatment effects are biased and need adjustment. ${ }^{5}$ Replicating such Difference-in-Differences studies with the necessary adjustments, Baker et al. (2021) shows that the bias can be large enough to reverse the direction of the treatment effect.

For instrumental variable approaches, treatment effects are estimated for compliers-those whose behaviour is changed through the instrument-and thus for external validity we have to make the assumption that the treatment effect for the compliers resembles that of other subpopulations. For internal validity, it is necessary that the instruments are strong enough and that the instruments only affect the outcome through the endogenous variable. However, this is untestable and rarely plausible in situations that would be of interest to economists or only valid in such a specific setting that it limits the external validity. A recent study by Young (2019) has also shown that while researchers usually wish to get a more accurate and unbiased estimate of their treatment effect from using an instrumental variable approach, it hardly ever is efficient enough to reject the original ordinary least squares point estimate and thus it is debatable if a clever instrumental variable approach provides meaningful additional information. Similar arguments can be extended to other approaches such as Regression Discontinuity designs.

While lab experiments sometimes struggle with external validity, alternative causal inference methods require conditions that are relatively rare to achieve in the field and do not necessarily provide more external validity than lab experiments. Especially when we want have high control over the environment and understand underlying mechanisms, lab experiments provide advantages that cannot be replicated in the field. For the phenomena addressed in this thesis, they provide an optimal environment, as they allow us to isolate treatment effects that are usually confounded by other factors in the field.

${ }^{5}$ Which in 2014/15 was true for around half of Difference-in-Differences papers published in the Top 5 journals (Goodman-Bacon, 2021). 




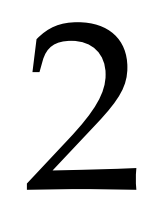

\section{Declining Wages And Redistribution}

Adapted from: Zaunbrecher, H. W., \& Gagnon, N. (2020). Declining wages increase selfish redistribution in an environment with fixed income inequality. GSBE Research Memoranda, (023). 


\section{Abstract}

We use a controlled laboratory experiment to study the causal impact of income decreases on redistribution decisions, in an environment where the income inequality that may be created with wage changes is kept fixed. While many studies examine the effect of income inequality on redistribution decisions, this is the first to isolate the effect of income changes. First, we investigate the role of a decreasing wage compared to one's past wage (intra-personal decrease). Second, we investigate the role of a wage that decreases relative to the wage of another person (inter-personal decrease). We hypothesize that if intra-personal or inter-personal decreases create dissatisfaction for an individual, that person may support redistribution policies that compensates them for the situation. Overall, we find evidence that individuals indeed behave more selfishly when they experience decreasing wages. 
The carriers of value or utility are changes rather than final asset positions

Kahneman and Tversky (1979), Prospect Theory: An Analysis of Decision under Risk

Heterogeneous income growth is a central issue of our times (Milanovic, 2016; Piketty, 2014). In the United States between 1980 and 2004, pretax real incomes have increased by $121 \%$ for the richest $10 \%$, by $42 \%$ for the richest $10-50 \%, 7 \%$ for the richest $50-80 \%$, and decreased by $25 \%$ for the poorest $20 \%$ (Piketty et al., 2018). ${ }^{1}$ At the same time, while understanding the determinants of redistribution is a longstanding priority of economists (Alesina \& Giuliano, 2009), there is surprisingly no study that isolates the possible role of income changes. Nevertheless, a combination of loss aversion and aversion to unequal earning trends could make an individual seek compensation for absolute or relative decreases in earning. Whether this is indeed the case is difficult to establish because income changes are intertwined with potential confounds, e.g., decreasing earnings are naturally intertwined with decreasing absolute incomes and changing levels of income inequality. Drawing on the tradition of controlled laboratory experiments isolating the influence of income inequality on redistribution (e.g., Bolton and Ockenfels, 2000; Fehr and Schmidt, 1999), our study offers the first evidence that earnings decreases indeed affect redistribution decisions, even after controlling for one's absolute income and for income inequality. ${ }^{2}$

${ }^{1}$ Comparable pictures emerge in other countries, more moderate in Europe and more extreme in Asia (Alvaredo et al., 2017). Some of this heterogeneity is spatial: against the backdrop of economic growth at the national level in the United States, several major industrial hubs experienced striking declines in average household incomes since the 1970s, e.g., Buffalo (-23\%), Cleveland (-32\%), and Detroit $(-35 \%)$ (Hartley, 2013). Other differences in the evolution of incomes are based on education (Goldin \& Katz, 2007), gender (Blau \& Kahn, 2017), and ethnicity (Bayer \& Charles, 2018).

${ }^{2}$ In terms of external validity, preferences elicited in experiments correlate with political support for redistributive policies at the societal level (e.g., Almås et al., 2020; Epper et al., 2020; Fisman et al., 2017; Kerschbamer and Müller, 2020). Social preferences elicited in experiments have also been shown to correlate with behavior outside of those experiments in other domains, such as loan repayments (Karlan, 2005), donations and other pro-social behaviors (Baran et al., 2010; Benz \& Meier, 
Studies have shown that individuals are especially averse to losses relative to a reference state (e.g., Kahneman and Tversky, 1979, Genesove and Mayer, 2001, and Rizzo and Zeckhauser, 2003) and that they dislike decreasing wage trends (Loewenstein \& Sicherman, 1991). One might be especially irate at an absolute or even relative wage decrease and seek compensation for it-irrespective of the income inequality engendered by the wage change. However, whether this is indeed the case or not is still unknown because income changes in observational data are intertwined with a myriad of potentially confounding factors, such as levels of income inequality and geographical or socio-demographic differences between those with increasing and decreasing incomes. We therefore isolate the role of income changes on redistribution decisions in an experiment.

We designed a laboratory experiment in which individuals complete real-effort tasks for wages that are exogenously assigned to them. The treatments that we implement vary the intra-personal and interpersonal wage changes faced by two matched participants over two periods. The wages are taxed and, after each treatment, each of the two participants individually decides how the money deducted from the wages of both participants is redistributed among them. We then implement one decisions per matched pair of participants. Crucially, we keep income inequality fixed in all treatments, only varying the wage changes. This feature allows us to make causal inferences between wage decreases and redistribution behavior.

Our contention that wage decreases can influence redistribution decisions is rooted in the large number of studies documenting different forms of reference dependence as well as loss aversion. Research on reference-dependent preferences has long modeled the dislike of individuals for losses relative to an intra-personal reference state (Kahneman \& Tversky, 1979; Kőszegi \& Rabin, 2006; Tversky \& Kahneman, 1991). Empirical research suggests that the behavior of workers is consistent with a dislike for falling behind one's earnings goals (Camerer

2008; Franzen \& Pointner, 2013), work productivity (Cohn et al., 2015), and sociallyresponsible investments (Riedl \& Smeets, 2017). Moreover, Snowberg and Yariv, 2021 provide evidence that students and the general population behave similarly in qualitative terms for a range of common experimental measures. 
et al., 1997; Crawford \& Meng, 2011), behind one's expectations (Abeler et al., 2011; Mas, 2006), and behind one's own past income (Cohn et al., 2015; DellaVigna et al., 2017). Loewenstein and Sicherman (1991) also report that individuals prefer increasing wage profiles to equivalent decreasing ones. ${ }^{3}$ Relatedly, self-reported well-being is lower when one's living standard decreases over time (Clark et al., 2008; Senik, 2009). However, none of these studies analyze the impact of wage decreases on redistribution decisions.

Moreover, inequality aversion models (Bolton \& Ockenfels, 2000; Fehr \& Schmidt, 1999) posit that individuals dislike to have less than others. In other words, individuals dislike to fall behind an inter-personal reference point, i.e., falling behind others. ${ }^{4}$ This literature often studies inequality aversion in contexts where income changes and income inequality are bundled together. For instance, Cohn et al., 2014, Breza et al., 2017, and Dube et al., 2019 study the effect of wage inequality on labor decisions, in a context where wage inequality appears after a period of wage equality between workers. Similarly, Kuhn et al., 2011 analyze changes in consumption after one's neighbor wins at a lottery. However, these studies cannot isolate the effect of wage changes from the effect of the income inequality that they create.

A key component of our investigation is the causal relationship that we obtain between wage decreases and redistribution decisions, which is provided by the controlled environment of a laboratory experiment. This methodology provides three main advantages. First, we randomly

${ }^{3}$ The same effect has been shown for other contexts such as experiences (Ross \& Simonson, 1991), environmental outcomes (Guyse et al., 2002), and health (Chapman, 1996).

${ }^{4}$ These models also posit that individuals dislike to have more than others, although to a lesser extent than they dislike to have less. We focus on disadvantageous inequality here for two reasons. First, disadvantageous inequality is assumed to be stronger in these models and a large number of empirical studies have gathered evidence supporting its existence. Second, our research is closely linked to research on loss aversion, which considers that individuals are especially sensitive to losses. The empirical evidence includes observational research (Clark \& Oswald, 1996; Luttmer, 2005; Solnick \& Hemenway, 1998), natural experiments (Card et al., 2012; Kuhn et al., 2011), field experiments (Breza et al., 2017; Cohn et al., 2014; Dube et al., 2019) as well as laboratory experiments (Bolton \& Ockenfels, 2000; Fehr \& Schmidt, 1999) and experiments with the general population (Bellemare et al., 2008). 
assign wage changes, which precludes that individuals experiencing different changes do so because of different underlying individual characteristics. Second, crucially, we can study wage changes without changing the overall income inequality. That is, we cleanly separate the role of income decreases from the role of disadvantageous income inequality. Third, our design rules out a role of expectations regarding future wages that income changes might create, which in turn is likely to affect redistribution decisions (Alesina \& La Ferrara, 2005; Bénabou \& Ok, 2001).

We find evidence that individuals behave more selfishly when they experience decreasing wages. Pooling together participants who earn more (High Earners) and participants who earn less (Low Earners), we find that they share significantly less when they face decreasing wages than other types of wage trends that we explore. Specifically, High Earners share significantly less with the other participant following an intra- or an inter-personal reduction in their wages. Low Earners share less after a combined intra- and inter-personal decline in their wage, although only at marginally significant levels. The effect size is between $-6 \%$ and $-8 \%$, which is quite considerable given the relatively short time span in which the participants experience the wage decrease. We do not find statistical differences between the effects of intra- and inter-personal wage decreases. Given that previous studies have shown that elicited social preferences correlate with political support for redistributive policies (e.g., Almås et al., 2020; Epper et al., 2020; Fisman et al., 2017; Kerschbamer and Müller, 2020), our results suggest that declining absolute or relative wages could contribute to the support for redistributive policies aiming to rectify those declines.

The rest of the paper is structured as follows: First, we introduce the experimental design. Second, we advance the hypotheses. Third, we present the empirical analyses and the results. Fourth, we conclude by briefly discussing implications of our findings for the literature and for public policies. 


\subsection{Experimental Design}

The experiment consists of five periods. In a period, two participants are anonymously matched. A period consists of two sub-periods in which participants perform a real-effort task and ends with a redistribution decision.

The real-effort task in every sub-period is to reduce the size of four circles on the computer screen until they disappear. This is done by repeatedly clicking on a circle with the mouse while it moves across the screen. Only one circle appears at a time, and each click on it slightly decreases its size. A new circle appears once a circle completely disappears. ${ }^{5}$ Participants have four minutes to complete the task, which can be completed easily by exerting a reasonable effort (most participants take approximately two minutes to finish the task). They are provided with a countdown and with a record of how many circles they have completed so far. Figure 1 provides a screenshot of the task as experienced by participants in sub-period 2. Note that, in the experiment, we call circles "balls" and that we provide participants with the reminder that they need to reach a "Ball Threshold" of four to indicate that they need to make four circles disappear in order to earn the wage.

At the start of a period, participants are informed of their wage for the first sub-period a few seconds before the first sub-period starts. During a period, they monitor how their own wage and the wage of their matched partner changes over the two sub-periods. This information is visualized through one graph exhibiting one's own wages and the wages of the other participant over the period up to the current subperiod. That is, participants see the wages in the current sub-period, and if they are in the second sub-period, they also see the wages from the previous sub-period. In addition to providing a screenshot of the task, Figure 2.1 also shows how participants see the wage change in sub-period 2. The screen presents the wage information from the first sub-period on the left part of the graph, and from the second sub-period on the right part of the graph. Participants have an additional minute

\footnotetext{
${ }^{5}$ Participants are not paid more if they complete more than four circles. The task is a modified version of the one developed by Cacault and Grieder (2019).
} 


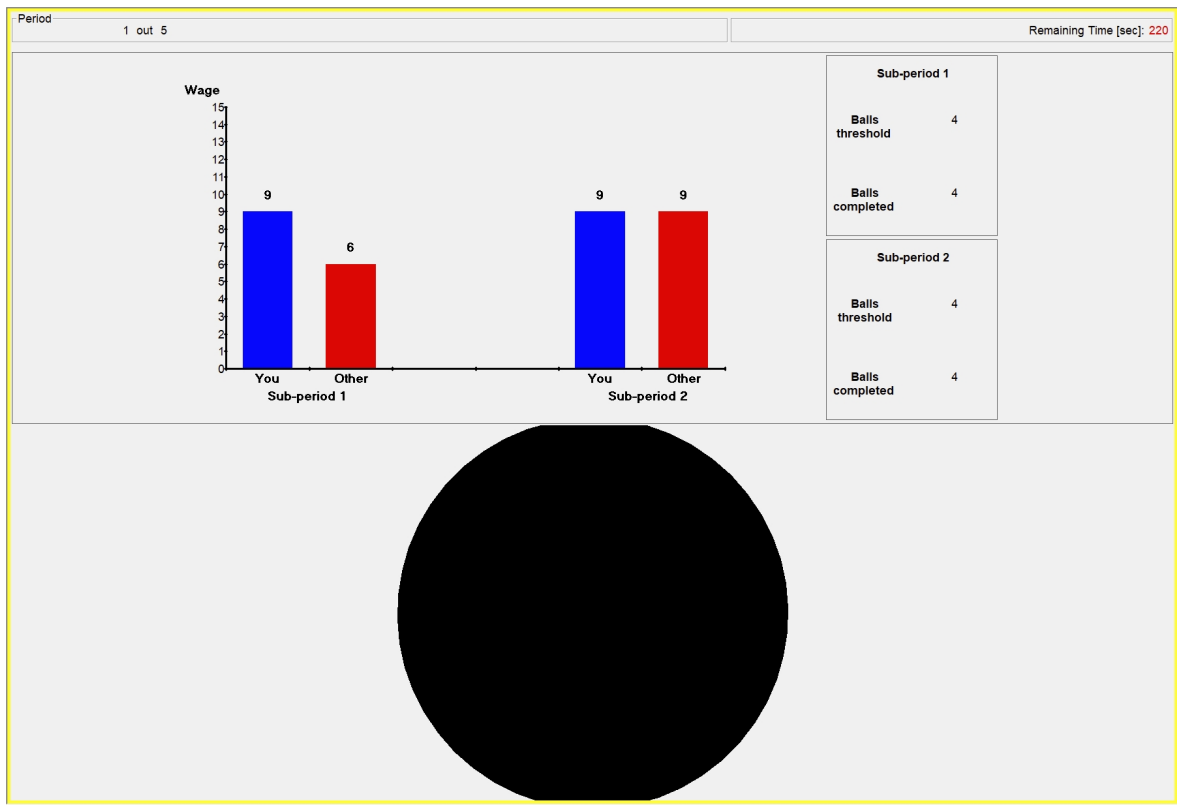

Figure 2.1: Screenshot of task in sub-period 2 (C A T C HIN G UP treatment)

to rest in between the two sub-periods. A few seconds before the second sub-period starts, they are informed about any wage changes that occur between the sub-periods.

The participants are paid the two wages of a period-one for each of the two sub-periods-only if they complete the task in both sub-periods. ${ }^{6}$ A third of each wage that they earn during the two sub-periods is taken from them as tax and placed in a joint account. That is, the joint account contains a third of the two wages of one participant, and a third of the two wages of the other participant. ${ }^{7}$

\footnotetext{
${ }^{6} \mathrm{~A}$ participant is paid nothing for a period if the task in one of the two sub-periods is not completed. However, we set the wage high enough relative to the effort required for the task so that this only affected 2 out of 298 participants. We excluded these participants and their matched participants because the matched participants could see that those did not complete the task. Therefore, a total of 4 participants were dropped for the data analysis.

${ }^{7}$ To ease the explanation for participants, we phrase the parts of the income taken as taxes and the distribution decisions as a redistribution of taxes collected. We
} 
At the end of each period, the two participants individually are asked to individually propose how to distribute the money contained in the joint account. This is implemented through a dictator game with role uncertainty. That is, one of the two choices is randomly chosen to count for the implementation of the redistribution. The money in the joint account always amounts to 11 Euro. Participants can keep the entire joint account for themselves, transfer its content to the other participant, or chose any in-between allocation in increments of 10 cents. ${ }^{8}$ Participants then take a two-minute break before the next period starts. They are not informed about the choice of the other participant. At the end of the experiment, one of the two participants' choices from one period is randomly chosen to count for payment.

We employ five treatments that we implement within-subject, thus each participant participates in all five treatments over the 5 periods of the experiments. The treatments vary the wage changes faced by participants between the first and second sub-period of a period. A participant is always in the role of either the High Earner or the Low Earner. ${ }^{9}$ In the first role (High Earner), a participant always experiences advantageous income inequality over the period. The sum of the two wages in a period is always 18 Euro. Similarly, the Low Earner always faces disadvantageous income inequality over the period-the sum of the two wages is always 15 Euro. Crucially, this allows us to maintain the same income inequality over the period in all treatments, such that income inequality cannot explain any treatment differences. ${ }^{10}$

We chose a within-subject design in order to increase statistical power (Bellemare et al., 2016). Table 1 details the wages of Low Earners and High Earners over the two sub-periods in the five treatments. The order

collect a fix percentage of income to make it easier for participants to understand and calculate how much was taken from them.

${ }^{8}$ Appendix 2.4 provides a screenshot showing how the redistribution decision is presented to participants.

${ }^{9}$ Participants are not informed that they stay in their role for the experiment.

${ }^{10} \mathrm{~A}$ possible alternative design could have been to impose income equality over the period in all treatments. However, we found it natural to create income inequality over each period, as income inequality is common outside of the laboratory. 
Table 2.1: Treatments overview

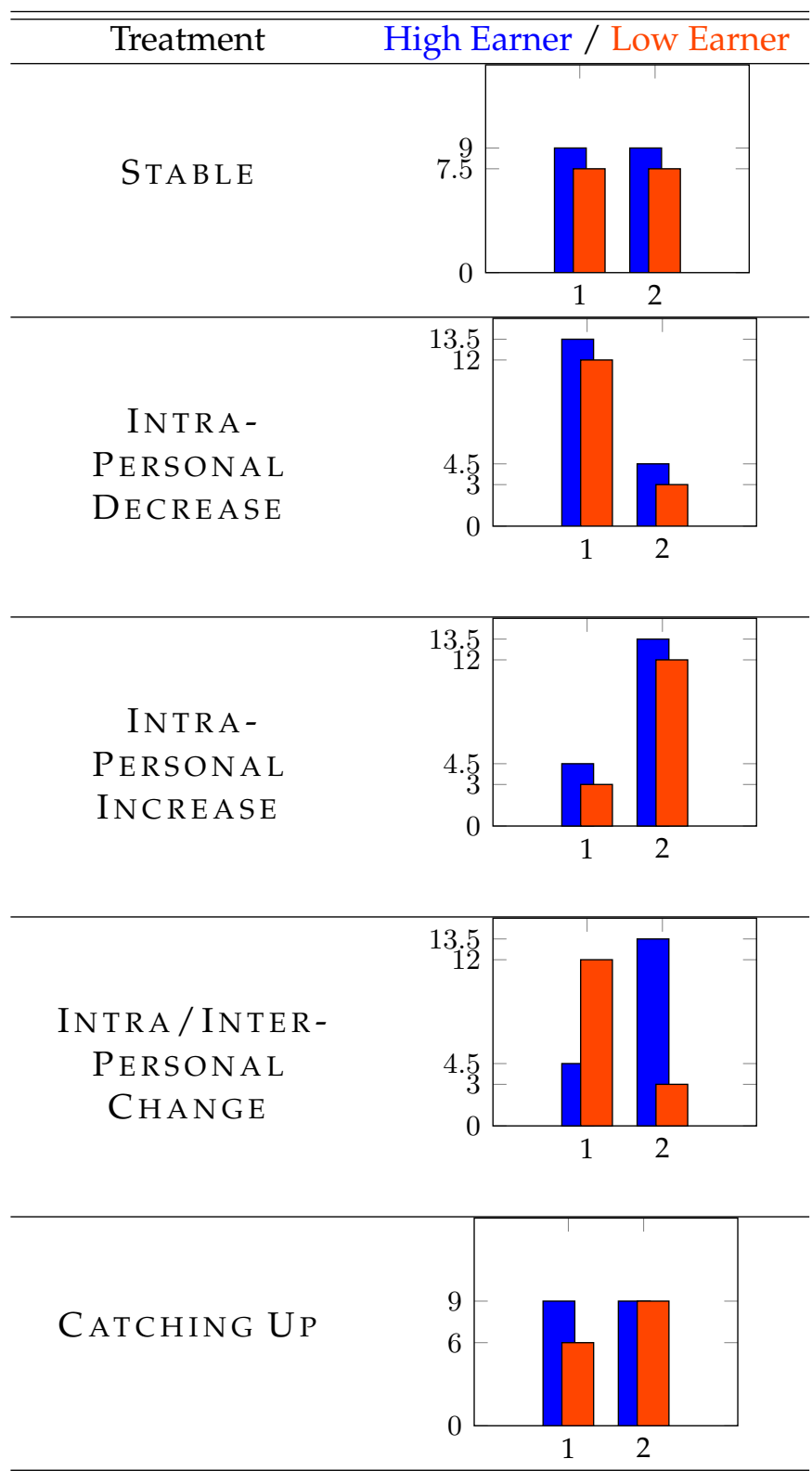

Wages are indicated on the vertical axis in Euro, and the two subperiods of a period are indicated on the horizontal axis. Income inequality is constant over the period: incomes are 15 Euro for the Low Earner and 18 Euro for the High Earner. 
of treatments is randomized. ${ }^{11}$ As we are interested in studying individual responses to absolute and relative wage decreases, we designed the following treatments varying wages changes. Note that while those treatments do not cover the whole universe of possible wage changes, they do provide a diverse set of them to study possible effects of declining wages. Those include stable wages as well as an increasing wage profile. In STABLE, the wage of each participant remains constant in the two sub-periods. In INTRA-PERSONAL DECREASE and INTRA-PERSONAL INCREASE, both participants face either an absolute wage increase or decrease. This allows us to study the effects of intra-personal wage changes. In INT R A / INTER-PERSONAL $\mathrm{CH}$ ANGE, the Low Earner experiences a wage decrease while the HighEarner experiences a wage increase. The wage changes are therefore both absolute and relative for the two participants. In CATCHING $\mathrm{UP}$, the wage of the Low Earner increases, while the wage of the High Earner is constant. That is, the High Earner encounters a relative wage decrease-the Low Earner is "catching up" with the High Earner.

Before starting the experiment, the experimenter reads the instructions aloud and participants are provided with a written copy detailing all steps of the experiment. ${ }^{12}$ After reading the instructions, participants complete comprehension questions, and help is provided if needed. They also go through a practice period, which is a shorter version of a real period, so that they become familiar with the proceedings of a period. This practice period includes the task and the redistribution decision, but does not count for payment. In it, each participant has the same wage, which stays constant of the two sub-periods.

In terms of participant matching, participants are informed that they are paired with a participant in the same laboratory session in each period.

${ }^{11}$ There are 120 possible orders (5!). We overly sample from a random subset of the orders due to a software problem. That is, approximately $70 \%$ of the orders are randomly drawn from a random subset of 30 orders - the subset itself is a random selection from the 120 orders-and the remaining $30 \%$ is randomly drawn from the 90 other orders. Conducting the data analysis separately for each of those two sub-samples qualitatively provides the same results.

${ }^{12}$ We provide the original instructions as well as important screenshots of the experiment in the Appendix. 
The experiment was designed using the software $z$-Tree (Fischbacher, 2007). It was conducted at the BEElab (Behavioural and Experimental Economics Laboratory) of Maastricht University. Our sample consists of 294 participants recruited over 16 sessions via the online recruitment software ORSEE (Greiner, 2015). ${ }^{13}$ The experiment lasted for about 90 minutes and participants earned 16.50 Euro on average.

\subsection{Hypotheses}

We posit that, if individuals face a wage decrease, they experience disutility and take from others to be compensated. We also assume that two forms of disutility are created by wage decreases. The first is intrapersonal disutility created from an absolute wage decrease because individuals are loss averse with respect to their past wage. That is, they take their past wage as the reference state, and deviations below this reference point create disutility. The second is inter-personal disutility created from a relative wage decrease. Individuals take the wage change of others as the reference state and they are loss averse with respect to this change-a decrease relative to the wage changes of others creates disutility. We do not explicitly model this process. Rather, we directly test whether individuals give less or take more from others when they experience intra- and inter-personal declining wages.

High Earners face an absolute wage decrease in INTRA-PERSONAL DECREASE and a relative wage decrease in CATCHING UP. In contrast, they experience no decrease in STABLE, INTRA-PERSONAL INCREASE, and INTRA / INTER-PERSONAL CHANGE. We therefore predict the following, which does not distinguish between absolute and relative wage decrease.

Hypothesis 1. High Earners give less in INTRA-PERSONAL DECREASE and CATCHING UP than in STABLE, INTRA-PERSONAL INCREASE, and INTRA / INTER-PERSONAL CHANGE.

\footnotetext{
${ }^{13}$ See footnote 6 explaining that four additional participants are not counted in our sample.
} 
Low Earners encounter an absolute wage decrease in INTRAPERSONAL DECREASE and an absolute and relative decrease in INTRA / INTER-PERSONAL CHANGE. In contrast, their wage is constant in the STABLE treatment. Moreover, they experience no wage decrease in INTRA-PERSONAL INCREASE and CATCHING U P. We posit that Low Earners compensate their absolute and relative decreasing wage by taking more from others, and therefore make the following predictions for them.

Hypothesis 2. Low Earners give less in INTRA / INTER-PERSONAL CHANGE and INTRA-PERSONAL DECREASE than in STABLE, INTRA-PERSONAL INCREASE, and CATCHING UP.

Low Earners face an absolute decrease as well as a relative wage decrease in INTRA / INTER-PERSONAL CHANGE, and at most an absolute decrease in the other treatments. Therefore, we also make the following prediction.

Hypothesis 3. Low Earners give less in INTRA / INTER-PERSONAL CHANGE than in INTRA-PERSONAL DECREASE, STABLE, INTRA-PERSONAL INCREASE, and CATCHING UP.

Similarly, since for Low Earners there is only an absolute income decrease in INTRA-PERSONAL DECREASE, we make the following more precise prediction-which isolates the additional effect of relative income decrease.

Hypothesis 4. Low Earners give less in INTRA / INTER-PERSONAL CHANGE than in INTRA-PERSONAL DECREASE.

In addition, Hypotheses 2-4 taken together imply a specific ordering of the treatments, namely that Low Earners give less in INTRA / INTERPERSONAL CHANGE than in INTER-PERSONAL DeCREASE, and less in INTER-PERSONAL DECREASE than in STABLE, INTER-PERSONAL INCREASE, and CATCHING UP. Thus we can also test these hypotheses jointly. 


\subsection{Results}

We first provide summary statistics and then test our hypotheses. Thereafter we report the results of two robustness checks: First, only considering participants who give at least once, and second, dropping those individuals who give almost everything.

\section{Summary Statistics}

Table 2.2 presents the average amount from the 11-Euro joint account that participants give to the other participant. We provide the data for all participants and then for those participants whom we call nonselfish, i.e., those who give a positive amount in at least one period. If we look at all participants, we see that mean giving is 1.53 Euro (SD = 2.23 Euro) or $14 \%$ of the joint account. High Earners are generally a little more generous than Low Earners. High Earners appear to be slightly less generous in the CATCHING UP and INTRA-PERSONAL DECREASE than in other treatments. Low Earners are less generous in INTRA / INTER-PERSONAL CHANGE than in other treatments. If we only look at the non-selfish participants, we observe the same patterns.

Compared to dictator games in general, average giving in our experiment is on the lower side of the spectrum found in the literature (see meta-study by Engel (2011) and comment by Zhang and Ortmann (2014); average giving in the dictator game is $28.3 \%$ ). Some factors present in our study have been shown to reduce generosity, namely using a student sample, endowing recipients, repeating the game, dictators earning the money that they can redistribute, and the option of taking money from others, but it has also been shown that having deserving recipients who earned the money that the dictator redistributes can increase giving. Moreover, role uncertainty about who will give and who will receive has also been shown to increase pro-sociality in dictator games (Iriberri \& Rey-Biel, 2011).

Figure 2.2 shows the cumulative distribution of the amounts given, separately for High Earners and Low Earners. There is extensive lowerbound censoring: Participants give nothing in $56 \%$ of the decisions $(59 \%$ 
Table 2.2: Summary statistics

\begin{tabular}{|c|c|c|c|c|}
\hline \multirow[b]{3}{*}{ Treatment } & \multicolumn{4}{|c|}{ Amount given } \\
\hline & \multicolumn{2}{|c|}{ All participants } & \multicolumn{2}{|c|}{ Non-selfish participants } \\
\hline & $\begin{array}{l}\text { High Earners } \\
\text { Mean (SD) }\end{array}$ & $\begin{array}{c}\text { Low Earners } \\
\text { Mean (SD) }\end{array}$ & $\begin{array}{l}\text { High Earners } \\
\text { Mean (SD) }\end{array}$ & $\begin{array}{c}\text { Low Earners } \\
\text { Mean (SD) }\end{array}$ \\
\hline STABLE & $\begin{array}{c}1.62 \\
(2.35)\end{array}$ & $\begin{array}{c}1.49 \\
(2.18)\end{array}$ & $\begin{array}{c}3.05 \\
(2.46)\end{array}$ & $\begin{array}{c}2.46 \\
(2.34)\end{array}$ \\
\hline INTRA-PERSONAL & 1.57 & 1.48 & 2.96 & 2.45 \\
\hline DECREASE & $(2.42)$ & $(2.15)$ & $(2.64)$ & $(2.31)$ \\
\hline INTRA-PERSONAL & 1.63 & 1.45 & 3.07 & 2.40 \\
\hline INCREASE & $(2.39)$ & $(2.13)$ & $(2.53)$ & $(2.30)$ \\
\hline INTRA / INTER-PERSONAL & 1.62 & 1.42 & 3.06 & 2.35 \\
\hline CHANGE & $(2.34)$ & $(2.03)$ & $(2.44)$ & $(2.15)$ \\
\hline \multirow[t]{2}{*}{ CATCHING UP } & 1.41 & 1.58 & 2.65 & 2.61 \\
\hline & $(2.20)$ & $(2.15)$ & $(2.42)$ & $(2.23)$ \\
\hline$N$ & 147 & 147 & 78 & 89 \\
\hline
\end{tabular}

Note: Participants could give any amount between 0 and 11 Euro from the 11-Euro joint account. The remaining amount was credited to their own account.

for High Earners, 53\% for Low Earners). Thus, the low average sharing across treatments is strongly driven by the large number of participants exhibiting fully selfish behavior. Moreover, participants share no more than 1 Euro in $68 \%$ of decisions.

\section{Hypothesis Testing}

Table 3 reports non-parametric tests of each of our four hypotheses. The upper part concerns High Earners (Hypothesis 1); the lower part concerns Low Earners (Hypotheses 2-4). The tests that we employ are mostly Wilcoxon signed-rank tests (WSR). We also make use of the rank-based Page test (Page, 1963), in which the null hypothesis is that the amount given is the same in all treatments, whereas the alternative hypothesis is that the amount given follows a pre-specified treatment order. When we compare sets of treatments, we compare average giving per individual in one set of treatments with average giving per individual in the other set of treatments. Since our hypotheses are directed, we always use one-sided tests in the predicted direction. ${ }^{14}$

\footnotetext{
${ }^{14} \mathrm{To}$ account for censoring and to provide a parametric alternative specification, we also conducted random-effects Tobit regressions, which employ a dummy for the
} 


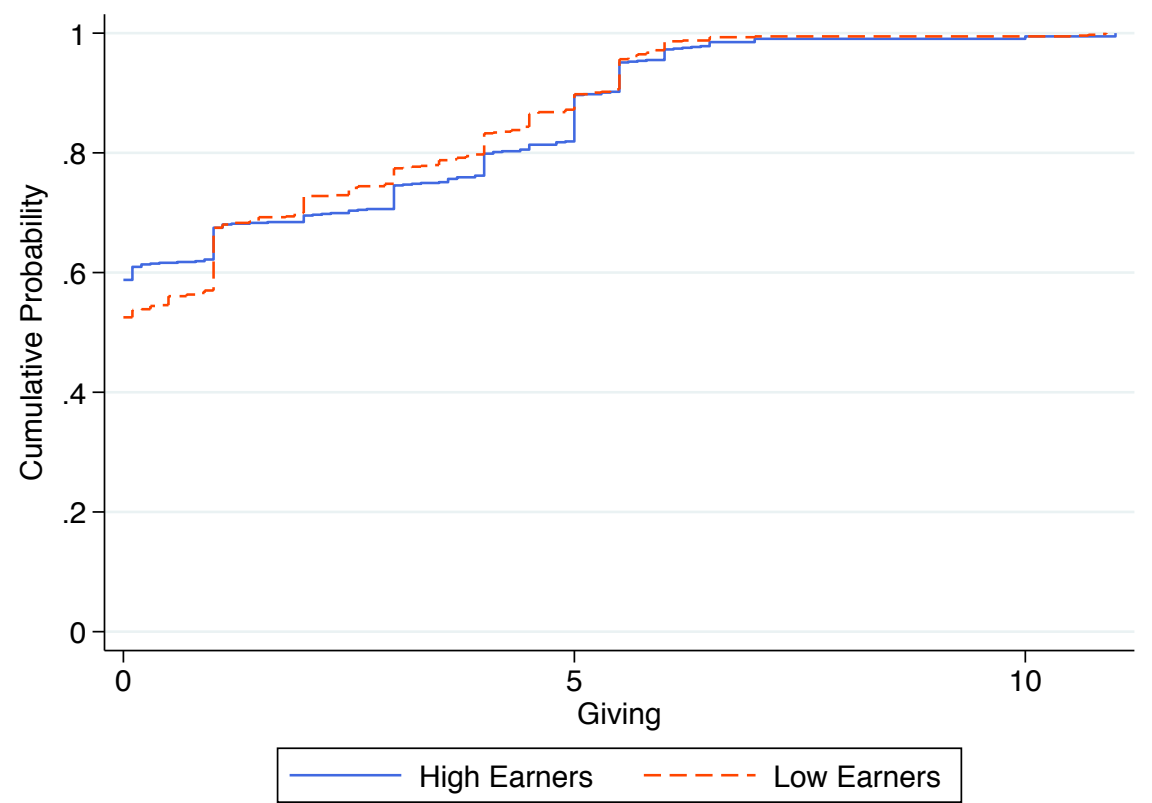

Figure 2.2: Cumulative distribution functions of giving 
Table 2.3: Tests of hypotheses

\begin{tabular}{|c|c|c|c|}
\hline & High Earners & $\begin{array}{l}\text { Change in } \\
\text { giving }\end{array}$ & $\begin{array}{l}\text { One-sided } \\
p \text {-value }\end{array}$ \\
\hline H1 & $\begin{array}{r}\text { CATCHING UP, } \\
\text { INTER-PERSONAL DECREASE }< \\
\text { STABLE, } \\
\text { INTER-PERSONAL INCREASE, } \\
\text { INTRA / INTER-PERSONAL CHANGE }\end{array}$ & $\begin{array}{c}-0.14 \text { Euro } \\
(-8.38 \%)\end{array}$ & 0.017 \\
\hline \multicolumn{4}{|c|}{ Low Earners } \\
\hline $\mathrm{H} 2$ & $\begin{array}{r}\text { INTRA / INTER-PERSONAL CHANGE, } \\
\text { INTRA-PERSONAL DECREASE }< \\
\text { STABLE, } \\
\text { INTRA-PERSONAL INCREASE, } \\
\text { CATCHING UP }\end{array}$ & $\begin{array}{c}-0.05 \text { Euro } \\
(-3.61 \%)\end{array}$ & 0.101 \\
\hline H3 & $\begin{array}{r}\text { INTRA / INTER-PERSONAL CHANGE }< \\
\text { StABle, } \\
\text { INTRA-PERSONAL DECREASE, } \\
\text { INTRA-PERSONAL INCREASE, } \\
\text { CATCHING UP }\end{array}$ & $\begin{array}{c}-0.08 \text { Euro } \\
(-5.33 \%)\end{array}$ & 0.052 \\
\hline $\mathrm{H} 4$ & $\begin{array}{r}\text { INTRA / INTER-PERSONAL CHANGE }< \\
\text { INTRA-PERSONAL DECREASE }\end{array}$ & $\begin{array}{c}-0.06 \text { Euro } \\
(-4.22 \%)\end{array}$ & 0.484 \\
\hline $\begin{array}{l}\text { Joint } \\
\mathrm{H} 2-4\end{array}$ & 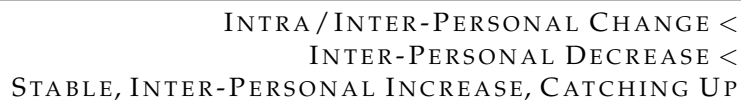 & & 0.076 \\
\hline
\end{tabular}

Note: Change in giving corresponds to the difference in Euro and percentage distributed to the other participant from the 11-Euro joint account between different sets of treatments. In line with the directed nature of the hypotheses, for H1-4 we report one-sided $p$-values of non-parametric Wilcoxon signed-rank tests (WSR). Furthermore, we report the one-sided $p$-value for a joint test of H2-4. We use Page's test for ordered alternatives which evaluates whether population means follow a pre-specified order. For both WSR and Page tests, we average giving per individual over each of the two treatment sets under consideration.

\section{For High Earners we predicted in Hypothesis 1 that those experiencing}

set of treatments of interest and combine the other treatments in the baseline. However, we rely on the non-parametric results for our analysis because an inspection of the residuals of an equivalent linear regression suggests a violation of the assumption that standard errors are normally distributed aside from the violation created by the lower-bound censoring. Table 2.C.2 of the Appendix 2.C details the regression specifications for the Tobit regressions. For completeness, Appendix 2.C also reports results from random-effects Tobit regressions where we include individual treatment dummies and employ the STA B LE treatment as reference group. 
the decreasing absolute or relative wage-in the treatments INTRAPERSONAL DECREASE and CATCHING UP-would give less to the other participant, compared to what they give in the combined other treatments. We find that, indeed, those High Earners whose wage decreased over the period become less generous. As indicated in the first row of Table 3, the effect is significant at the 5\% level (WSR $p$-value $=0.017)$. Moreover, we cannot statistically distinguish between the effects of intra- and inter-personal wage decreases on giving (INTRAPERSONAL DECREASE vs. CATCHING UP, WSR $p$-value $=0.458)$. We can also analyze the effect of the two decreasing-wage treatments separately. The reduction in giving induced by an intra-personal wage decrease (INTRA-PERSONAL DECREASE) and the reduction in giving induced by an inter-personal wage decrease (C ATC HING UP) relative to the treatments without any wage decreases are both significant $($ WSR $p$-value $=0.007 ;$ WSR $p$-value $=0.001$, respectively).

For Low Earners, we formulated three hypotheses. Hypothesis 2 states that those participants who experienced wage decreases-in the treatments INTRA-PERSONAL DECREASE and INTRA / INTERPERSONAL CHANGE-share less with the other participant, relative to the combined other treatments. We find only weak evidence that the combined decreasing-wage treatments reduce the amount given (WSR $p$-value $=0.101)$. Then, Hypothesis 3 states that Low Earners who specifically experienced the combined intra- and inter-personal wage decrease-in treatment INTRA/INTER-PERSONAL CHANGEbecome less generous than in all other treatments combined. Our tests find support for this contention at marginal significance levels (WSR $p$-value $=0.052$ )

Hypothesis 4-that Low Earners give less when facing the combined intra- and inter-personal wage decrease than when facing the intrapersonal wage decrease-is not supported. That is, giving is not significantly lower in INTRA / INTER-PERSONAL CHANGE than in INTRA-PERSONAL DECREASE (WSR $p$-value $=0.484)$.

Our three hypotheses regarding Low Earners (Hypotheses 2-4) can be combined into a single extensive hypothesis, which is reported in the last row of Table 3. We use a Page test to evaluate the null hypothesis 
that the amount given is the same in all treatments, relative to the alternative hypothesis that the amount given follows the pre-specified treatment order. When evaluated in this manner, we find some (limited) evidence that Low Earners compensate their decreasing wage by giving less to the other participant ( $p$-value $=0.076$ ). Finally, Table 2.4 shows that we find highly significant evidence of the negative effect of decreasing wages on giving when we pool High Earners and Low Earners together, and evaluate whether they give less when they face decreasing absolute or relative wages $(p$-value $=0.007)$.

Table 2.4: Analysis for Low and High Earners pooled together

\begin{tabular}{ccc}
\hline \hline & $\begin{array}{c}\text { Change in } \\
\text { giving }\end{array}$ & $\begin{array}{c}\text { One-sided } \\
p \text {-value }\end{array}$ \\
\hline DECREASING < OTHER & $\begin{array}{c}-0.10 \text { Euro } \\
(-6.09 \%)\end{array}$ & 0.007 \\
& & \\
\hline \hline
\end{tabular}

Note: Change in giving corresponds to the difference in Euro and percentage. The set DECREASING contains treatments CATCHING UP and INTRA-PERSONAL DECREASE for High Earners, and INTRA / INTER-PERSONAL CHANGE and INTRA-PERSONAL DECREASE for Low Earners. The set OTHER contains all treatments excluded from DECREASING for High and Low Earners. We report one-sided $p$-values of non-parametric Wilcoxon signed-rank test (WSR). Giving is averaged per individual over each of the two treatment sets under consideration.

Result 1. High Earners: Participants become more selfish when facing decreasing wages in comparison to other wage trends. This holds both for intrapersonal wage decreases and for inter-personal wage decreases (supports Hypothesis 1).

Result 2. Low Earners: (a) Participants become more selfish when facing combined intra-personal and inter-personal decreasing wages than when facing other wage trends - at marginally significant levels (supports Hypothesis 3). (b) The combined intra- and inter-personal wage decrease treatment and the intra-personal wage decrease treatment together only decrease giving at near marginally significant levels (only qualitatively supports Hypothesis 2), 
although (c) the (non-)effect of intra-personal wage decreases is statistically indistinguishable from the effect of the combined intra-personal and interpersonal decreasing wages (does not support Hypothesis 4).

We conduct two additional analyses. First, we consider whether our results are similar when we examine only participants who give at least once, i.e., whose behavior is not always censored. We do find very similar results (see Appendix 2.D), which suggests that the effects are not driven by the censored nature of the data. Second, we check that our results are robust to dropping the rare individuals who give almost everything during a period (i.e., 9 Euro or more out of the 11-Euro joint account), which would result in greater earnings for the participant they are matched with than for themselves. We do this because those participants might have misunderstood the instructions (alternatively, they could also simply be very generous). The results are unchanged for High Earners, but for Low Earners only the joint test of the treatment order remains significant (see Appendix 2.E). In sum, result 1 concerning High Earners hypothesis stands unaffected by both robustness checks, and results 2 concerning the Low Earners hypotheses is weakened when excluding very generous individuals.

Finally, we assess the magnitude of the effect of decreasing wages on giving. For a simple evaluation, we employ the summary statistics contained in Table 2. First, for High Earners, average giving declines from around 1.62 Euro in the three treatments without decreasing wages to 1.49 Euro in the two treatments with decreasing wages (INTRAPERSONAL DECREASE and CATCHING UP). This corresponds to an effect size of 0.06 pooled standard deviations, but which still translates into an $8 \%$ reduction in giving. If we consider only non-selfish High Earners, giving declines from approximately 3.06 Euro to 2.85 Euro-an effect size of 0.08 pooled standard deviations, and a $7 \%$ reduction in giving. Second, for Low Earners, average giving goes from approximately 1.51 Euro in the three treatments without decreasing wages to 1.42 Euro in the treatment with decreasing intra- and inter-personal wages (INTRA / INTER-PERSONAL CHANGE) and 1.48 Euro in the treatment with decreasing intra-personal wages (INTRA-PERSONAL DECREASE). Consequently, the reduction caused by INTRA / INTER- 
PERSONAL CHANGE corresponds to an effect size of 0.04 pooled standard deviations, and a $6 \%$ decrease. Furthermore, the picture we obtain from considering only Low Earners who are not completely selfish is nearly identical.

\subsection{Discussion}

In this study, we conducted an experiment designed to identify how decreases in wages causally affect redistribution behavior. We hypothesized that individuals act more selfishly when they experience intraor inter-personal wage decreases, i.e., in absolute terms or relative to others. We find evidence that individuals indeed share less with others when they face decreasing wages.

We investigate the effect on High Earners as well as on Low Earners. We find more convincing evidence that the redistributive behavior of High Earners is affected by decreasing wages. For Low Earners, the evidence is qualitatively in the direction predicted, but on the border of marginal significance. Specifically, High Earners are significantly less generous when they face a wage decrease. This occurs both in the case of an intra-personal decrease and in the case of an inter-personal decrease. In comparison, Low Earners share less with others when they face the combined intra- and inter-personal wage decreases, although the effect is only marginally significant. They are not less generous when they only experience an intra-personal wage decrease. All in all, we find some evidence that decreasing wages increase selfish redistribution decisions, even though income inequality remains unchanged in our experimental environment.

This carries several implications for the effect of inequality on redistributive behavior. For instance, not taking into account the specific effect of changes may lead to understatement of the importance of decreasing wages on support for public policies-e.g., for individuals who are worse off compared to their previous situation or compared to others. E.g. High income individuals could oppose fiscal stimulus packages that have elements of redistribution in economics downturns because they experience a decreasing income trend and thus become less 
generous. Similarly, we would expect less support for policies that aim to close earning gaps-e.g. between men and women-from people who are averse to relative wage decreases. More generally, our findings highlight the important role of reference points in redistribution decisions beyond static income inequality, a topic that has previously been neglected.

An alternative mechanism that can explain our finding that High Earners become less generous after facing decreasing wages is suggested by the literature on avoidance behavior in charitable giving (Andreoni et al., 2017; Dana et al., 2007; Grossman \& Van Der Weele, 2017). That is, it is possible that Higher Earners in the experiment use their wage decrease as an excuse to justify being less generous while still maintaining a positive self-image. However, by the same argument, they could also use the wage increase by the Low Earner in the Intra-Personal Increase treatment as excuse to give less, which is not what we observe.

In addition, we note that the wage decreases that participants encounter in the laboratory are very short lived and the wage differences small compared to the time frame and scale over which wage changes occur in the economy. In this sense, it appears quite remarkable that even with small wage differences and relatively short time periods, we are able to find significant differences in redistribution decisions. As such, the small effect sizes that we measure are likely to be lower bounds on the effects of income trends on redistribution.

The main objective for future research on the topic could be be to investigate if increasing the duration and the wage differences indeed results in larger effects. For instance, one could conduct an experiment with a duration of several weeks or even months. As such, our study should be seen as first step for that type of studies. As additional avenues for future studies on the topic, one could also vary the identity of the reference group as several diverging income trends concern specific societal groups, such as ethnic minority and majority groups. That would allow one to study whether individuals react more strongly to relative wage decreases when the other person is an individual sharing their social identity or if the other person belongs to an opposing or outgroup. 
Furthermore, we only investigate the effect of decreasing wages on redistributive preferences when the redistribution is zero sum. But many fights over resources are arguably wasteful rent-seeking activities, so that studying the effect of wage decreases in more complex settings could also be a fruitful avenue for research. 

Appendices 


\section{A Instructions}

\section{Instructions}

Welcome to this economic experiment. Please read these instructions carefully. In the experiment, your decisions and the decisions of other participants will determine how much money you earn. You will be paid in cash at the end of the session, provided that you follow the rules. If you do not follow the rules, you will not be paid. You are forbidden from using your phone and from communicating with other participants at any time during the session. If you have any questions, please do not hesitate to raise your hand to ask the experimenter for help.

The session lasts for up to 90 minutes. You need to stay until the end to be paid. To complete the task in this experiment, you are also required to be able to click many times with a computer mouse (e.g., you need to have no injuries to your arms and fingers).

\section{General Instructions}

There are 5 periods, each lasting 8 minutes. Each period, you are matched with 1 anonymous other person. This can be any participant in the session. All participants work on the exact same task. Each period consists of 2 sub-periods of 4 minutes. In each sub-period, you are asked to complete a task to earn a wage. You need to complete the task in each of the 2 sub-periods in a period to earn the 2 wages for the period. Over the 2 sub-periods, you observe your wage and the wage of the other participant. Your wage and the wage of the other participant may vary over the 2 sub-periods, but the task stays the same.

In each of the 2 sub-periods, a tax is deducted from your wage and the wage of the other participant for this period. The tax is $1 / 3$ of the wage. You are left with the after-tax wages (wage minus tax). At the end of the period, the taxes that are taken from you and the other participant over the 2 sub-periods are joined together into the Total Tax Collected.

At the end of each of the 5 periods, you decide how to distribute the Total Tax Collected between you and the other participant. The other participant also decides how to distribute the Total Tax Collected. The decisions are anonymous. Either your distribution or the distribution of the other participant is randomly chosen to count for payment. If you do not complete the task for 1 of the 2 sub-periods for a period, then you do not earn anything in this period and you cannot choose a distribution in this period. The tax taken from the other participant is returned to him or her and there are no distribution decisions.

Until the end of the experiment, you do not receive feedback regarding what distribution the other participant chooses, and the other participant is not told what distribution you choose. Only at the end of the experiment, 1 of the $\mathbf{5}$ periods is randomly chosen to count for payment by the computer.

You are paid the following two parts for the chosen period. First, you are paid the $\mathbf{2}$ after-tax wages you earned in that period. Second, either your distribution of the Total Tax Collected or the distribution of the other participant you were matched with for this period is randomly chosen to be paid.

You need to answer a few comprehension questions and go through a Practice period before you start the experiment. In the next two sections, you are given more details regarding specific components of 
the experiment, and examples of how your wage and the wage of the other participant are presented during the experiment. Finally, a timeline summarizing the different steps is presented at the end of these instructions.

\section{Details}

Other Participant: The other participant is real and always works on the exact same task as you. $\mathrm{He}$ or she is someone else in the session. At the start of each period, you are matched with a participant for this period. That is, you are matched with the same participant for the 2 sub-periods of this period.

Periods: There are 5 periods, each lasting 8 minutes. Between every period, you have a 2-minute break to relax.

Sub-periods: Within every period, there are 2 sub-periods of 4 minutes each.

Task: The task is always exactly the same for every participant in every sub-period. It is a simple task that can be completed by exerting a reasonable effort. The task is to repeatedly click on a ball that appears on your computer screen. Every time you click on the ball, it decreases in size until it disappears. Click on the ball, and wait for it to move until you click again. If you click multiple times before it moves, the ball does not disappear faster. The minimum number of balls that need to disappear (Balls Threshold) in each sub-period to earn your wage is $\mathbf{4}$ balls. You need to reach this Ball Threshold in each of the 2 sub-periods of a period to earn the 2 wages for the period. This means that if you complete the task in only one of the 2 sub-periods of a period, you do not earn any of the 2 wages for the period. If you want, you can make more than $\mathbf{4}$ balls disappear, but this will not change your wage. That is, you cannot increase your wage by working more than meeting the Balls Threshold.

Wage and Tax: In a period, you earn two wages for completing the task: one wage in each of the two sub-periods. The wage may not be the same in the first sub-period and the second sub-period. If you do not complete the task in each of the $\mathbf{2}$ sub-periods, you are not paid at all for this period. That is, you neither earn the wage of the first sub-period nor the wage of the second sub-period. In each sub-period, a tax of $1 / 3$ is removed from your wage and from the wage of the other participant. The tax always amounts to $1 / 3$ of the wage, both for you and the other participant. You are left with the after-tax wage (wage minus tax).

Total Tax Collected: Taxes collected from you and from the other participant in the 2 sub-periods are added at the end of the period into the Total Tax Collected.

Distribution: At the end of each period, you choose how to distribute the money in the Total Tax Collected between yourself and the other participant. The other participant also decides how to distribute the Total Tax Collected. Either your distribution or the distribution chosen by the other participant is randomly chosen for payment, for the period randomly selected to be paid out. If you do not complete the task in sub-period 1 or 2 of a period, you cannot choose a distribution. In this case, the tax taken from the other participant is returned to him or her, and there are no distribution decisions. Similarly, if the other participant does not complete the task in one or both of the 2 sub-periods, you and the other 
participant do not make a distribution choice, and the tax collected on your wages is returned to you. The distribution decisions are anonymous and you are not informed about any of them before the end of the session.

Payment: At the end of the session, the computer randomly selects 1 period for payment. There are 2 parts to your payment, provided that you have completed the task in the 2 sub-periods of the chosen period. First, you receive your after-tax wage for each of the 2 sub-periods. Second, your distribution or the distribution of the other participant you were matched with in this period is randomly chosen and paid out. The randomly selected distribution is the only one you are informed about during the experiment. If you do not complete the task in each the 2 sub-periods of this period, you are paid nothing.

Comprehension Questions: You are asked a few comprehension questions before the experiment starts to make sure that you understand the instructions. If you do not understand a comprehension question, please ask the experimenter for help by raising your hand.

Practice Period: During the Practice period, you try the task and become familiar with the experiment, including the distribution decision. The practice period is shorter than the regular periods, and does not count for payment. The experiment starts after the practice period.

Questions: If anything is unclear, please do not hesitate to raise your hand to ask the experimenter. 


\section{Examples}

The following are three examples of how your wage and the wage of the other participant you are matched with for a period are indicated in each of the 2 sub-periods of a period.

Example 1: You are matched with a participant for the period. In sub-period 1, your wage is 3 EUR and the wage of the other participant is 4.5 EUR:

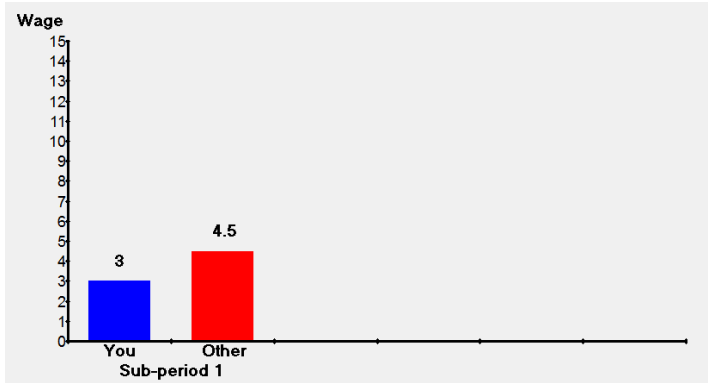

Then, in sub-period 2, your wage increases to 12 EUR and the other participant's wage increases to 13.5 EUR:

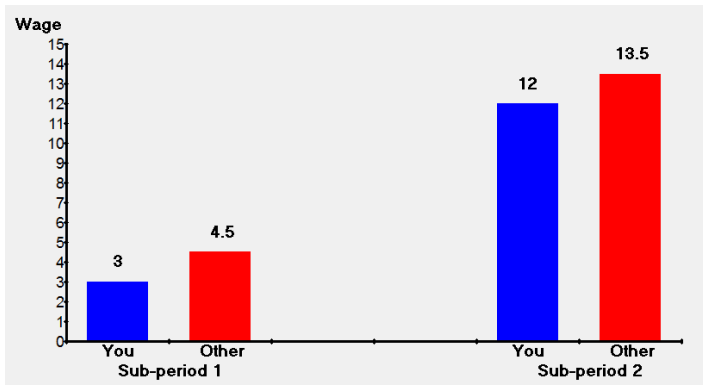


Example 2: You are matched with a participant for the period. In sub-period 1, your wage is 12 EUR and the wage of the other participant is 13.5 EUR:

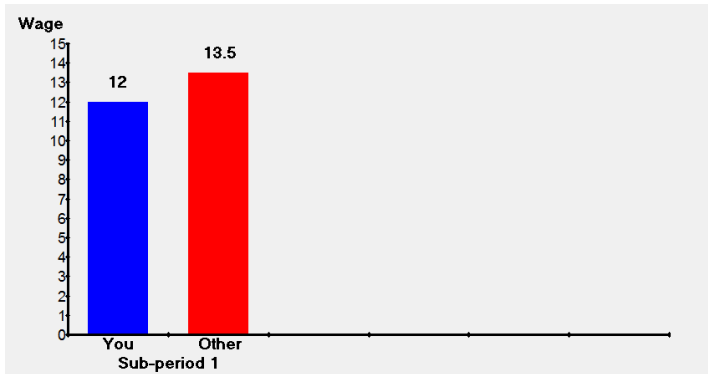

Then, in sub-period 2, your wage decreases to 3 EUR and the other participant's wage decreases to 4.5 EUR:

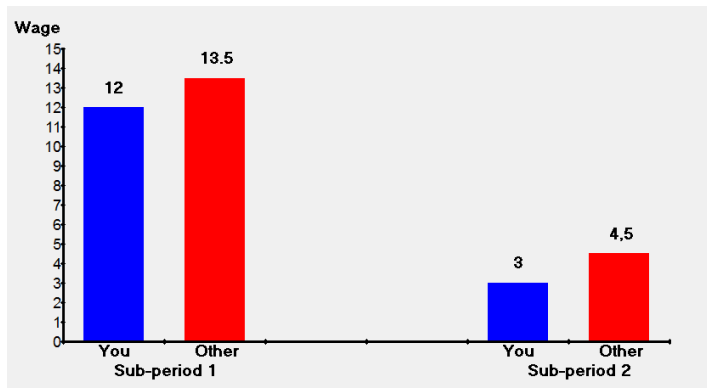


Example 3: You are matched with a participant for the period. In sub-period 1, your wage is 6 EUR and the wage of the other participant is also 6 EUR:

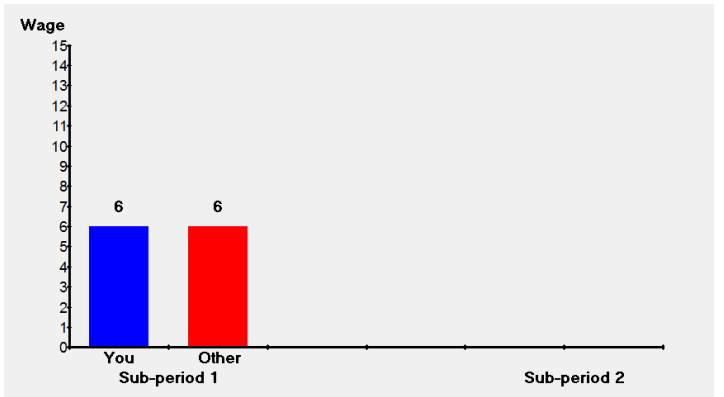

Then, in sub-period 2, your wage stays 6 EUR and the other participant's wage also stays 6 EUR:

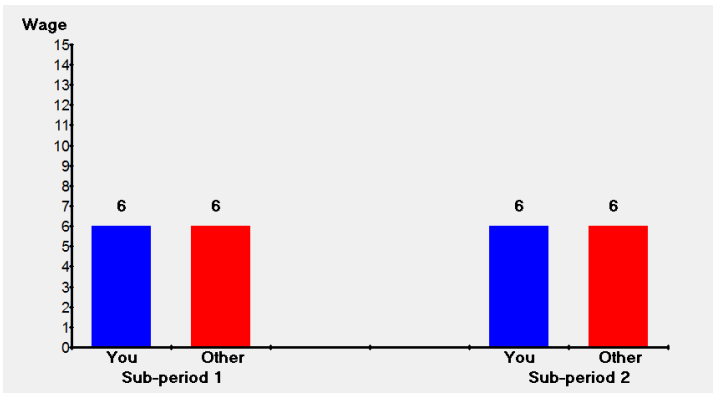




\section{Timeline}

The following timeline summarizes the different steps in this experiment.

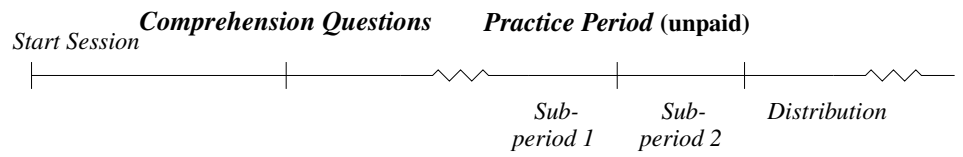

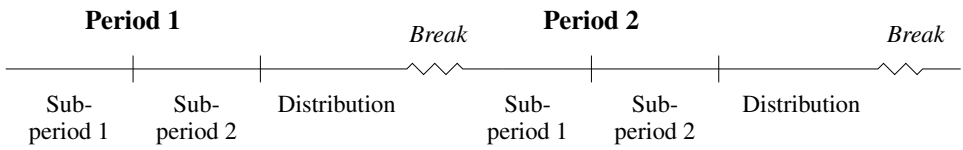

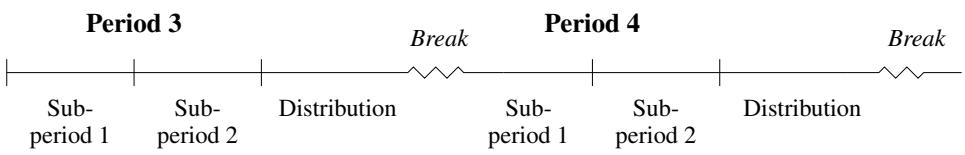

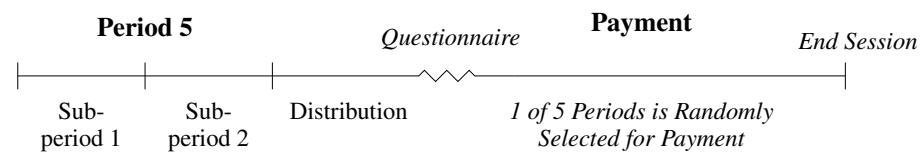

We call participants one by one at the end of the session to pay them. Please stay seated in your cubicle while you wait. 


\section{B Screenshots}

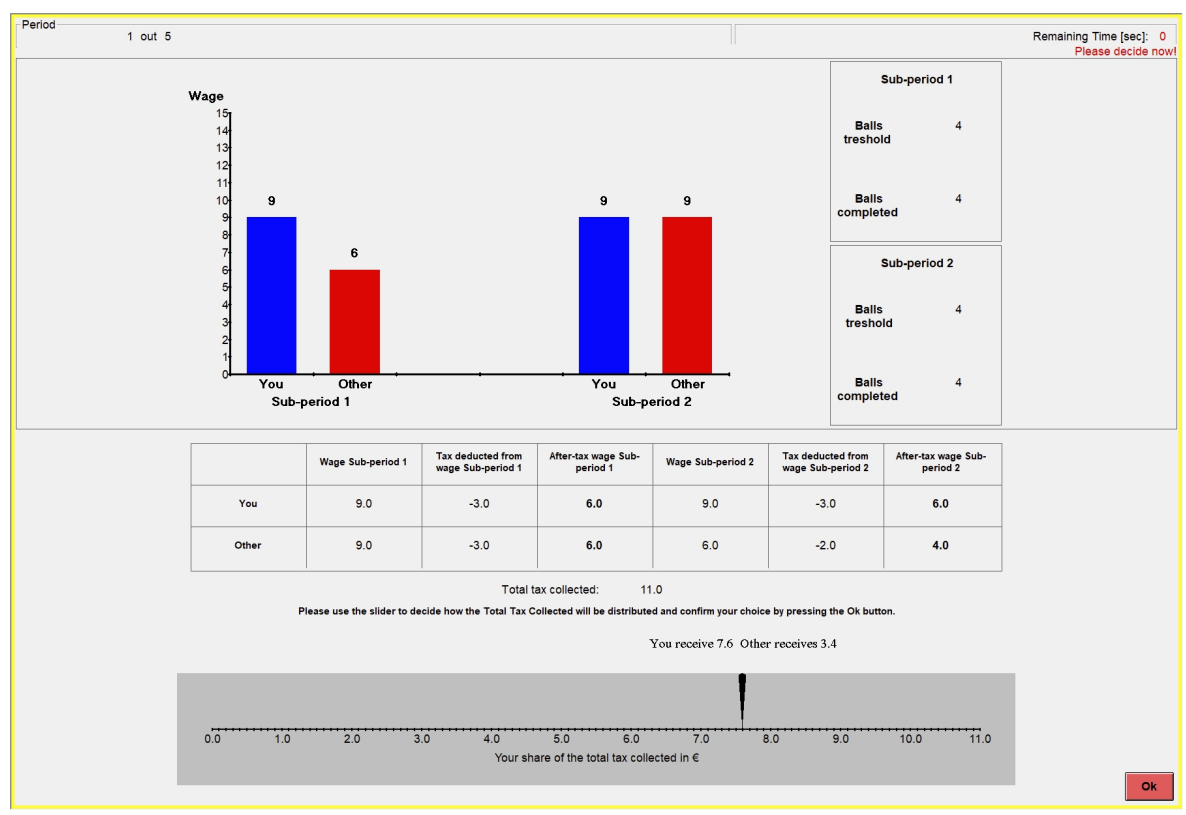

Figure 2.B.1: Screenshot of redistribution stage (C A T C H ING UP treatment) 


\section{C Random-Effects Tobit regressions}

Table 2.C.1: Tests of hypotheses

\begin{tabular}{|c|c|c|}
\hline & High Earners & $\begin{array}{c}\text { One-sidec } \\
p \text {-value }\end{array}$ \\
\hline \multirow[t]{2}{*}{$\mathrm{H} 1$} & $\begin{array}{r}\text { CATCHING UP, } \\
\text { INTER-PERSONAL DECREASE }< \\
\text { STABLE, } \\
\text { INTER-PERSONAL INCREASE, } \\
\text { INTRA / INTER-PERSONAL CHANGE }\end{array}$ & 0.054 \\
\hline & Low Earners & \\
\hline $\mathrm{H} 2$ & $\begin{array}{r}\text { INTRA / INTER-PERSONAL CHANGE, } \\
\text { INTRA-PERSONAL DECREASE < } \\
\text { STABLE, } \\
\text { INTRA-PERSONAL INCREASE, } \\
\text { CATCHINGUP }\end{array}$ & 0.180 \\
\hline H3 & $\begin{array}{r}\text { INTRA / INTER-PERSONAL CHANGE }< \\
\text { STABLE, } \\
\text { INTRA-PERSONAL DECREASE, } \\
\text { INTRA-PERSONAL INCREASE, } \\
\text { CATCHINGUP }\end{array}$ & 0.055 \\
\hline $\mathrm{H} 4$ & $\begin{array}{r}\text { INTRA / INTER-PERSONAL CHANGE }< \\
\text { INTRA-PERSONAL DECREASE }\end{array}$ & 0.146 \\
\hline
\end{tabular}


Table 2.C.2: Random-effects Tobit regressions

\begin{tabular}{|c|c|c|c|c|c|c|}
\hline \multicolumn{3}{|c|}{ High Earner, giving } & \multirow[b]{2}{*}{ Treatment } & \multicolumn{3}{|c|}{ Low Earner, giving } \\
\hline Treatment & (1) & $(2)$ & & (3) & (4) & (5) \\
\hline INTER-PERSONAL & -0.305 & & INTER-PERSONAL & -0.104 & & \\
\hline DECREASE \& & $(0.190)$ & & DECREASE \& & $(0.114)$ & & \\
\hline CATCHING UP & & & INTRA / INTER- & & & \\
\hline & & & PERSONAL CHANGE & & & \\
\hline INTER-PERSONAL & & -0.171 & INTER-PERSONAL & & & \\
\hline DECREASE & & $(0.239)$ & DECREASE & & & \\
\hline CATCHING UP & & $\begin{array}{c}-0.438^{*} \\
(0.240)\end{array}$ & CATCHING UP & & & \\
\hline INTRA / INTER- & & & INTRA / INTER- & & -0.222 & -0.220 \\
\hline PERSONAL CHANGE & & & PERSONAL CHANGE & & $(0.139)$ & $(0.209)$ \\
\hline Constant & $\begin{array}{c}-0.919^{*} \\
(0.523)\end{array}$ & $\begin{array}{c}-0.925^{*} \\
(0.523)\end{array}$ & Constant & $\begin{array}{c}0.194 \\
(0.399) \\
\end{array}$ & $\begin{array}{c}0.211 \\
(0.398)\end{array}$ & $\begin{array}{c}0.311 \\
(0.464) \\
\end{array}$ \\
\hline Baseline & & & Baseline & & & \\
\hline Treatment(s) & & & Treatment(s) & & & \\
\hline STABLE & $\checkmark$ & $\checkmark$ & STABLE & $\checkmark$ & $\checkmark$ & \\
\hline INTRA-PERSONAL & & & INTRA-PERSONAL & & $\checkmark$ & $\checkmark$ \\
\hline DECREASE & & & DECREASE & & & \\
\hline INTRA / INTER- & $\checkmark$ & $\checkmark$ & INTRA / INTER- & & & \\
\hline PERSONAL CHANGE & & & PERSONAL CHANGE & & & \\
\hline INTRA-PERSONAL & $\checkmark$ & $\checkmark$ & INTRA-PERSONAL & $\checkmark$ & $\checkmark$ & \\
\hline INCREASE & & & INCREASE & & & \\
\hline CATCHING UP & & & CATCHING UP & $\checkmark$ & $\checkmark$ & \\
\hline Time Period Dummies & $\checkmark$ & $\checkmark$ & & $\checkmark$ & $\checkmark$ & $\checkmark$ \\
\hline$\chi^{2}>0$ & $<0.01$ & $<0.01$ & & $<0.01$ & $<0.01$ & 0.128 \\
\hline$N$ & 735 & 735 & & 735 & 735 & 294 \\
\hline
\end{tabular}

Standard errors in parentheses. Unlike when we test the directed hypotheses, we use two-sided $p$-values here for simplicity: * $\mathrm{p}<0.10,{ }^{* *} \mathrm{p}<0.05,{ }^{* * *} \mathrm{p}<0.01$ 
Table 2.C.3: Random-effects Tobit regressions with individual treatments

\begin{tabular}{|c|c|c|}
\hline \multirow[b]{2}{*}{ Treatment } & \multicolumn{2}{|c|}{ Giving } \\
\hline & High Earner & Low Earner \\
\hline INTRA-PERSONAL DECREASE & $\begin{array}{l}-0.171 \\
(0.293)\end{array}$ & $\begin{array}{c}0.057 \\
(0.175)\end{array}$ \\
\hline INTRA-PERSONAL INCREASE & $\begin{array}{c}0.107 \\
(0.289)\end{array}$ & $\begin{array}{l}-0.117 \\
(0.176)\end{array}$ \\
\hline INTRA / INTER-PERSONAL CHANGE & $\begin{array}{l}-0.114 \\
(0.289)\end{array}$ & $\begin{array}{l}-0.176 \\
(0.175)\end{array}$ \\
\hline CATCHING UP & $\begin{array}{l}-0.441 \\
(0.291)\end{array}$ & $\begin{array}{c}0.243 \\
(0.174)\end{array}$ \\
\hline Constant & $\begin{array}{c}-0.917^{*} \\
(0.556)\end{array}$ & $\begin{array}{c}0.177 \\
(0.412)\end{array}$ \\
\hline Baseline Treatment & STABLE & STABLE \\
\hline Time Period Dummies & $\checkmark$ & $\checkmark$ \\
\hline $\begin{array}{r}\chi^{2}>0 \\
N\end{array}$ & $\begin{array}{c}0.010 \\
735\end{array}$ & $\begin{array}{c}<0.01 \\
735\end{array}$ \\
\hline
\end{tabular}

Standard errors in parentheses. Unlike when we test the directed hypotheses, we use two-sided $p$-values here for simplicity: ${ }^{*} \mathrm{p}<0.10,{ }^{* *} \mathrm{p}<0.05,{ }^{* * *} \mathrm{p}<0.01$ 


\section{D Non-Selfish—individuals giving at least once}

\begin{tabular}{|c|c|c|c|}
\hline & High Earners & $\begin{array}{l}\text { Change in } \\
\text { giving }\end{array}$ & $\begin{array}{c}\text { One-sided } \\
p \text {-value }\end{array}$ \\
\hline H1 & $\begin{array}{r}\text { CATCHING UP, } \\
\text { INTER-PERSONAL DECREASE }< \\
\text { STABLE, } \\
\text { INTER-PERSONAL INCREASE, } \\
\text { INTRA / INTER-PERSONAL CHANGE }\end{array}$ & $\begin{array}{c}-0.256 \text { Euro } \\
(-8.38 \%)\end{array}$ & 0.010 \\
\hline
\end{tabular}

\begin{tabular}{|c|c|c|c|}
\hline \multicolumn{4}{|c|}{ Low Earners } \\
\hline $\mathrm{H} 2$ & $\begin{array}{r}\text { INTRA / INTER-PERSONAL CHANGE, } \\
\text { INTRA-PERSONAL DECREASE }< \\
\text { STABLE, } \\
\text { INTRA-PERSONAL INCREASE, } \\
\text { CATCHING UP }\end{array}$ & $\begin{array}{l}-0.090 \text { Euro } \\
(-3.61 \%)\end{array}$ & 0.132 \\
\hline H3 & $\begin{array}{r}\text { INTRA / INTER-PERSONAL CHANGE }< \\
\text { STABLE, } \\
\text { INTRA-PERSONAL DECREASE, } \\
\text { INTRA-PERSONAL INCREASE, } \\
\text { CATCHINGUP }\end{array}$ & $\begin{array}{c}-0.132 \text { Euro } \\
(-5.33 \%)\end{array}$ & 0.068 \\
\hline $\mathrm{H} 4$ & $\begin{array}{r}\text { INTRA / INTER-PERSONAL CHANGE }< \\
\text { INTRA-PERSONAL DECREASE }\end{array}$ & $\begin{array}{l}-0.103 \text { Euro } \\
(-4.22 \%)\end{array}$ & 0.483 \\
\hline $\begin{array}{l}\text { Joint } \\
\text { H2-4 }\end{array}$ & $\begin{array}{r}\text { Intra / InTER-PERSONAL CHANGE }< \\
\text { INTER-PERSONAL DECREASE }< \\
\text { Stable, INTER-PERSONAL INCREASE, CATCHING UP }\end{array}$ & & 0.033 \\
\hline $\begin{array}{l}\text { Note: C } \\
\text { he } 11-\mathrm{E} \\
\text { Ne repor } \\
\text {-value } \\
\text { ollow a }\end{array}$ & $\begin{array}{l}\text { nge in giving corresponds to the difference in Euro and percentage distribu } \\
\text { joint account between different sets of treatments. In line with the directed n } \\
\text { ne-sided } p \text {-values of non-parametric Wilcoxon signed-rank tests (WSR). Furt } \\
\text { a joint test of H2-4. We use Page's test for ordered alternatives which eval } \\
\text {-specified order. For both WSR and Page tests, we average giving per individ } \\
\text { onsideration. }\end{array}$ & $\begin{array}{l}\text { ted to the other } \\
\text { ture of our hypc } \\
\text { termore, we repc } \\
\text { lates whether pc } \\
\text { tal over each of } t\end{array}$ & $\begin{array}{l}\text { cipant } \\
\text { es, for } \\
\text { le one- } \\
\text { tion } n \\
\text { o trea }\end{array}$ \\
\hline
\end{tabular}


Table 2.D.2: Analysis for Low and High Earners pooled together, individuals giving at least once

\begin{tabular}{ccc}
\hline \hline & $\begin{array}{c}\text { Change in } \\
\text { giving }\end{array}$ & $\begin{array}{c}\text { One-sided } \\
p \text {-value }\end{array}$ \\
\hline DECREASING $<$ OTHER & $\begin{array}{c}-0.17 \text { Euro } \\
(-6.09 \%)\end{array}$ & 0.011 \\
\hline \hline
\end{tabular}

Note: Change in giving corresponds to the difference in Euro and percentage. The set DECREASING contains treatments CATCHING UP and INTRA-PERSONAL DECREASE for High Earners, and IntRa / INTER-PERSONAL CHANGE and INTRA-PERSONAL DECREASE for Low Earners. The set OTHER contains all treatments excluded from DECREASING for High and Low Earners. We report one-sided $p$-values of non-parametric Wilcoxon signed-rank test (WSR). Giving is averaged per individual over each of the two treatment sets under consideration. 


\section{E Non-Altruists-individuals giving less than 9 Euro}

Table 2.E.1: Tests of hypotheses, individuals giving less than 9 Euro

\begin{tabular}{|c|c|c|c|}
\hline & High Earners & $\begin{array}{l}\text { Change in } \\
\text { giving }\end{array}$ & $\begin{array}{l}\text { One-sided } \\
p \text {-value }\end{array}$ \\
\hline $\mathrm{H} 1$ & $\begin{array}{r}\text { CATCHING UP, } \\
\text { INTER-PERSONAL DECREASE }< \\
\text { STABLE, } \\
\text { INTER-PERSONAL INCREASE, } \\
\text { INTRA / INTER-PERSONAL CHANGE }\end{array}$ & $\begin{array}{c}-0.15 \text { Euro } \\
(-9.79 \%)\end{array}$ & 0.030 \\
\hline \multicolumn{4}{|c|}{ Low Earners } \\
\hline $\mathrm{H} 2$ & $\begin{array}{r}\text { INTRA / INTER-PERSONAL CHANGE, } \\
\text { INTRA-PERSONAL DECREASE }< \\
\text { STABLE, } \\
\text { INTRA-PERSONAL INCREASE, } \\
\text { CATCHING UP }\end{array}$ & $\begin{array}{c}-0.04 \text { Euro } \\
(-2.61 \%)\end{array}$ & 0.254 \\
\hline H3 & $\begin{array}{r}\text { INTRA / INTER-PERSONAL CHANGE }< \\
\text { STABLE, } \\
\text { INTRA-PERSONAL DECREASE, } \\
\text { INTRA-PERSONAL INCREASE, } \\
\text { CATCHING UP }\end{array}$ & $\begin{array}{c}-0.04 \text { Euro } \\
(-1.90 \%)\end{array}$ & 0.134 \\
\hline $\mathrm{H} 4$ & $\begin{array}{r}\text { INTRA / INTER-PERSONAL CHANGE }< \\
\text { INTRA-PERSONAL DECREASE }\end{array}$ & $\begin{array}{c}-0.03 \text { Euro } \\
(-1.93 \%)\end{array}$ & 0.841 \\
\hline Joint & $\begin{array}{r}\text { IntRa / INTER-PERSONAL CHANGE }< \\
\text { INTER-PERSONAL DECREASE }< \\
\text { Stable, INTER-PERSONAL INCREASE, CATCHING UP }\end{array}$ & & 0.038 \\
\hline
\end{tabular}


Table 2.E.2: Analysis for Low and High Earners pooled together, individuals giving less than 9 Euro

\begin{tabular}{ccc}
\hline \hline & $\begin{array}{c}\text { Change in } \\
\text { giving }\end{array}$ & $\begin{array}{c}\text { One-sided } \\
p \text {-value }\end{array}$ \\
\hline DECREASING < OTHER & $\begin{array}{c}-0.09 \text { Euro } \\
(-6.09 \%)\end{array}$ & 0.018 \\
\hline \hline
\end{tabular}

Note: Change in giving corresponds to the difference in Euro and percentage. The set DECREASING contains treatments CATCHING UP and INTRA-PERSONAL DECREASE for High Earners, and IntRa / INTER-PERSONAL CHANGE and INTRA-PERSONAL DECREASE for Low Earners. The set OTHER contains all treatments excluded from DECREASING for High and Low Earners. We report one-sided $p$-values of non-parametric Wilcoxon signed-rank test (WSR). Giving is averaged per individual over each of the two treatment sets under consideration. 




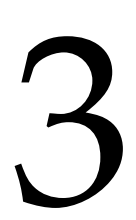

\section{Social Identity and Social Preferences in the Lab}

Adapted from: Zaunbrecher, H. W., Williams, T., \& Riedl, A. (2021b). Social identity in the lab: A horse race between methods. Working Paper. 


\section{Abstract}

Social identity affects the economic behavior of individuals and groups. However, studying the effect of social identity remains difficult. It is often not possible to directly observe or manipulate social identity in natural settings, which makes causal inference challenging. An alternative approach is to create new social identities experimentally in the lab. In this paper, we propose to use social value orientation tests as manipulation checks for social identity experiments and explore social identity from two perspectives: First, we consider alternative methods to induce social identity. Second, we explore different ways to econometrically measure the strength of social identity. We find that inducing social identity through a task-irrelevant contest game is effective regardless of measurement approach, while other methods typically fail to have an effect. However, we also find that any of the investigated induction methods effectively generates an ingroup bias when measured withinsubject which appears to be driven by salience effects. 


\subsection{Introduction}

Social identity, the part of the self that is derived from one's membership of a group, is an important explanatory factor in individual as well as intergroup behaviour. It has become increasingly important in election- and marketing campaigns, and in the analysis of economic decision making. ${ }^{1}$ Studying the role of social identity in the field often comes with endogeneity issues: People belong to multiple social groups, each having their own set of social norms and interactions with other groups, and not all are easily observable. Thus, identifying whether an effect comes from being in "a group" or if the effect is unique to the group studied is only possible through repeated replication with different groups and interactions. Due to these difficulties, creating and manipulating new identities in the laboratory has been a popular way to study social identities. However, only about a third of lab studies that aim to investigate identity-based discrimination find a significant ingroup bias (Lane, 2016). If this is due to the absence of an effect of social identity or due to a failure to successfully induce or manipulate social identity in the lab is often unclear, as most of the studies lack an incentivized manipulation check. In this study, we propose to use social value orientation (SVO) tests as simple manipulation check for social identity studies in the lab. The measure we use is the slider measure developed by Murphy et al. (2011). Compared to other social preference and social value orientation measures, it has the advantage of providing a high resolution and test-retest reliability while also requiring relatively few decisions. Furthermore, we test a variety of methods and check which one is most successful in inducing identity in the lab and how "successful" can best be measured econometrically.

Starting with the seminal paper by Akerlof and Kranton (2000) that formalized the theory of Tajfel and Turner, 1979 and introduced it to economics, many studies have shown that social identity shapes our preferences, beliefs, and how we interact with each other. Experiments have shown that social identity creates an ingroup bias and a positive effect on coordination and cooperation in dictator and two-player response games (Chen \& Li, 2009), voting over redistribution (Klor \&

\footnotetext{
${ }^{1}$ For a contemporary overview of the literature, see Charness and Chen (2020).
} 
Shayo, 2010), public good games (Eckel \& Grossman, 2005), minimumeffort games (Chen \& Chen, 2011), and beliefs about intelligence Cacault and Grieder, 2019. In more competitive settings, salient group identities increase the choice of an aggressive stance in the battle of the sexes and lead to more defections in the prisoners dilemma game (Charness et al., 2007) but results from individual and group contest games are mixed (Cason et al., 2012; Chakravarty et al., 2016; Chowdhury et al., 2016; Mago et al., 2016; Zaunbrecher \& Riedl, 2016). Researchers have used the lab to study social identities because careful experimental design can avoid the endogeneity and selection issues that exist in the field. With control over the available information, social identities can be made salient (Benjamin, Choi, et al., 2010; Chen et al., 2014; Kranton et al., 2020) or new identities can be created (e.g. Charness et al., 2007; Chen \& Li, 2009; Eckel \& Grossman, 2005; Kranton et al., 2020).

Using existing identities in the lab often comes with similar problems as studying identity in the field. Because the experimenter does not control the identity formation process, subjects are not randomly allocated into their natural identities and thus the effect of being in a group cannot be separated from the specific characteristics of the natural identity made salient in the lab. ${ }^{2}$ The alternative, creating new identities in the lab, is usually achieved through variations of the "Minimal group paradigm" developed by Tajfel (1970). Therein, subjects are randomly allocated into groups or quasi-randomly allocated based on an unrelated criterion, such us picture preferences. Since the identity formation is random, any effect observed of being in such groups can be attributed to being in a group itself rather than to specific group characteristics.

However, recent studies cast doubt on the robustness of some of the results that have been obtained in social identity studies in the lab. While Chen and Li (2009) and Müller (2019) show a systematic effect of identity on social preferences, Guala and Filippin (2016) presents evidence that this effect is not well behaved and rather unsystematic. ${ }^{3}$ Similarly,

\footnotetext{
${ }^{2} \mathrm{~A}$ notable exception to this are experiments that exploit a naturally occurring random allocation into groups such as random allocation into army platoons (Goette et al., 2006) or dorms (Bacine \& Eckel, 2020; Banuri et al., 2012).

${ }^{3}$ Guala and Filippin (2016) show this using a larger set of modified dictator games that includes both negative and positive costs of giving. Furthermore, they show
} 
Camerer et al. (2016) could not replicate the effect of social identity on coordination that was reported in Chen and Chen (2011), however a response by Chen et al. (2020) suggests that this failed replication was a result of minor deviations from the original experimental protocol. In a comprehensive meta-analysis of economic experiments that study discrimination between groups, either preexisting or newly created in the lab, Lane (2016) finds that $61 \%$ of the studies fail to produce a significant discriminatory effect. Because most of the analyzed studies do not include an incentivized manipulation check, it is unclear if this is due to a failure to induce a social identity or the absence of an effect of social identity on the variable of interest.

The conflicting results and failures to replicate existing findings both highlight the need for a better understanding of what methods can successfully be used to induce social identity and how "successful" can be measured quantitatively. ${ }^{4}$

While very minimal methods such as random allocation into two groups might not be enough to induce social identity, more elaborate methods have the potential to introduce confounding factors into the research design. For example, inducing a group identity through a problem solving task that allows participants to communicate could result in significant treatment effects that are not driven by the common identity, but by communication specific effects.

Similarly, we would like to measure the strength of the social identity in a way that provides us with a precise estimate but also does not introduce confounding factors. A within-subject design that uses multiple measurements for each participant has the advantage that each subject serves as their own control group and thus we can calculate ingroup bias on an individual level. This results in higher statistical power but might bias behavior by telegraphing the research questions

that even sign reversals can be achieved if the complexity of the dictator games is slightly increased by adding strictly dominated choice options.

${ }^{4}$ Gächter et al. (2015) showed that an 'Inclusion of other in self' task is a powerful tool to measure social relationships, however this task is designed for preexisting social relationships, making it less useful in circumstances in which identity is induced by the experimenter. 
or introducing other unintended behaviour. For instance, if subjects suspect that the experiment is about group discrimination, it could lead to an increased bias due to an experimenter demand effect or lower bias due to social norms and image concerns. Moreover, repeating the same measurement while only varying information about group affiliations could in itself affect social identity by making the group identity more salient.

Ideally we would like to find the minimal method that successfully induces social identity and measure it to assure that the induction was successful, without the measurement affecting the social identity itself. In this paper, we compare different methods to create social identities in the lab as well as different econometric approaches to measure the induced social identity. We ran an experiment in which we first elicited participants' baseline social preferences using a social value orientation test (SVO) that was conducted online one week before the lab experiment. Second, participants took part in one of five social identity treatments in the laboratory. These treatments were (1) simple categorization into two groups (minimal group paradigm); (2) problem solving and communication; (3) group real effort task; (4) endogenous identity creation task; and (5) group contest. After the treatment, the participants completed three SVOs, one with respect to a member of the ingroup, one with respect to a member of the outgroup, and one with respect to someone who belonged to neither in-nor outgroup. From these SVOs, we determine the strength of the social identity by the strength of the ingroup bias that participants show in their social preferences. As the order of the three SVOs was randomized and counterbalanced, our design does not only allow us to compare the different treatments but also to compare different between-subject, within-group (comparing SVO decisions within a group), and within-subject measures for social identity.

We find that only the group contest consistently induces an ingroup bias. All other methods only exhibit a significant effect in the withinsubject analysis. An analysis of potential order effects on the pooled data reveals that subjects that have to make a decision towards an ingroup person first do not chose significantly different allocations than subjects that have to make a decision towards an outgroup person first. 
It is only in the subsequent decisions, when it is more salient that they have to make decisions towards ingroup AND outgroup members, that subjects treat these members differently. ${ }^{5}$ This suggests that the choice of between- or within subject design interacts with the treatment in ways that could potentially confound the analysis of social identity effects.

The rest of the paper is organized as follows. Section 3.2 describes the experimental design and procedures. Section 3.3 introduces the different measurement approaches used. Section 3.4 reports the empirical results, and Section 3.5 provides a discussion.

\subsection{Experimental Methods}

We have two primary goals. First, we want to determine which, if any, methods of inducing social identity in the lab will significantly affect social preferences. Second, we want to find out if different measurement designs (e.g., within- and between-subject) yield similar results.

In section 3.2.1, we describe the overall sequence of events in the experiment. Section 3.2.2 explains the matching and procedures. This is followed by a detailed description of our measure of social preferences in section 3.2.3, and the different methods of inducing social identity in section 3.2.4.

\subsubsection{Sequence of Events}

The experiment has two parts which are summarized in Figure 3.2.1. In part A, subjects completed the SVO online in order to elicit baseline social preferences. This test was performed one week before the lab experiment to minimize choice inertia due to anchoring. In part B, subjects took part in a lab experiment during which a social identity was induced. Subjects then immediately completed the SVO with three

\footnotetext{
${ }^{5}$ Qualitatively, this does not only hold for the pooled treatments but also for each individual treatment.
} 
different people. Subjects were informed that the other person was either (i) a member of their group, (ii) a member of the other group, or (iii) another randomly selected person in the lab who neither belongs to their own nor the other group. Subjects therefore knew the group membership of the other person with whom they were interacting with but did not know the person's identity. The order of theses SVO tests was randomized and counterbalanced across subjects. This part ended with a short questionnaire. All subjects completed both parts A and B.

Figure 3.2.1: Sequence of Events During the Experiment

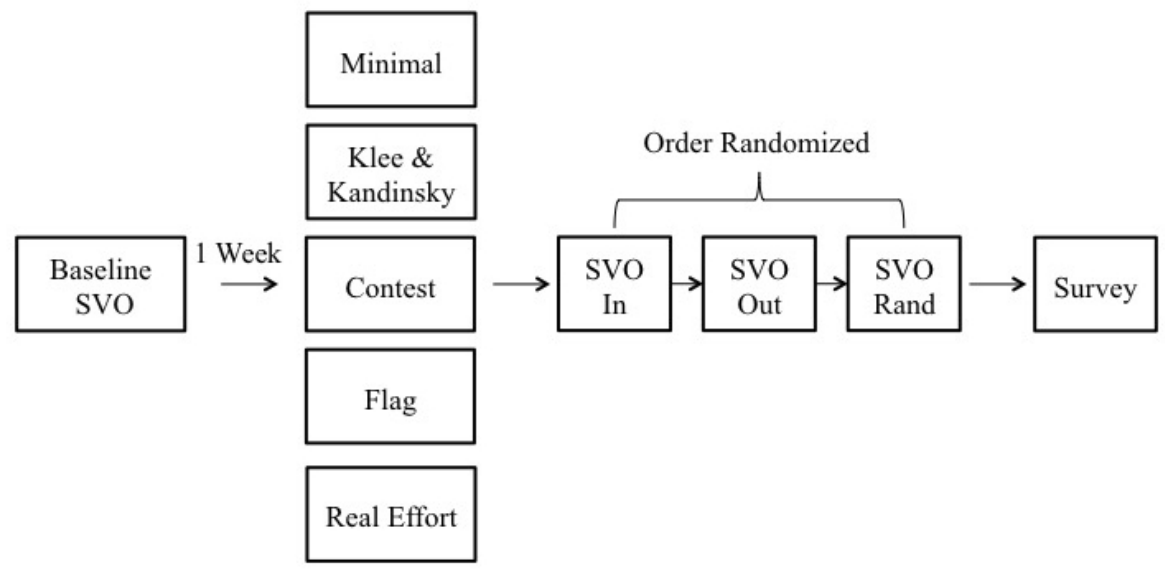

Part A: Baseline SVO

Part A was conducted using Qualtrics (2005). Subjects that signed up for the experiment received a link to a Qualtrics experiment that contained the six primary items of the SVO slider measure developed by Murphy et al. (2011). The instructions informed subjects that they would make a series of allocation decisions between themselves and a random other student. After completing the survey, they received a unique code that they had to bring to the laboratory to participate in Part B. 


\section{Part B: Lab Experiment}

Part B was conducted using the experiment software z-tree (Fischbacher, 2007) at the BEElab of Maastricht University. Subjects had to enter the code they received in the online experiment. Subjects took part in one of the five treatments that only varied in the social identity induction method applied. After the social identity induction, subjects did three rounds of SVO-tests. ${ }^{6}$ Subjects completed one SVO test with respect to a person that was not part of the own or the other group (random), one with respect to an own group member (ingroup) and one with respect to a member of the other group (outgroup). The order of the tests was randomized within a group such that in any round of SVO tests, one group member performed an ingroup, one performed an outgroup, and one performed a random test. This allowed us to study potential order effects and to compare different econometric approaches to measure the strength of social identity. Subjects knew that they would do the test three times and that they would receive some additional information about their match but were not explicitly told beforehand that they did the decisions with respect to an outgroup, ingroup and random person. At the end of the experiment, subjects had to fill out a short questionnaire that included questions about group closeness, risk attitudes and demographics.

\subsubsection{Matching and Procedures}

All payment took place at the end of the lab session in part B. For the payment, each subject was matched with different other subjects in each part of the experiment. In both parts it was randomly determined which of the two was the allocator and which was the receiver. For part A, one of the SVO decisions of the allocator was chosen and the respective payoffs were implemented for allocator and receiver. For part B, the identity of the matched subject determined if an outgroup, ingroup or random decision was relevant for payout. If the matched subject was from the ingroup, one of the dictators ingroup decisions was randomly

\footnotetext{
${ }^{6}$ The z-tree implementation of the tests is partly based on the manual from Crosetto
} et al. (2012). 
selected and the respective payouts implemented for allocator and receiver. The procedure for an outgroup and a random match followed analogously. Subjects did at no point get information whom they were matched with. This was done to rule out heterogeneity in second order beliefs as explanation for differences between the different treatments. ${ }^{7}$ They only got information whether they were allocator or receiver and the respective payment at the end of the experiment. The remuneration scheme was explained in both parts of the experiment. Furthermore, it was made clear that a potential receiver never made a decision towards the dictator. This was implemented to avoid unintended effects of anticipated reciprocity (Iriberri \& Rey-Biel, 2013). In some of the identity induction treatments participants could earn additional money. These payoffs were paid out together with the other payments at the end of the experiment

Instructions were provided on-screen during each of the parts. ${ }^{8}$ To allow matching of the Part A and Part B results, subjects received a code in Part A which they had to bring to the lab for Part B. They were also informed that they would only be paid out if they participate in all parts of the experiment. Subjects were invited via ORSEE (Greiner, 2015). Subjects could earn tokens and coins which were exchanged 75 Euro cent $=10$ tokens $=100$ coins. In total, we ran 17 sessions with average earnings of 12.20 Euros. The duration of the experiment was around 45 minutes with slight variations between treatments. 204 subjects participated in the experiments.

\subsubsection{Measuring Social Preferences}

The concept of social value orientation is used in the social sciences as well as biology to describe how a person distributes resources between herself and others. Various schemes are used to classify individuals into one of four categories: Individualistic, Competitive, Prosocial, and

\footnotetext{
${ }^{7}$ Ockenfels and Werner (2014) have shown that second order beliefs can be an important mediator in social identity experiments.

${ }^{8}$ See Appendix 3.A.
} 
Altruistic. In economic terms, individualistic and altruistic people simply maximize the material payoffs of themselves or others, respectively. Here, we use use the SVO slider measure developed by Murphy et al. (2011) to measure social preferences. Similar to Andreoni and Miller (2002), the slider measure elicits social preferences with modified dictator games that vary in budget constraint and relative cost of giving. Table 3.2.1 shows the budget sets and relative price of giving of the six modified dictator games that are used to elicit the social value orientation. There are six budget sets in total, and each budget set contains nine evenly spaced options so that the options are a linear combination of the two endpoints. Option 1 and 9 are the start and endpoints of the respective budget constraint in the self-other allocation space. For each budget set, subjects have to chose one of the allocations between themselves and the other. For example, in the first budget set, subjects always get 85 tokens themselves but can vary the amount of tokens given to the other between 85 and 15 tokens. In this case, giving is costless. In the second budget set, the price of giving is negative. Thus, the payoffs for both players increase along the budget set, from 85 tokens for the oneself and 15 for the other to 100 tokens for oneself and 50 for the other. Budget sets 3 to 6 are characterized by different positive prices of giving, thus allocating more resources to the other comes at a cost of tokens for oneself.

While still often used categorical, already very early studies showed that social value orientation is continuous and can be conceptualized geometrically as a circle in the self-other allocation space (Griesinger \& Livingston, 1973; Liebrand \& McClintock, 1988). The SVO measure we use was developed by Murphy et al. (2011) to measure social preferences with higher resolution and statistical power than the previous elicitation methods of social value orientation and has been shown to provide very high test-retest reliability (Murphy \& Ackermann, 2014; Murphy et al., 2011). Figure 3.2.2 shows the six budget constraints of the SVO slider measure in the self-other allocation space. The angle $\theta$ is the social value orientation that is calculated from the six budget sets as follows:

$$
\theta=\arctan \left(\frac{\bar{A}_{o}-50}{\bar{A}_{s}-50}\right)
$$


Table 3.2.1: SVO Budget Sets

\begin{tabular}{cccc}
\hline \hline $\begin{array}{c}\text { Budget } \\
\text { Set }\end{array}$ & $\begin{array}{c}\text { Option } 1 \\
\left(\pi_{\text {self }}, \pi_{\text {other }}\right)\end{array}$ & $\begin{array}{c}\text { Option } 9 \\
\left(\pi_{\text {self }}, \pi_{\text {other }}\right)\end{array}$ & $\begin{array}{c}\text { Relative price of giving } \\
-\left(\Delta \pi_{\text {self }} / \Delta \pi_{\text {other }}\right)\end{array}$ \\
\hline 1 & $(85,85)$ & $(85,15)$ & 0 \\
2 & $(85,15)$ & $(100,50)$ & -0.43 \\
3 & $(50,100)$ & $(85,85)$ & 2.33 \\
4 & $(50,100)$ & $(85,15)$ & 0.41 \\
5 & $(100,50)$ & $(50,100)$ & 1.00 \\
6 & $(100,50)$ & $(85,85)$ & 0.43 \\
\hline \hline
\end{tabular}

Note: The budget sets represent the six items of the SVO slider measure. Option 1 and Option 9 represent the start and endpoint of a budget constraint in the self-other allocation space. Subjects have to chose a point on the budget constraint that is a linear combination of Option 1 and 9 for each budget set. The relative price of giving represents the tradeoff between own payoff and payoff of the other person for each of the budget sets. E.g. for budget set 3, increasing the payoff to self by one token decreases the payoff to the other by 0.43 tokens.

where $\bar{A}_{o}$ is the average allocation of payoffs to the other, $\bar{A}_{s}$ is the average allocation for the self, and subtracting the radius 50 centers the starting point of the angle within the circle. This SVO angle is higher if more prosocial choices are made and can turn negative if very competitive options are chosen across the budget sets.

\subsubsection{Inducing Social Identity}

We used five different methods that have been used in the literature to induce social identity. A simple categorization into groups by randomly assigned color ("Minimal"), a problem-solving task with communication ("Klee and Kandinsky"), group competition ("Group Contest"), endogenously created identity ("Flag"), and a real effort task ("Real Effort"). 


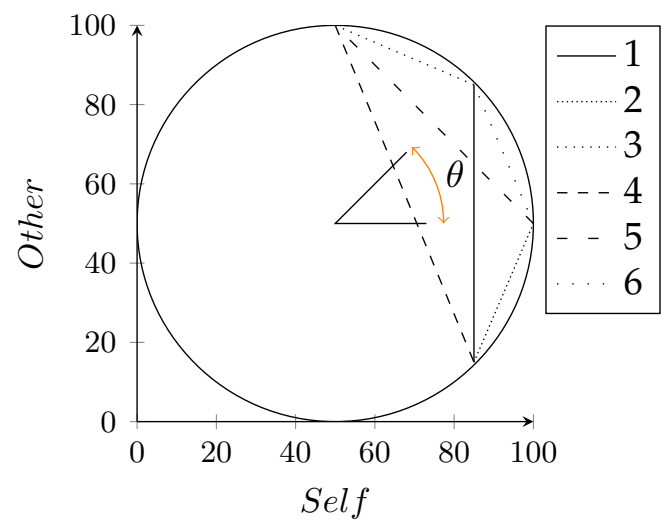

Note: The six budget constraints represent the six items of the SVO slider measure. The angle $\theta$ is the parameter that is calculated from the six points that subjects chose on the six budget constraints. The four endpoints of the budget sets on the circle are the idealized allocation decisions that perfectly competitive, individualistic, prosocial or altruistic persons would make.

Figure 3.2.2: SVO Budget Sets and SVO Angle in the Self-Other Payoff Space

\section{Minimal}

Subjects were assigned to groups of three which were labeled as either the Red, Blue, Green, or Yellow group. The colors were assigned randomly without replacement such that each group ends up with a different colour. Subjects were informed about their group membership and associated colour. This information was also given at the beginning of all other treatments. This is a variant of the "Minimal Group Paradigm" developed by Tajfel (1970).

\section{Klee and Kandinsky}

In this treatment, each subject was given five minutes to individually review five pairs of paintings by Wassily Kandinsky and Paul Klee. ${ }^{9}$

\footnotetext{
${ }^{9}$ The paintings are the same as in Chen and $\mathrm{Li}$ (2009) and Chen and Chen (2011): Gebirgsbildung, 1924, by Klee; Subdued Glow, 1928, by Kandinsky; Dreamy Improvisation, 1913, by Kandinsky; Warning of the Ships, 1917, by Klee; Dry-Cool
} 
In addition to the description on the screen, subjects also got a printout of the pictures that indicated which artist painted which painting. After the 5 minute period subjects were shown two more paintings. They had 5 minutes to determine for each painting if it was painted by either Klee or Kandinsky. ${ }^{10}$ They could make use of the printout to compare the two new paintings with paintings that they reviewed before. Furthermore, subjects were allowed to communicate within their group via a chat program. The decision input could only be made after the five minutes were over. Each correct answer earned ten tokens. Participants were not informed about the result of this stage until the end of the experiment. This treatment was adapted from Chen and $\mathrm{Li}$ (2009) and Chen and Chen (2011). As they discuss in their studies, using the Klee and Kandinsky task with random assignment into groups is strictly preferable to the original version of the task in which subjects are assigned to groups based on their painting preferences, as those preferences can potentially correlate with observable or non-observable characteristics. Furthermore, subjects could get the impression that the experimenter does them a favor in assigning them based on their preferences which could trigger experimenter demand effects (Chen \& Li, 2009).

\section{Group Contest}

Subjects received an endowment of 100 coins and decided how much of the endowment they wanted to invest in a one-shot contest game. Endowment that was not invested was added to their private account. In the contest game, investments of group members of group A are labeled $a_{i}$ where $A=\{1,2,3\}$ and $i \in A$, analogously for investments of group B. The winning probability $p_{A}$ is the probability of group A to win the contest over group B and is calculated by dividing all investments of group A by the sum of all investments by both groups:

Garden, 1921, by Klee; Landscape with Red Splashes I, 1913, by Kandinsky; Gentle Ascent, 1934, by Kandinsky; A Hoffmannesque Tale, 1921, by Klee; Development in Brown, 1933, by Kandinsky; The Vase, 1938, by Klee.

${ }^{10}$ Monument in Fertile Country, 1929, by Klee; Start, 1928, by Kandinsky. 
$p_{A}\left(\sum_{i \in A} a_{i}, \sum_{k \in B} b_{k}\right)=\frac{\sum_{i \in A} a_{i}}{\sum_{i \in A} a_{i}+\sum_{k \in B} b_{k}}$. If no one invests the probability of winning is $\frac{1}{2}$. Thus it is guaranteed that one group wins the contest. The contest prize is $z=300$ coins and is equally split among all group members of the winning group. Each member of the winning group thus gets an individual payoff of $300 / 3=100$ coins. Each unit of investment is equivalent to a lottery ticket and at the end of the round one ticket is drawn from the investment pool of lottery tickets to decide who won the contest. Thus, holding constant the other group's investment, the more investments are made by a group, the higher the chance to win the contest. Subjects did not get any feedback and were not informed about the outcome of the game or the investments of the others until the end of the experiment. This is similar to a one shot version of the group contest played in Abbink et al. (2010).

\section{Flag}

Subjects found envelopes with colored paper at their desk and were asked to cut the paper into any shape they wanted. The color was identical to their group color such that each group got different colored papers. The shapes of each group were collected and assembled into a group flag by the experimenter. The assembled group flags were photographed and the pictures uploaded to be displayed in the following SVO stages. The flag of the other group was represented by the group color only to avoid potential effects of the design of the opponents flag on behavior and thus on the independence of observations between groups. This treatment was adapted from Cacault and Grieder, 2019.

\section{Real Effort}

Subjects had to do a task in which they had to click on a circle on the computer screen to reduce its size. The color of the circle coincided with the color of the other group. Each click by a group member could contribute to the reduction of the circle. After the task, subjects did a similar task but this time the task was to increase the size of the circle. The color of the circle in this stage coincided with the own groups color. 
As an additional feature, the circle was now moving around the screen. The members of the group with the smallest circle in the first game, and the group with the largest circle in the second game each received ten tokens as reward. If the same group won at both of the games, its individuals received twenty tokens. Subjects were not informed about the outcome of these games before the end of the experiment. This treatment was adapted from Cacault and Grieder, 2019.

\subsection{Measurement Approaches and Econometrics}

We want to measure the success of social identity induction by estimating if subjects show an ingroup bias. This means that they behave more prosocially towards an ingroup member then to a random other person or someone from an outgroup after they completed the treatment. There are multiple ways to implement this, all with their own advantages and drawbacks.

For instance, many experiments on social identity use a betweensubjects design, which is easy to use and reduces chances of experimenter demand effects. In this case, one could elicit the SVO towards the ingroup from one subset of the sample and the SVO towards the outgroup and random other groups from other subsets and investigate if on average, subjects show an ingroup bias. However, this means that each individual only provides one observation and there is usually no correction for baseline differences in subjects' social value orientation. As the effects of social identity induced in the lab are likely to be rather small, any effect might be hidden in the statistical noise unless individual heterogeneity in social value orientation is small or the sample size is very large.

If a baseline measure of social value orientation is taken before the lab experiment, it is potentially possible to improve on the simple betweensubject measure by adjusting ingroup and outgroup SVO measures by the Baseline SVO. The object of comparison after the social identity induction is then no longer the SVO level but the change compared to the Baseline SVO which controls for individual differences in the Baseline SVO play. This is essentially a Difference-in-Differences analysis. 
In practice, this approach is more costly as it includes an additional measurement and requires to anonymously track subjects across two sessions to match the data. Attrition, Data integrity, anonymity of subjects, and the additional financial costs and resources to conduct more than one session per subject may become serious issues.

Another issue with both aforementioned approaches is that there might be group contingent effects. While this is unlikely to be an issue for the original minimal group paradigm where group members don't interact during the creation of the social identity, it might become an issue with techniques that use communication, interaction, or allow group members influence on the identity creation itself. The problem itself is similar to individual heterogeneity in social value orientation. If the heterogeneity in SVO between groups is large compared to the differences in SVO caused by the social identity induction, any effect might be hidden in the statistical noise unless the sample size is large enough. If the only issue is group contingent effects, it is possible to solve this by estimating the ingroup bias on group level. For this, the different group members conduct ingroup, outgroup, and random SVOs and ingroup bias on group level is measured by comparing the group members that did the ingroup SVO with those that performed random or outgroup SVOs. While this provides a within-group measure of social identity, it has the drawback that it reduces the effective sample size and that it does not control for individual heterogeneity.

If a Baseline SVO is available, it is possible to control for both, group and individual heterogeneity. For this, the SVOs of the group members in the within-group measure are adjusted for the Baseline SVO. This still has the drawbacks of reducing the effective sample size and the additional costs of measuring and linking the Baseline SVO with the laboratory data, but it should at the same time deal effectively with individual and group-level heterogeneity in social value orientation.

Finally, one can also consider a within-subjects design. The primary benefits of the within-subject design are increased statistical power and that it will reduce the noise present in a between-subjects design, as every subject serves as her own control group. At the same time, the repetition of the SVO with respect to subjects of different groups might 
make the group differences more salient and could thus act as an additional factor strengthening social identity. This salience of the group information might then create experimenter demand effects. If subjects get the idea that the experiment is about ingroup bias it could cause them to intentionally engage in biased behavior or, if it activates social norms and self-image concerns regarding discriminatory behaviour, could reduce the ingroup bias displayed in the experiment. We randomized and counterbalanced the order in which subjects do the different SVOs in our experiment, therefore we can estimate measures for all of the described approaches. For the between-subject and within-group measures, we only use the data from the first round SVO that subjects do in Part B, the lab part of the experiment. The standard errors are clustered on group level to account for potential interdependence created by the social identity induction. ${ }^{11}$

In the rest of this section, we describe the five statistical approaches that we use to measure the strength of social identity in more detail. We suppress subscripts whenever possible for the sake of clarity.

\subsubsection{Between-subjects measure}

Here, we use data only from the first round of Part B in the experiment, ignoring the remaining two rounds as well as the baseline SVO measurement from part $\mathrm{A}$. We use the following regression specification:

$$
\theta_{i, 1}=\beta_{0}+\left[\beta_{\text {In }} \times \delta_{\text {In,1 } 1}\right]+\left[\beta_{\text {Out }} \times \delta_{\text {Out }, 1}\right]+\varepsilon_{i}
$$

where $\theta_{i, 1}$ is individual $i^{\prime}$ s SVO score in round $1, \delta_{I n, 1}$ and $\delta_{O u t, 1}$ are dummy variables identifying whether the person was interacting with a member of their in-group or out-group in round 1 , and $\beta_{0}$ serves as a between-subjects baseline when interacting with a randomly selected other person in round 1.

\footnotetext{
${ }^{11}$ Cameron and Miller (2015) discuss that having few clusters can result in overrejection of the null hypothesis. As the number of clusters is relatively small in our experiment, we used the wild cluster bootstrap procedure suggested by Cameron and Miller (2015) to check if this is a problem in our dataset. We found minor differences in p-values but no differences in significance levels and thus report the non-bootstrapped standard errors and p-values.
} 
For valid social identity induction, we expect two conditions to hold $\beta_{\text {In }}>0$ and $\beta_{\text {In }}>\beta_{\text {Out }}$. The first condition, $\beta_{\text {In }}>0$, simply means that an individual is more generous on average to an in-group member than to a random person. The second condition, $\beta_{\text {In }}>\beta_{\text {Out }}$, means that an individual is more generous to in-group members than out-group members.

\subsubsection{Between-subjects measure with Baseline SVO Adjustment}

While the between-subjects design is commonly used, its biggest shortcoming is that real effects may disappear in statistical noise due to individual heterogeneity in baseline SVO disposition. To address this shortcoming, we can use each subject's SVO from Part A as a within-subject correction. Although we are still examining effects between subjects, we are now examining the changes in SVO due to social identity rather than SVO levels towards members of the different groups. As we are indeed more interested in the changes that social identity causes in SVO than in the differences in SVO levels, this measure appears more appropriate. This is essentially a Difference-in-Differences analysis in which we calculate the first difference on the left hand side of the regression equation. We use the following regression specification:

$$
\theta_{i, 1}-\theta_{i, 0}=\beta_{0}+\left[\beta_{\text {In }} \times \delta_{\text {In }, 1}\right]+\left[\beta_{\text {Out }} \times \delta_{\text {Out }, 1}\right]+\varepsilon_{i}
$$

where $\theta_{i, 1}$ is individual $i$ 's SVO score in round $1, \theta_{i, 0}$ is $i^{\prime}$ 's baseline SVO in Part $\mathrm{A}, \delta_{I n, 1}$ and $\delta_{O u t, 1}$ are dummy variables indicating whether the person was interacting with a member of their in-group or out-group in round 1 , and $\beta_{0}$ serves as a between-subjects baseline when interacting with a randomly selected other person in round 1 . The conditions for valid social identity induction are analogue to the Between-subjects Design.

\subsubsection{Within-group measure}

Since each member of a given group interacts with a different type of counterpart in the first round of Part B, we can use the difference in 
SVO between the in-group interaction and random or out-group interaction within a group as a within-group measure of the effect of social identity. This makes the group the independent unit of observation. Econometrically, this is achieved by including group fixed effects in the regression specifications:

$$
\theta_{i, 1}=\beta_{0}+c_{g}+\left[\beta_{\text {In }} \times \delta_{i, \text { In }, 1}\right]+\left[\beta_{\text {Out }} \times \delta_{i, \text { Out }, 1}\right]+\varepsilon_{i}
$$

where the $\theta_{i, 1}$ is the individual SVO in round 1 of Part $\mathrm{B}, \delta_{i, I n, 1}$ and $\delta_{i, \text { Out }, 1}$ are dummy variables indicating whether the group member was interacting with a member of their in-group or out-group in round 1 , and $c_{g}$ are the group specific fixed effects. The decision with respect to someone who was not part of the in- or outgroup serves as baseline.

For valid social identity induction we expect $\beta_{\text {In }}>0$ and $\beta_{\text {In }}>\beta_{\text {Out }}$ to hold, meaning that that participants are more generous towards their ingroup than to the random- or outgroup.

\subsubsection{Within-group measure with Baseline SVO Adjustment}

For this measure we combine the approach of the within-group measure with the Baseline SVO adjustment from the between-subjects measure. Which results in the following specification:

$$
\left[\theta_{i, 1}-\theta_{i, 0}\right]=\beta_{0}+c_{g}+\left[\beta_{\text {In }} \times \delta_{i, \text { In }, 1}\right]+\left[\beta_{\text {Out }} \times \delta_{i, \text { Out }, 1}\right]+\varepsilon_{i}
$$

Compared to the within-groups design, everyhting stays the same except that we now account for the baseline $\operatorname{SVO} \theta_{i, 0}$ by subtracting it from each group member's first round SVO. For valid social identity induction we expect $\beta_{\text {In }}>0$ and $\beta_{\text {In }}>\beta_{\text {Out }}$ to hold, meaning that that participants are more generous towards their ingroup than to the random- or outgroup.

The approaches up until now only used information of round 1 of Part $\mathrm{B}$ and of Part A when adjusting for Baseline SVO. Next we fully utilize the repeated measure for each individual. 


\subsubsection{Within-subject Design}

Here, we look at the within-subject differences between interactions with an in-group, random, and out-group member. We can do this for all subjects, as every subject made all of these decisions in Part B. Recall, also, that the type of counterpart was randomized and counterbalanced across subjects, which should average out potential confounds arising from the order of the decisions. The within-subject measure is estimated using a fixed-effects model, with the individual as cross-sectional and the round as time dimension.

$$
\theta_{i, t}=\beta_{0}+\left[\alpha_{i} \times c_{i}\right]+\left[\beta_{\text {In }} \times \delta_{i, \text { In }, t}\right]+\left[\beta_{\text {Out }} \times \delta_{i, \text { Out }, t}\right]+\varepsilon_{i, t}
$$

where $\theta_{i, t}$ is individual $i^{\prime}$ s SVO score in round $t, \delta_{i, I n, t}$ and $\delta_{i, O u t, t}$ are dummy variables identifying whether the person was interacting with a member of their in-group or out-group in round $t$, and $c_{i}$ is an individual specific fixed effect. The inclusion of the fixed effects term in this regression has the same function as the Baseline SVO adjustments in the other approaches, namely controlling for the heterogeneity between subjects that is not caused by the social identity induction. As before, we expect $\beta_{\text {In }}>\beta_{\text {Out }}$ and $\beta_{\text {In }}>0$ to hold if a social identity was successfully induced, implying that subjects are more prosocial towards their own group when compared to the out- or random group. In addition, we also ran a specification in which we included controls for the decision order to see if the order in which subjects made the three SVO decisions with respect to ingroup, outgroup, and random group has an effect on the ingroup bias.

\subsection{Results}

Table 3.4.1 presents a qualitative overview of the main results for the different research designs and social identity induction techniques we evaluate. The contest treatment is the only induction method that consistently satisfies the requirements for social identity induction. For the between-subjects and within-group measures, this treatment contest 
treatment is the only treatment that satisfies the conditions for effective social identity induction, which are that $\beta_{\text {In }}$ is both positive and larger than $\beta_{\text {Out }}$. However, only the comparison to the outgroup is reaching at least marginally significant in 4 out of the 5 treatment. The within-subject measure is the only one in which all treatments satisfy the requirement for social identity induction. All treatments introduce a (marginally) significant ingroup bias in comparison with the out- and random group. Furthermore, we show that treatment effects are very heterogeneous with respect to initial social value orientation which means that measuring an individual's baseline social value orientation and correcting for it in a between-subjects or difference-in-differences design does not necessarily increase precision of the estimates.

Table 3.4.1: Overview of main results

\begin{tabular}{llccccc}
\hline \hline Design & Property & Minimal & Klee & Contest & Flag & Real effort \\
\hline Between-subjects & In $>$ Rand & $\mathrm{Y}$ & $\mathrm{Y}$ & $\mathrm{Y}$ & $\mathrm{Y}$ & - \\
& In $>$ Out & $\mathrm{Y}$ & $\mathrm{Y}$ & $\mathrm{Y}^{* *}$ & - & - \\
\hline Between-subjects, & In $>$ Rand & - & $\mathrm{Y}$ & $\mathrm{Y}$ & $\mathrm{Y}$ & - \\
baseline adjusted & In $>$ Out & $\mathrm{Y}$ & - & $\mathrm{Y}^{*}$ & - & - \\
\hline Within-group & In $>$ Rand & - & $\mathrm{Y}$ & $\mathrm{Y}$ & $\mathrm{Y}$ & - \\
& In $>$ Out & $\mathrm{Y}$ & - & $\mathrm{Y}^{*}$ & - & - \\
\hline Within-group & In $>$ Rand & - & $\mathrm{Y}$ & $\mathrm{Y}$ & $\mathrm{Y}$ & - \\
baseline adjusted & In $>$ Out & - & - & $\mathrm{Y}$ & - & - \\
\hline Within-subject & In $>$ Rand & $\mathrm{Y}^{* * *}$ & $\mathrm{Y}^{* * *}$ & $\mathrm{Y}^{* *}$ & $\mathrm{Y}^{* *}$ & $\mathrm{Y}^{*}$ \\
& In $>$ Out & $\mathrm{Y}^{* *}$ & $\mathrm{Y}^{* * *}$ & $\mathrm{Y}^{* * *}$ & $\mathrm{Y}^{* * *}$ & $\mathrm{Y}^{* * *}$ \\
\hline \hline
\end{tabular}

Note: $Y$ marks the instances in which the treatments successfully induced social identity based on the specified property. P-value below significance level: ${ }^{*} p<0.10$ ** $p<0.05,{ }^{* * *} p<0.01$.

In the following, we first present summary statistics of the the different SVO measures. Next we compare the different treatments with the between-subject, adjusted between-subject, within-group, adjusted within-group and within-subject measures using parametric tests. Then we analyze the role that the order of the social preference elicitations and the baseline SVO measure play in determining individual discriminatory behavior. 


\subsubsection{Summary Statistics}

Figure 3.4.1 shows the cumulative distribution functions of the four different SVO-measurements that are taken during the experiment from all 204 participants across all treatments. About $80 \%$ of all subjects' SVO angles fall in the range of 7.82 and 37.48 , where 7.82 represents the benchmark for perfectly consistent individualists, who always maximize their own payoff. 37.48 represents the benchmark for a consistent inequality minimizing subject and values above 37.09 represent subjects that are consistent welfare maximizers. ${ }^{12}$ Thus the decision space that subjects actually use only spans over approximately 30 degrees. ${ }^{13}$ Compared to the the baseline-SVO that subjects do a week before the lab sessions, subjects are more prosocial in the ingroup decisions in the lab with the average SVO towards the ingroup being 24.34 and the average SVO towards a random other in the baseline being $21.56 .^{14}$ The outgroup and random SVOs in the lab are very similarly distributed, both classifying approximately $10 \%$ more participants as consistent individualistic than in the baseline or the ingroup-SVO which is represented by the spike around 7.8 in Figure 3.4.1. There is hardly any difference between the mean of the random and outgroup decisions, 19.89 and 19.17 respectively. ${ }^{15}$ Comparing the baseline-SVO with the Random decision in the lab reveals that while both decisions are made with respect to a random other person, the lab decisions tend to be less prosocial. ${ }^{16}$ The ingroup decisions are more prosocial than both, the outgroup and the random decisions in the lab. ${ }^{17}$

${ }^{12}$ As we did not use the secondary SVO-items, we cannot fully disentangle welfare maximizing and inequality minimizing behavior

${ }^{13}$ The possible range is -16.26 to 61.39 . The range we observe in our experiment is quite similar to Murphy et al. (2011) but subjects in the original experiment are somewhat more prosocial and thus the range in which most people fall is somewhat larger.

${ }^{14}$ Wilcoxon signed-rank test with H0: Baseline=Ingroup, $p=0.031$

${ }^{15}$ Wilcoxon signed rank test with H0: Random=Outgroup, $p=0.080$

${ }^{16}$ But this difference is not significantly different at 5\% significance level (Wilcoxon signed rank test with H0: Random=Baseline, $p=0.094)$.

${ }^{17}$ Wilcoxon signed rank tests with H0: In=Out $p<0.001$; H0: In=Rand, $p<0.001$. Additional summary statistics concerning subject characteristics can be found in Appendix 3.B. 


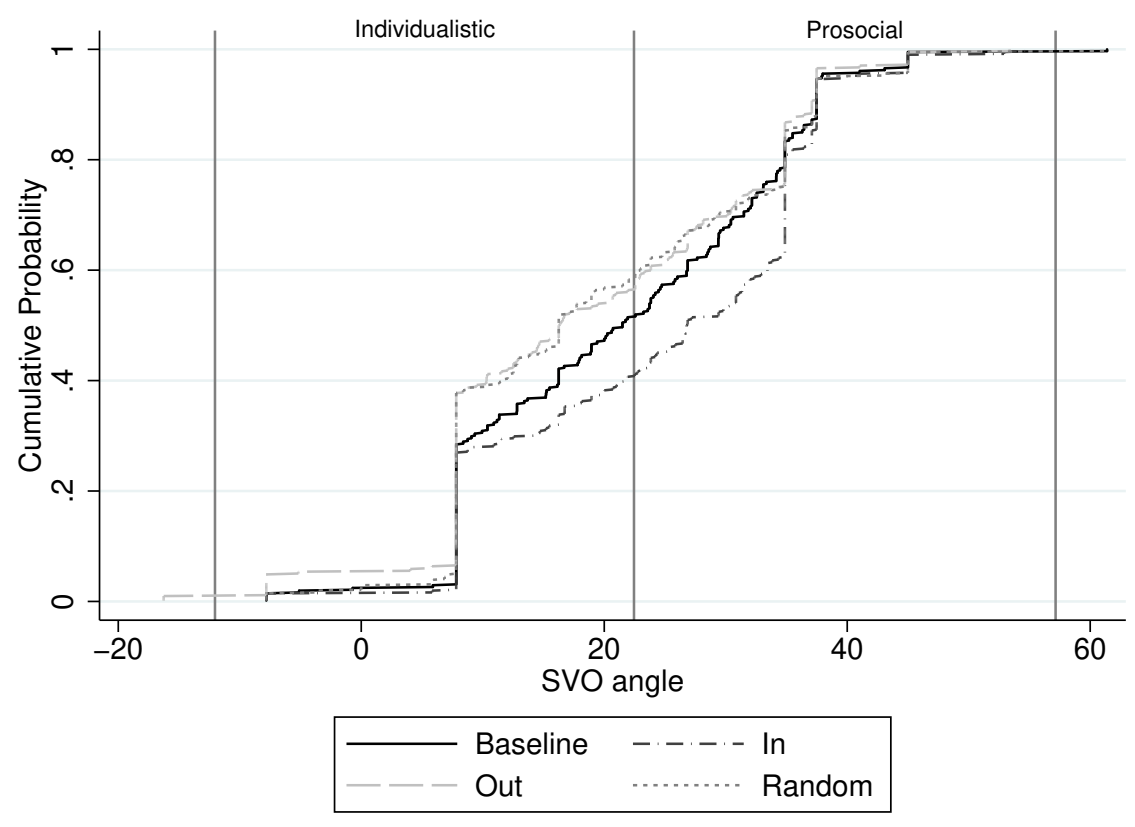

Figure 3.4.1: SVO Cumulative Distribution Functions 


\subsubsection{Between-Subject}

To identify the between-subject treatment effect we run OLS regressions with the social value orientation angle as dependent variable and dummies for the decision type on the first round data from the lab experiment. The dummy for the SVO decision that is made with respect to a random person serves as baseline and standard errors are clustered by group. The results in Table 3.4.2 show that while the Minimal, Klee, Contest, and Flag treatments induce a positive difference between the SVO decision towards an ingroup member and a random person, none of these differences reaches statistical significance. The contest game is the only treatment to induce a significant positive difference between ingroup and outgroup decisions $(\mathrm{p}=0.021)$. In the Flag and the Real Effort treatment, subjects are more prosocial to the outgroup relativ to random but this is only significant for the Flag treatment.

Table 3.4.2: Between-subject

\begin{tabular}{|c|c|c|c|c|c|}
\hline & \multicolumn{5}{|c|}{$\begin{array}{c}\text { Treatment effect } \\
\text { (between-subjects) } \\
\left(S V O_{i}\right)\end{array}$} \\
\hline & Minimal & Klee & Contest & Flag & Real Effort \\
\hline In & $\begin{array}{c}1.213 \\
(5.840)\end{array}$ & $\begin{array}{c}6.316 \\
(4.986)\end{array}$ & $\begin{array}{c}5.603 \\
(6.792)\end{array}$ & $\begin{array}{c}9.415 \\
(5.612)\end{array}$ & $\begin{array}{c}-1.859 \\
(5.199)\end{array}$ \\
\hline Out & $\begin{array}{r}-6.778 \\
(6.139)\end{array}$ & $\begin{array}{c}5.908 \\
(4.070)\end{array}$ & $\begin{array}{r}-4.602 \\
(8.398)\end{array}$ & $\begin{array}{l}11.225^{* *} \\
(3.891)\end{array}$ & $\begin{array}{c}2.404 \\
(6.393)\end{array}$ \\
\hline Constant & $\begin{array}{l}23.966^{* * *} \\
(3.675)\end{array}$ & $\begin{array}{l}21.615^{* * *} \\
(2.967)\end{array}$ & $\begin{array}{l}22.925^{* * *} \\
(4.825)\end{array}$ & $\begin{array}{l}14.987^{* * *} \\
(3.593)\end{array}$ & $\begin{array}{l}19.943^{* * *} \\
(3.750)\end{array}$ \\
\hline$N$ & 36 & 48 & 36 & 36 & 48 \\
\hline F-test In=Out & 0.182 & 0.931 & $0.021^{* *}$ & 0.746 & 0.390 \\
\hline
\end{tabular}

Note: Between-subjects and same round (round 1). SVO decisions towards the random group serve as reference group. Standard errors clustered by group in parentheses. ${ }^{*} p<0.10$ ** $\mathrm{p}<0.05,{ }^{* * *} \mathrm{p}<0.01$. 


\subsubsection{Between-Subject Adjusted For Baseline SVO}

Subtracting the baseline-SVO measure taken before the lab sessions from each first round SVO provides us with a between subject comparison of treatment effects (Table 3.4.3). None of the treatments produces a significant difference between an ingroup and a random person, with only the Klee, Flag, and Contest treatment producing a positive coefficient of the ingroup variable. Only the Minimal and Contest treatment create a positive ingroup bias between the ingroup and the outgroup but only the effect for the Contest is marginally significant $(\mathrm{p}=0.071)$. While we expected this procedure to eliminate some of the noise by adjusting for the individuals' different baseline social value orientation, the increase in standard errors indicates that adjusting for the baseline SVO actually added noise to the analysis.

Table 3.4.3: Between-subject adjusted for Baseline SVO

\begin{tabular}{lccccc}
\hline \hline \multicolumn{5}{c}{$\begin{array}{r}\text { Treatment effect adjusted for baseline } \\
\text { (between-subjects) } \\
\end{array}$} & \multicolumn{5}{c}{$\left(S V O_{i, 1}-S V O_{i, 0}\right)$} \\
\cline { 2 - 6 } & Klee & Contest & Flag & Real Effort \\
\cline { 2 - 6 } In & -2.303 & 7.005 & 4.710 & 7.685 & -4.081 \\
& $(8.198)$ & $(5.126)$ & $(6.254)$ & $(7.803)$ & $(7.460)$ \\
Out & -3.119 & 8.179 & -11.561 & 8.350 & 11.306 \\
& $(6.892)$ & $(6.712)$ & $(10.61)$ & $(6.875)$ & $(7.115)$ \\
Constant & 2.799 & -0.278 & 5.676 & $-8.252^{*}$ & -3.703 \\
& $(5.551)$ & $(3.606)$ & $(5.832)$ & $(3.960)$ & $(3.925)$ \\
\hline$N$ & 36 & 48 & 36 & 36 & 48 \\
F-test In=Out & 0.894 & 0.864 & $0.071^{*}$ & 0.920 & $<0.001^{* * *}$ \\
\hline \hline
\end{tabular}

Note: Between-subjects with baseline adjustment (the baseline adjustment is within subject), same round (round 1 compared to baseline). Subscript 1 (0) refers to the first-round of the lab session (online session). SVO decisions towards the random group serve as reference group. Standard errors clustered by group in parentheses. ${ }^{*} p<0.10{ }^{* *} p<0.05,{ }^{* * *} p<0.01$. 


\subsubsection{Within-Group}

Instead of accounting for correlation on group level through clustering, we can also create a within-group measure to assess the treatment effect. To do this, we include group-level fixed effects, which controls for between-group variation and gives us the within-group treatment effect of the social identity induction methods. The results in Table 3.4.4 show that all except for the Real Effort treatment induce a positive ingroup bias compared to the random but all are insignificant. When compared to the outgroup, the Minimal, Klee, and Contest treatment create an ingroup bias but only the effect of the Contest treatment is significant at the $10 \%$ level $(p=0.052) .{ }^{18}$.

Table 3.4.4: Within-Group

\begin{tabular}{|c|c|c|c|c|c|}
\hline & \multicolumn{5}{|c|}{$\begin{array}{c}\text { Treatment effect } \\
\text { (Within-group) } \\
\quad\left(S V O_{g, 1}\right)\end{array}$} \\
\hline & Minimal & Klee & Contest & Flag & Real Effort \\
\hline In & $\begin{array}{c}1.213 \\
(7.153)\end{array}$ & $\begin{array}{c}6.316 \\
(6.106)\end{array}$ & $\begin{array}{c}5.603 \\
(8.318)\end{array}$ & $\begin{array}{c}9.415 \\
(6.873)\end{array}$ & $\begin{array}{c}-1.859 \\
(6.367)\end{array}$ \\
\hline Out & $\begin{array}{r}-6.778 \\
(7.519)\end{array}$ & $\begin{array}{c}5.908 \\
(4.985)\end{array}$ & $\begin{array}{l}-4.602 \\
(10.29)\end{array}$ & $\begin{array}{l}11.225^{*} \\
(4.765)\end{array}$ & $\begin{array}{c}2.404 \\
(7.829)\end{array}$ \\
\hline Control & $\begin{array}{l}33.574^{* * *} \\
(4.323)\end{array}$ & $\begin{array}{l}27.951^{* * *} \\
(3.196)\end{array}$ & $\begin{array}{l}24.300^{* *} \\
(6.038)\end{array}$ & $\begin{array}{l}21.321^{* * *} \\
(3.252)\end{array}$ & $\begin{array}{l}27.886^{* * *} \\
(4.331)\end{array}$ \\
\hline$N$ & 36 & 48 & 36 & 36 & 48 \\
\hline F-test In $=$ Out & 0.269 & 0.944 & $0.052^{*}$ & 0.792 & 0.481 \\
\hline Fixed effects & Group & Group & Group & Group & Group \\
\hline
\end{tabular}

Note: Within-group and same round (round 1) with group level fixed effects. SVO decisions towards the random group serve as reference group. Standard errors clustered by group in parentheses. * $\mathrm{p}<0.10^{* *} \mathrm{p}<0.05{ }^{* * *} \mathrm{p}<0.01$.

\footnotetext{
${ }^{18}$ As contest contributions could trigger a sunk cost effect for the SVO decisions and drive subjects to discriminate more, as they already committed to the conflict between the groups, we also tested if contest contributions affect the degree to which subjects discriminate. This does not turn out to be the case. For the analysis see Appendix 3.C.
} 


\subsubsection{Within Group Adjusted For Baseline SVO}

Similarly to the between subject measures, we can adjust the withingroup measure with a within-subject correction for differences in the Baseline SVO. This provides a difference-in-differences measure, comparing the difference between baseline and first round measure of one group member with the difference of baseline and first round measure of another member of the same group. This measure has the advantage of eliminating noise from individual as well as group level heterogeneity. Table 3.4.5 shows that, against our expectation, making the withingroup measure a difference-in-differences measure is not beneficial for the precision of the measurement as standard errors generally increase compared to the within-group measure. Only the Klee, Contest, and Flag treatment induce a ingroup bias compared to the random group but none of the differences is significant. The difference between the ingroup and outgroup decision in the Contest treatment is now even higher at 16.3, but due to the increase in the error terms, not significant at conventional levels $(\mathrm{p}=0.131)$. The only other treatment with a positive ingroup bias compared to the outgroup is the minimal treatment, but the difference is not significant. All other treatments show a negative effect with the mean effect of the Real Effort treatment being -15.4 and significant at $1 \%$ significance level.

\subsubsection{Within-Subject}

Considering all three lab rounds, we can analyze the strength of the social identity on an individual level and construct a within-subject measure. Table 3.4.6 shows that all of the treatments induce a positive ingroup bias compared to the random group and thus are successful in inducing social identity. The effects are at least marginally signficant in all treatments. The difference between the ingroup decisions and the outgroup decisions are also positive in all treatments and except for the Minimal treatment, the p-values are all below a $1 \%$ significance level. The ingroup bias compared to the outgroup in the Minimal treatment is significant at $p=0.015$.

The mean difference between ingroup SVO and random or outgroup 
Table 3.4.5: Within-Group adjusted for Baseline SVO

\begin{tabular}{|c|c|c|c|c|c|}
\hline & \multicolumn{5}{|c|}{$\begin{array}{c}\text { Treatment effect adjusted for baseline } \\
\text { (Within-Group) } \\
\left(S V O_{i, 1}-S V O_{i, \text { Base }}\right)\end{array}$} \\
\hline & Minimal & Klee & Contest & Flag & Real Effort \\
\hline In & $\begin{array}{l}-2.303 \\
(10.04)\end{array}$ & $\begin{array}{c}7.005 \\
(6.278)\end{array}$ & $\begin{array}{c}4.710 \\
(7.660)\end{array}$ & $\begin{array}{c}7.685 \\
(9.557)\end{array}$ & $\begin{array}{c}-4.081 \\
(9.136)\end{array}$ \\
\hline Out & $\begin{array}{r}-3.119 \\
(8.440)\end{array}$ & $\begin{array}{c}8.179 \\
(8.221)\end{array}$ & $\begin{array}{r}-11.561 \\
(13.00)\end{array}$ & $\begin{array}{c}8.350 \\
(8.420)\end{array}$ & $\begin{array}{l}11.306 \\
(8.714)\end{array}$ \\
\hline Constant & $\begin{array}{l}11.655 \\
(5.682)\end{array}$ & $\begin{array}{c}7.670 \\
(4.028)\end{array}$ & $\begin{array}{c}22.642^{* *} \\
(6.285)\end{array}$ & $\begin{array}{r}-6.607 \\
(5.397)\end{array}$ & $\begin{array}{l}12.070 \\
(5.781)\end{array}$ \\
\hline$N$ & 36 & 48 & 36 & 36 & 48 \\
\hline F-test In=Out & 0.913 & 0.889 & 0.131 & 0.934 & $<0.002^{* * *}$ \\
\hline Fixed effects & Group & Group & Group & Group & Group \\
\hline
\end{tabular}

Note: Within-Group with baseline adjustment (the baseline adjustment is within subject), same round (round 1 compared to baseline). SVO decisions towards the random group serve as reference group. Standard errors clustered by group in parentheses. ${ }^{*} p<0.10^{* *} p<0.05,{ }^{* * *} p<0.01$.

SVO varies between treatments from 2.387 to 6.698 . Given that most subjects have a social value orientation between 7.82 and 37.48 , this effect size amounts to $8-22 \%$ of the used decision space.

The findings from the different social identity measures can be summarized as follows. The approaches that are based on between-subject or within-group measures are relatively noisy, even when additional means such as correcting for initial social value orientation or for group level effects are used. In those circumstances, only the Contest treatment reliably induced an ingroup bias but this was only statistically significant with some measures and only when the comparison was made with the outgroup. Using an within-subject approach resulted in a significant ingroup bias in all treatments and compared to both, the outgroup and the random group.

Result 1. Only the Contest treatment creates an ingroup bias when compared to random and outgroup across all econometric approaches and thus succeeds in inducing social identity. However, this effect is only significant for comparisons to both-random and outgroup-in the within-subject treatment and 
Table 3.4.6: Within-Subject

\begin{tabular}{lccccc}
\hline \hline & \multicolumn{5}{c}{$\begin{array}{c}\text { Treatment effect } \\
\text { (within-subjects) } \\
\end{array}$} \\
& Minimal & Klee & Contest & Flag & Real Effort \\
\cline { 2 - 6 } & $4.261^{* * *}$ & $5.411^{* * *}$ & $5.495^{* *}$ & $5.067^{* *}$ & $2.387^{*}$ \\
& $(0.937)$ & $(1.340)$ & $(2.148)$ & $(1.860)$ & $(1.140)$ \\
& & & & & \\
In & 0.686 & $-1.287^{*}$ & -0.0769 & -0.279 & $-2.021^{*}$ \\
& $(1.209)$ & $(0.645)$ & $(2.094)$ & $(1.533)$ & $(0.971)$ \\
Constant & $18.790^{* * *}$ & $23.177^{* * *}$ & $18.702^{* * *}$ & $19.170^{* * *}$ & $18.865^{* * *}$ \\
$N$ & $(0.591)$ & $(0.492)$ & $(1.362)$ & $(1.022)$ & $(0.547)$ \\
& 108 & 144 & 144 & 108 & 108 \\
\hline F-test In=Out & $0.015^{* *}$ & $<0.001^{* * *}$ & $<0.001^{* * *}$ & $0.004^{* * *}$ & $0.005^{* * *}$ \\
Fixed effects & Ind. & Ind. & Ind. & Ind. & Ind. \\
\hline \hline
\end{tabular}

Note: Within-subjects with individual fixed effects. SVO decisions towards the random group serve as reference group. ${ }^{*} p<0.10^{* *} p<0.05,{ }^{* * *} p<0.01$.

for the outgroup comparisons in the (adjusted) Between-subjects, and Withingroup treatments.

Result 2. All treatments successfully induce social identity when measured within-subject.

\subsubsection{Further analysis of within-subject data}

We further analyze the within-subject measure by regressing the ingroup bias on additional data we collected for the individual participant. We use demographic controls, risk aversion and perceived closeness to the own group from the post-experiment questionnaire, dummies for the treatments and order in which the SVOs were taken, and run regressions on the within-subject difference between ingroup and outgroup SVO. Table 3.4.7 reports the results from four regressions with standard errors clustered by group and the minimal treatment as reference group. In (1) we only regress the treatment dummies on the 
Table 3.4.7: OLS Analysis of Within-Subject Measure

\begin{tabular}{|c|c|c|c|c|}
\hline & \multicolumn{4}{|c|}{$\left(S V O_{i, \text { In }}-S V O_{i, \text { Out }}\right)$} \\
\hline & (1) & $(2)$ & (3) & (4) \\
\hline \multirow[t]{2}{*}{ Klee } & 3.124 & & 3.124 & 0.252 \\
\hline & $(0.103)$ & & $(0.102)$ & $(0.888)$ \\
\hline \multirow[t]{2}{*}{ Contest } & 1.997 & & 1.997 & 0.657 \\
\hline & $(0.224)$ & & $(0.225)$ & $(0.693)$ \\
\hline \multirow[t]{2}{*}{ Flag } & 1.772 & & 1.772 & -0.104 \\
\hline & $(0.347)$ & & $(0.339)$ & $(0.962)$ \\
\hline \multirow[t]{2}{*}{ Real Effort } & 0.833 & & 0.833 & 0.805 \\
\hline & $(0.640)$ & & $(0.637)$ & $(0.650)$ \\
\hline \multirow[t]{2}{*}{ InRandOut } & & $-4.574^{*}$ & $-4.574^{*}$ & $-4.525^{*}$ \\
\hline & & $(0.065)$ & $(0.063)$ & $(0.092)$ \\
\hline \multirow[t]{2}{*}{ OutInRand } & & $-8.020^{* * *}$ & $-8.020^{* * *}$ & $-6.410^{* *}$ \\
\hline & & $(0.002)$ & $(0.002)$ & $(0.020)$ \\
\hline \multirow[t]{2}{*}{ OutRandIn } & & $-7.092^{* * *}$ & $-7.092^{* *}$ & $-6.667^{* *}$ \\
\hline & & $(0.010)$ & $(0.010)$ & $(0.011)$ \\
\hline \multirow[t]{2}{*}{ RandInOut } & & -1.920 & -1.920 & -2.190 \\
\hline & & $(0.569)$ & $(0.573)$ & $(0.500)$ \\
\hline \multirow[t]{2}{*}{ RandOutIn } & & -1.277 & -1.277 & -1.228 \\
\hline & & $(0.675)$ & $(0.677)$ & $(0.672)$ \\
\hline \multirow[t]{2}{*}{ Baseline-SVO } & & & & -0.002 \\
\hline & & & & $(0.972)$ \\
\hline \multirow[t]{2}{*}{ Closeness to Group } & & & & $1.182^{* * *}$ \\
\hline & & & & $(0.001)$ \\
\hline \multirow[t]{2}{*}{ Constant } & $3.575^{* * *}$ & $8.985^{* * * *}$ & $7.389^{* * *}$ & 2.925 \\
\hline & $(0.004)$ & $(0.000)$ & $(0.009)$ & $(0.469)$ \\
\hline$N$ & 204 & 204 & 204 & 204 \\
\hline Other Controls (Survey) & No & No & No & Yes \\
\hline
\end{tabular}

Note: Within-subject. Standard errors clustered by group in parentheses. The Minimal and InOutRand dummies are omitted to avoid perfect multicollinearity and are thus the reference group. Coefficients for the survey variables are reported in the Appendix. ${ }^{*} p<0.10{ }^{* *} p<0.05,{ }^{* * *}$ $p<0.01$. 
In-Out Difference and find no significant difference between treatments. Regression (2) includes the order dummies but not the treatments. InRandOut is the dummy for the participants that did the ingroup decisions first, the random decision second, and the outgroup decision last. The other orders are named analogously with InOutRand being the reference group. Compared to the reference order InOutRand, all other orders produce a lower ingroup bias. We find that the orders that start with the outgroup decision have a highly negative coefficient and are significant at $1 \%$ level, suggesting a much lower ingroup bias $(\mathrm{p}=0.002$, $\mathrm{p}=0.010$ ). The size of the effect is higher than the average treatment effect found in Table 3.4.6. Regressing both the treatment and the order dummies on the within-subject measure does not change the statistical significance of the order effects (specification (3)). Regression (4) additionally includes the Baseline-SVO, self-reported closeness to the own group, and additional demographic controls from the post-experiment questionnaire. Differences between treatments are still insignificant after controlling for other variables and baseline social value orientation has no effect on the measure. Closeness to the own group as indicated on a 1-10 likert scale after the experiment significantly correlates with the measure $(\mathrm{p}=0.001)$, which provides a useful robustness check for our use of ingroup bias as a proxy for social identity. The order of the social value orientation tests still affects the measure considerably, with orders that start with the outgroup decision reducing the difference between ingroup and outgroup SVO by over 6 degrees. These negative order effects are significant at a 5\% level (p-values: 0.020, 0.011). None of the other controls were significant. ${ }^{19}$

We additionally analyzed the order effects by pooling the data across treatments and comparing the different SVO decisions by round in which they were taken. In Table 3.4.8 we show the difference in social value orientation towards ingroup, outgroup, and random person by round aggregated over all treatments. All SVO measures in a row are taken in the same round whereas all SVO measures in a column share the same decision type. As each individual only performs one SVO test per round and each type of SVO test exactly once, compar-

\footnotetext{
${ }^{19}$ An overview of the questionnaire and the respective summary statistics is provided in Appendix 3.B.
} 
isons within a column or within a row are always between-subjects and analysed with Kruskal-Wallis tests. The difference between decisions is not statistically significant in the first round but turns significant in the following rounds (Round 1: In=Out=Rand, $\mathrm{p}=0.226$; Round 2: In=Out=Rand, $\mathrm{p}=0.008$; Round 3 : $\mathrm{In}=\mathrm{Out}=$ Rand, $\mathrm{p}=0.016) .{ }^{20}$ This indicates that in the first round, subjects do not make use of the information about group membership or at least do not let it affect their decision and only start to discriminate between the in- and outgroup in the following rounds. While it does not matter in which round the ingroup and the random decision are taken (In: Round1=Round2=Round3, p=0.929; Rand: Round $1=$ Round $2=$ Round $3, p=0.686$ ), it does matter for the outgroup decision as the SVO in the first round is significantly higher than in later rounds (Out: Round1=Round2=Round3, $\mathrm{p}=0.022$ ) ${ }^{21}$ The order effects for the outgroup decision could be a result of different costs of discrimination: For subjects that made the random or ingroup decision first, it is relatively cheap to start to discriminate in the second and third round, as giving less money to the other person is also payoff maximizing for themselves in most of the modified dictator games. However, for subjects that start with outgroup decisions, discriminating in later rounds is materially costly as they can only discriminate between the outgroup and ingroup by giving more to the ingroup in the subsequent decisions, which in most cases comes with a decrease in own payoff.

Result 3. If the first SVO decision is towards an outgroup member, there there is no subsequent discrimination between groups.

\section{Heterogeneous Treatment Effects}

We already know from specification (4) in Table 3.4.7 that there is no significant correlation between the Baseline-SVO and ingroup bias and

\footnotetext{
${ }^{20}$ There is also no difference between the first round decisions in the lab and the baseline SVO taken one week in advance (Wilcoxon signed-rank test In=Online, $\mathrm{p}=0.423$; Out=Online, $\mathrm{p}=0.258$; Rand $=$ Online, $\mathrm{p}=0.437$ ).

${ }^{21} \mathrm{~A}$ breakdown by treatment can be found in Appendix 3.D
} 
Table 3.4.8: Mean SVO by Order and Decision Type

\begin{tabular}{lcccc}
\hline \hline Round & In & Out & Rand & p-value \\
\hline 1 & 24.611 & 22.626 & 20.698 & 0.226 \\
2 & 23.893 & 15.767 & 20.176 & $0.008^{* * *}$ \\
3 & 24.523 & 19.122 & 18.801 & $0.016^{* *}$ \\
\hline p-value & 0.929 & $0.022^{* *}$ & 0.686 & \\
\hline \hline & & & & \\
\hline
\end{tabular}

thus no systematic heterogenous treatment effect based on baseline social value orientation. However, to investigate why controlling for the Baseline-SVO failed to reduce the statistical noise in the Within-group measure, we map the baseline-SVO against the within-subject ingroup bias (In-Out Difference). Figure 3.4.2 shows that there is much heterogeneity in the baseline-SVO as well as in the degree to which subjects discriminate between in- and outgroup. There is a high concentration of subjects along two imaginary axes representing consistent individualistic behavior $\left(7.8^{\circ}\right)$ in the baseline-SVO and no discrimination between in- and outgroup in the lab SVOs (0 on the vertical axis). The data also shows considerable clustering of observations at the point where subjects are consistent individualists and do not discriminate. The high heterogeneity helps explain why accounting for the baseline-SVO in the adjusted between-subjects and diff-in-diff designs does not result in a more precise estimate. Ideally, we would like to see that the induced ingroup bias is always in a similar range no matter what the Baseline-SVO is. In that case, once we control for individual differences in baseline social value orientation, we would would get relatively precise estimates of the ingroup bias also with the Within-group measure. However, as the ingroup bias given any specific social value orientation is rather dispersed as without a clear trend, it can actually increase the variance if differences in the size of the social identity treatment effect are larger than the differences in social value orientation.

Result 4. Baseline social value orientation does not correlate with discrimi- 


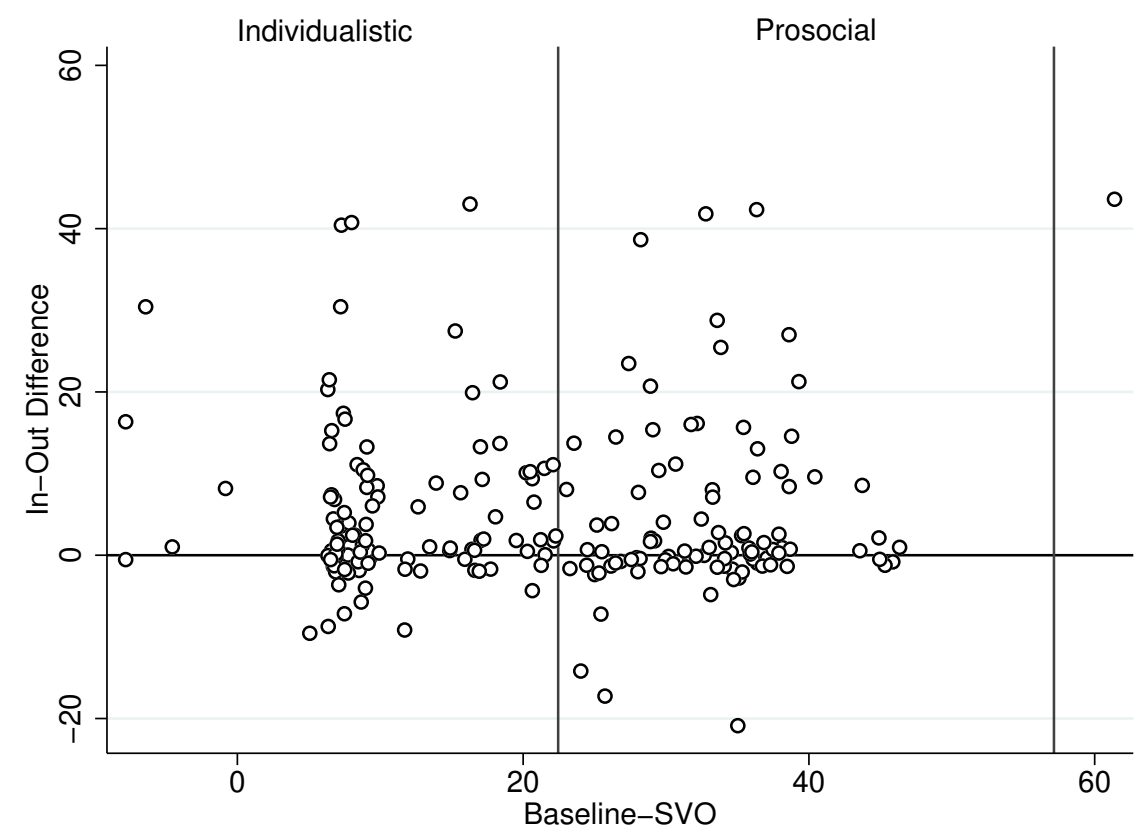

Note: Jitter was added to improve visibility of mass points.

Figure 3.4.2: Scatter Plot of Baseline-SVO Decision and Within-Subject In-Out Difference 
nation between in- and outgroup.

\subsection{Discussion and Conclusion}

We have shown that only the Contest treatment is successful in inducing social identity with all of the different between-subject and within-group measures. However, this effect is not statistical significant for the baseline adjusted Within-group measure and only reaches statistical significance for the ingroup-outgroup-not for the ingrouprandom-comparisons in the other cases. Accounting for the baselineSVO of participants does neither improve the between-subject nor the within-group measure. The good performance of the contest treatment is consistent with results from studies in economics (e.g. Eckel \& Grossman, 2005) and social psychology (e.g. Sherif et al., 1961), showing that between-group competitive settings can lead to favorable views and behavior towards the ingroup. Paradoxically, the real-effort task, which also contained a competitive component, does not lead to a successful inducement of social identity.

When the within-measure is considered, all social identity manipulations are significant and the commonly used Klee and Kandinsky task is most successful in inducing identity. The difference between the treatments is insignificant. While this could be seen as an encouraging sign that it does not matter which method is used, this result needs to be qualified. The anatomy of the order effects suggests that subjects treat the first decision they make in the lab as an independent social value orientation test and only discriminate between the groups once the focus on discrimination between in- and outgroup becomes salient in the second round. The order effects for the outgroup decision could then be a result of the different costs of discrimination: Being ingroup biased is costlier if they acted very prosocial in the first round towards an outgroup or random group member and only become aware of the ingroup-outgroup nature of the experiment in the later rounds.

This suggests that results of within-subject designs that study the effect of social identity might be more affected by the contrasting nature of the within-subject design than by the induced social identity. This is 
problematic as the tool of measurement becomes a social identity manipulation in itself, which can potentially lead to an overestimation of the true effect of social identity and a misidentification of the mechanism through which social identity affects behavior. ${ }^{22}$

Furthermore, the results also provide evidence in contrast to Aaldering et al. (2013) who find evidence that prosocial agents drive intergroup conflict, as we do not find that discrimination between the in- and outgroup is correlated with subjects' baseline social value orientation.

A potential shortcoming of our study is its reliance on social value orientation as proxy for studying social identity. While this follows the literature that models social identity through social preferences (e.g. Chen \& Chen, 2011; Chen \& Li, 2009), it is still debated if this is the right mechanism to study. Work by Müller (2019) indicates that the effect of social identity on social preferences follows well-behaved social preference utility functions which provides support for the social preference approach. However, this work also stands in contrast to the findings by Guala and Filippin (2016) who provide evidence that the effects are unsystematic and not robust to slight changes to the framing. They use a wider range of mini dictator games than previous studies-including both negative and positive tradeoffs between self and other-and increase the complexity by adding dominated choice options. They report that social identity effects are not consistent across all types of mini dictator games and can even be reversed by adding strictly dominated choice options. The order effects in our own data indicate that salience is an important mediator in creating behavioral differences between in- and outgroup in the laboratory which supports Guala and Filippin (2016) who proposed that social identity is a heuristic that depends on cognitive salience and not a well-behaved preference.

Overall, there seems to be great heterogeneity in discrimination behavior and researchers face a trade-off when choosing how to design an experiment to study it. In a between-subject setup the data can be noisy and salience of discrimination possibilities low. In a within-subject setting, it does not matter which method is chosen, as all cause subjects to

${ }^{22}$ Pedroni et al. (2017) have recently shown that a similar problem persists in the context of risk elicitation methods. 
discriminate between in- and outgroup, but this appears to be largely driven by a salience effects. Combined with the findings by the meta study by Lane (2016) that induced or artificial identities produce more discrimination than real identities, this seems to suggest that making in- and outgroup differences in the lab very salient will generate the desired social identity but might end up providing a upper and not a lower bound for situations outside of the lab. The alternative of using natural groups has its own shortcomings in that findings for natural groups are more likely to reflect the dynamics between those specific groups than generalizable intergroup patterns. 


\section{Appendices}

3.A Instructions

3.A.1 Part A: Online SVO 
Welcome to this experiment in decision making. In the experiment you can earn money with the decisions you make. It is important for us that you fully understand the rules of the experiment. Therefore, please read the following instructions carefully.

This experiment consists of two parts. One online part and one other part for which you will be required to come to the BEElab. You will now participate in the online part. You can earn money in both parts of the experiment but you will only be paid out if you participate in both, the online AND the BEElab part.

\section{At the end of this online experiment you will receive a personalized code which you have to write down and bring with you to the other part that takes place in the BEElab. If you do not have your code with you, you cannot participate in the BEElab part and will not earn any money.}

In this online part of the experiment you will be asked to make $\mathbf{6}$ decisions. Your decisions will affect the earnings of both you and another person, whom we refer to as "the Other." All decisions will remain anonymous and confidential. You will not get to know the identity of the Other nor will the Other (or anybody else) get to know your identity.

The order of the 6 decisions will be determined randomly by the computer.

In each decision situation you will allocate tokens between you and the Other. Each decision situation will have 9 options. Here is an arbitrary example of a decision situation:
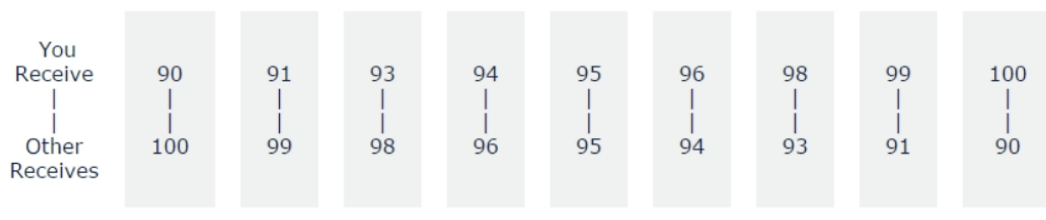

You will make your choice by clicking on the one allocation you prefer most. Each allocation may have different earnings consequences for you and/or the Other. In this example decision situation, if the leftmost allocation would be selected, you would earn 90 tokens and the Other would earn 100 tokens. If the rightmost allocation would be selected, you would earn 100 tokens and the Other would earn 90 tokens. Similarly for the allocations inbetween. 
After an allocation is selected the earnings for you and the other will be highlighted as shown in the example screen below::
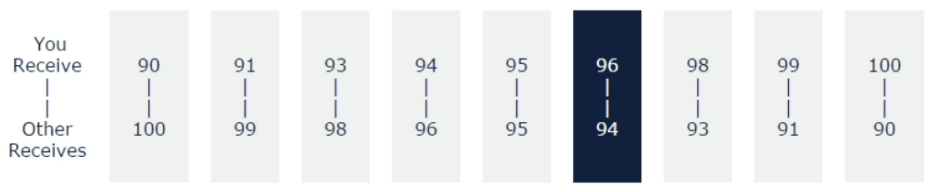

After all participants have finished making all of their decisions, the payment for each participant will be determined using the following procedure, which has three steps.

Half of the participants will be randomly assigned to be paid as "deciders" and the other half to be paid as "receivers.

Each decider is matched with exactly one receiver. One of the decider's six decisions will be randomly selected. The decider's tokens are determined by the amount "You receive," and the receiver's tokens are determined by the amount "Other receives."

The matching procedure guarantees that each participant receives money from one - and only one - decision. Please notice that the receiver towards whom you make an allocation decision will never be the decider of an allocation decision towards you. All participants will be paid in cash based on the exchange rate

10 tokens $=€ 0,75$.

When making your decision you will not know your role relevant for payment (decider or receiver) nor will you know the decision situation that counts for payment. Therefore, you should view each decision situation as equally important and consider each of your choice as the one that counts for payment to you and the other.

Further, your choice in one decision situation does not affect any other decision situation; therefore you should consider each decision situation independent of each other.

Finally, there are no right or wrong answers. We are solely interested in your choices. 


\section{A.2 Part B: General Instructions (Adjustments in Contest treatment in parentheses)}

\section{General Instructions}

Welcome and thank you for participating in this experiment. Please read these instructions carefully. If you have any questions, please raise your hand and one of the experimenters will come to your cubicle to answer your question in private.

Talking or using mobile phones or any other electronic devices is strictly prohibited. Mobile phones and other electronic devices should be left in the waiting room or switched off. If you are found violating these rules, you will both forfeit any earnings from this experiment, and may be excluded from future experiments as well.

This is an experiment in decision-making. The amount of money you earn will depend upon the decisions you make, on the decisions other people make and random events. You will never be asked to reveal your identity to anyone during or after the course of the experiment or after. Your name will never be associated with any of your decisions. In order to keep your decisions private, do not reveal your choices to any other participant. Everyone will be paid in private.

Your total earnings from this experiment will be the sum of your payoffs in this experiment and your payoff from the online part.

Your earnings are given in (coins and) tokens. At the end of the experiment you will be paid in cash based on the exchange rate (100 coins $=) 75$ Euro cent $=10$ tokens.

Please do not communicate with each other during the experiment unless asked to do so. If you have a question, feel free to raise your hand, and an experimenter will come to help you.

For the course of the experiment you will be a member of a group. There are 3 people in each 
group. Your group assignment will remain the same throughout the experiment. That is, if you were assigned to the BLUE group, you will be in the BLUE group for the rest of the experiment. Your group will be matched with an other group during the experiment. If you are in the RED group, the other group will be the BLUE group and vice versa. If you are in the YELLOW group, the other group is the GREEN group and vice versa.

At the end of the experiment you are asked to fill out a questionnaire. 


\section{A.3 Part B: Treatment instructions}

\section{Flag}

In this part, the other members of your group and yourself will construct the flag that will represent you throughout the experiment. For this purpose, each of you will be in charge of decorating one part of the flag using colored paper (each group has a different color). In other words, the flag of your group will be composed of a representative element of each one of you.

On your table you will find a pair of scissors and an envelope containing colored paper. Please cut out a shape from the coloured paper. You are free to cut out any shape you want, but you are not allowed to cut out words, nor are you allowed to write on the shape. The shape must be composed of a single element (you are not allowed cut out two separate shapes).

When you finish, write your place number on the back of the shape and put it inside the envelope. After 5 minutes, the envelopes containing the shapes will be collected. The shapes will then be pasted on the flag. You will see what the flag of your group looks like in the next part of the experiment.

You can now open the envelope and start working.

\section{Real Effort}

You and the other members of your group will see a very big circle in the middle of your screen. The members of the other group will see a circle of the same size on their screens. The aim of the game is to reduce the size of the circle. To reduce the size of the circle you just have to click on it. Every click of a member of your group reduces the size of the circle. The game is over after 30 seconds. The group that finishes with the smallest circle, wins the game, and each member of the winning group earns a reward of 10 tokens. The members of the losing group do not earn anything. In case of a tie, the computer will toss a coin to determine which group earns the reward. 
In the next game, you and the other members of your group will see a small circle in the middle of your screen. The members of the other group will see a circle of the same size on their screens. The aim of the game is to enlarge the circle. To enlarge the circle you just have to click on it. Every click of a member of your group enlarges the circle. You will notice that the circle will move around the screen. You will have to carefully target the moving circle to be able to enlarge it. The game is over after 30 seconds. The group that finishes with the largest circle, wins the game, and each member of the winning group earns a reward of 10 tokens. The members of the losing group do not earn anything. In case of a tie, the computer will toss a coin to determine which group earns the reward.

You will be informed of your earnings in this part at the end of the experiment.

\section{Klee and Kandinsky}

In this part everyone will be shown 5 pairs of paintings by two artists. You will get information about the title and artist for each painting. You will have 5 minutes to study these paintings. Then you have another 5 minutes to analyse two additional paintings. You may get help from other members of your group and help other members in your group while analysing the pictures. After the five minutes you are asked which artist painted which of the two additional paintings. Each correct answer will bring you 10 additional tokens. Details will be provided during the experiment.

You will receive information on how much you earned at the end of the experiment.

\section{Contest}

In this part of the experiment your group and one of the other groups are competing for a prize 
in the following way: At the beginning you will receive 100 coins. Then you can use these coins to buy lottery tickets for your group. Any token you invest gives one lottery ticket your group. Any token you do not invest in lottery tickets will remain in your private coin account. Likewise, your group members can buy tickets for your group and the members of the other group can buy tickets for their group in exactly the same way.

As soon as everybody has chosen how many tickets to buy, a lottery will determine whether your group or the other group wins a prize of 300 coins. All bought tickets are put in a "virtual" urn. One of the bought tickets will be randomly drawn as the winning ticket. Each ticket has the same chance to be drawn. Hence, the more tickets your group buys, the higher is your group's chance of winning the prize.

Examples: If your group and the other group buy the same amount of tickets then the chance of winning the prize is 50:50. This is also the case if none of the groups buy any tickets. If your group buys three times as many tickets as the other group, then also your group's chance is three times as high as that of the other group. If only one of the groups buys tickets then this group wins the prize with certainty.

If neither you nor the other players buy a ticket, then the prize is randomly allocated to one of the players with equal chances.

After the winning group is determined the prize of 300 coins is equally shared between the members of the winning group and added to the private coins accounts. As your group consists of 3 members, everyone in the winning group gets 100 coins.

Earnings of a member of the winning group: 100 - bought lottery tickets +100

Earnings of a member of the losing group: 100 - bought lottery tickets

You will receive information on how much you earned at the end of the experiment.

The experiment starts with a trial period in which you will be asked to fill in some questions in order to check your understanding of the experiment and to give you the opportunity to get 
acquainted with the setup. Tokens earned in this trial period will not be paid off. 


\title{
3.A.4 Part B: SVO instructions
}

\author{
Instructions for Part 2
}

In this part you will be asked to make decisions in $\mathbf{3}$ rounds, and in each round you will make 6 decisions. Your decisions will affect the earnings of both you and another person, whom we refer to as "the Other." All decisions will remain anonymous and confidential. You will not get to know the identity of the Other nor will the Other (or anybody else) get to know your identity. You will however, get information on the group membership of the Other.

- In one of the rounds, the Other will be a member of your own group.

- In one of the rounds, the Other will be a member of the other group.

- In one of the rounds, the Other is another participant in the lab who is neither from your group nor from the other group.

The order of rounds as well as the order of the 6 decisions within each round will be determined randomly by the computer.

\section{Decision Situations}

In each decision situation you will allocate tokens between you and the Other. Each decision situation will have 9 options. Here is an arbitrary example of a decision situation:

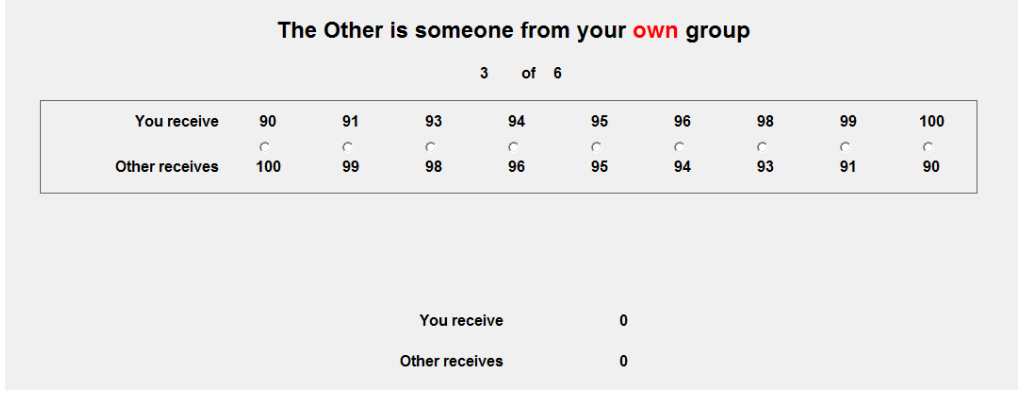

You will make your choice by clicking on the one allocation you prefer most. Each allocation may have different earnings consequences for you and/or the Other. In the example above, you would be making allocation decisions between your and another member of your own group during this round. In this example the word "own" is in red. In the actual decision situations the color of the word "own" will be the same as your own group's color in Part 1. In this example decision situation, if the leftmost allocation would be selected, you would earn 90 tokens and the Other would earn 100 tokens. If the rightmost allocation 
would be selected, you would earn 100 tokens and the Other would earn 90 tokens.

Similarly for the allocations in-between.

After an allocation is selected the earnings for you and the other will appear at the bottom of the screen as shown in the example screen below.

\section{The Other is someone from your own group}

3 of 6

\begin{tabular}{rllllllllll|}
\hline You receive & 90 & 91 & 93 & 94 & 95 & 96 & 98 & 99 & 100 \\
& $r$ & $c$ & $r$ & $c$ & $c$ & 6 & $r$ & $c$ & $c$ \\
Other receives & 100 & 99 & 98 & 96 & 95 & 94 & 93 & 91 & 90 \\
& & & &
\end{tabular}

You receive

Other receives 94

When you are satisfied with your selected allocation you will need to confirm your decision by clicking on the "OK button" in the bottom-right corner of the screen (not shown).

Thereafter, you will be asked for a final confirmation of your decision before you move on to the next decision situation.

\section{Payment}

After all participants have finished making all of their decisions, the computer will determine the payment for each participant using the following procedure, which has four steps.

[Step 1] The computer will randomly assign half of the participants in the lab to be paid as "deciders" and the other half to be paid as "receivers."

[Step 2] Each decider is matched with exactly one receiver.

[Step 3] The round relevant for the payment is determined. This will depend on whether the receiver is from the own, the other or neither from the own group nor the other group of the decider.

[Step 4] One of the decider's six decisions from that round will be randomly selected by the computer. The decider's tokens are determined by the amount "You receive," and the receiver's tokens are determined by the amount "Other receives."

The matching procedure guarantees that each participant receives money from one - and only one-decision. Please notice that in no decision situation the receiver towards whom you make an allocation decision will be the decider of an allocation decision towards you.

All participants will be paid in cash based on the exchange rate

$$
10 \text { tokens }=€ 0,75 \text {. }
$$


Important!

When making your decision you will not know your role relevant for payment (decider or receiver) nor will you know the decision situation that counts for payment. Therefore, you should view each decision situation as equally important and consider each of your choice as the one that counts for payment to you and the other.

Further, your choice in one decision situation does not affect any other decision situation; therefore you should consider each decision situation independent of each other.

Finally, there are no right or wrong answers. We are solely interested in your choices.

\section{Comprehension Questions}

You will now be asked to answer some comprehension questions about how your decisions affect your earnings and earnings of others. After you have completed the comprehension questions, please wait for the experiment to continue.

If you have any questions, please raise your hand, and one of the experimenters will come to you to answer your question in private. 


\section{B Randomization check}

To make sure that potential treatment effects are not driven by unbalanced characteristics of our sample, we compare the responses to the baseline SVO and the questionnaire asked after the experiment across treatments. We test for differences between the treatments with KruskalWallis tests with Holm-Sidak correction to adjust for multiple comparisons. Table 3.B.1 reports the summary statistics. The average baseline social value orientation ranges from 19.87 in the contest treatment to 24.77 in the flag treatment with all averages being close the boundary between the individualistic and prosocial value orientation categories. Differences across treatments are not significant $(\mathrm{p}=0.486)$. The mean age is between 21 and 22 years and very similar in all treatments $(\mathrm{p}=0.474)$. The percentage of female subjects ranged from $50 \%$ (Flag treatment) to $72 \%$ (Contest treatment) but differences between treatments are not significant $(\mathrm{p}=0.362)$. The average number of siblings that subjects' report is about $1.5(\mathrm{p}=0.986)$. The percentage of Dutch students is lowest in the Minimal treatment with $11 \%$ and highest in the Real Effort treatment with 23\% ( $\mathrm{p}=0.440)$. The number of German students varies from $17 \%$ in the contest treatment to $53 \%$ in the Flag treatment $(\mathrm{p}=0.028)$. The ratio of Economics and Business students is between $42 \%$ in the contest and $78 \%$ in the Flag treatment $(p=0.037)$. Most of the students that participated were bachelor students with only about $20 \%$ being master students participating in the different treatments ( $p=0.865)$. The English phrasing of the German Socio Economic Panel questionnaire question for general risk was used to measure risk attitude (Dohmen et al., 2011). The question is "How do you see yourself: are you generally a person who is fully prepared to take risks or do you try to avoid taking risks?" and subjects answer on a 1 to 10 scale where 1 is "not at all willing to take risks" and 10 is "very willing to take risks". The means in all of the treatments are very close to the middle of the scale such that the students in the sample do not seem to be particular risk averse or risk seeking and treatment differences are not significant $(\mathrm{p}=0.443)$. In a similar fashion, subjects were asked if they preferred working in a team or working alone. The mean response is very close to the middle of the scale and not very different between treatments $(p=0.484)$. About two-thirds of the subjects indicated that 
they participate or participated in teamsports, with slightly less people having participated in teamsports in the contest treatment $(\mathrm{p}=0.135)$. To measure closeness to their group, subjects were asked to answer to rate how closely they felt attached to their group on a 1 to 10 scale, where 1 is "Not closely at all" and 10 is "Very closely". Students felt closest to their teammates in the Klee treatment, with a mean closeness of 5, and least close in the real effort treatment with an average closeness of 2.7 $(\mathrm{p}<0.001)$. The only significant pairwise comparisons in demographics are between the Contest and the Flag with respect to the number of Economics $(p=0.010)$ and German $(p=0.007)$ students. Closeness to the own group is significantly different between the Klee task and the Real Effort task ( $\mathrm{p}=0.002)$ but this is an additional measure of the strength of social identity and thus not one of the variables that we intended to randomize on. While the significant differences between the Contest and the Flag treatment are undesirable, we would expect to find some significant differences solely based on the fact that we compare the treatments on a large number of demographic variables. We do not find that being German or being an Economics or Business student has any effect on the strength of the induced social identity in the withinsubject measure regression and therefore conclude that the random assignment of subjects to treatments was successful. 
Table 3.B.1: Summary statistics for controls

\begin{tabular}{|c|c|c|c|c|c|c|}
\hline Variables & All & Minimal & Klee & Contest & Flag & Real Effort \\
\hline Baseline & $\begin{array}{c}21.56 \\
(12.83)\end{array}$ & $\begin{array}{c}21.12 \\
(13.61)\end{array}$ & $\begin{array}{c}20.91 \\
(12.30)\end{array}$ & $\begin{array}{c}19.87 \\
(12.85)\end{array}$ & $\begin{array}{c}24.77 \\
(10.94)\end{array}$ & $\begin{array}{c}21.42 \\
(14.09)\end{array}$ \\
\hline Age & $\begin{array}{l}21.47 \\
(2.28)\end{array}$ & $\begin{array}{l}22.17 \\
(2.78)\end{array}$ & $\begin{array}{l}21.62 \\
(2.38)\end{array}$ & $\begin{array}{l}21.25 \\
(2.08)\end{array}$ & $\begin{array}{l}21.33 \\
(2.31)\end{array}$ & $\begin{array}{l}21.06 \\
(1.78)\end{array}$ \\
\hline Female & $\begin{array}{c}0.61 \\
(0.49)\end{array}$ & $\begin{array}{c}0.53 \\
(0.51)\end{array}$ & $\begin{array}{c}0.58 \\
(0.50)\end{array}$ & $\begin{array}{c}0.72 \\
(0.45)\end{array}$ & $\begin{array}{c}0.50 \\
(0.51)\end{array}$ & $\begin{array}{c}0.69 \\
(0.47)\end{array}$ \\
\hline Siblings & $\begin{array}{c}1.46 \\
(1.04)\end{array}$ & $\begin{array}{c}1.42 \\
(1.05)\end{array}$ & $\begin{array}{c}1.40 \\
(0.96)\end{array}$ & $\begin{array}{c}1.56 \\
(1.21)\end{array}$ & $\begin{array}{c}1.53 \\
(0.97)\end{array}$ & $\begin{array}{c}1.44 \\
(1.05)\end{array}$ \\
\hline Dutch & $\begin{array}{c}0.18 \\
(0.39)\end{array}$ & $\begin{array}{c}0.11 \\
(0.32)\end{array}$ & $\begin{array}{c}0.21 \\
(0.41)\end{array}$ & $\begin{array}{c}0.22 \\
(0.42)\end{array}$ & $\begin{array}{c}0.11 \\
(0.32)\end{array}$ & $\begin{array}{c}0.23 \\
(0.42)\end{array}$ \\
\hline German & $\begin{array}{c}0.37 \\
(0.48)\end{array}$ & $\begin{array}{c}0.33 \\
(0.48)\end{array}$ & $\begin{array}{c}0.38 \\
(0.49)\end{array}$ & $\begin{array}{c}0.17 \\
(0.38)\end{array}$ & $\begin{array}{c}0.53 \\
(0.51)\end{array}$ & $\begin{array}{c}0.42 \\
(0.50)\end{array}$ \\
\hline Economics & $\begin{array}{c}0.56 \\
(0.50)\end{array}$ & $\begin{array}{c}0.56 \\
(0.50)\end{array}$ & $\begin{array}{c}0.54 \\
(0.50)\end{array}$ & $\begin{array}{c}0.42 \\
(0.50)\end{array}$ & $\begin{array}{c}0.78 \\
(0.42)\end{array}$ & $\begin{array}{c}0.52 \\
(0.50)\end{array}$ \\
\hline Master & $\begin{array}{c}0.23 \\
(0.42)\end{array}$ & $\begin{array}{c}0.25 \\
(0.44)\end{array}$ & $\begin{array}{c}0.19 \\
(0.39)\end{array}$ & $\begin{array}{c}0.19 \\
(0.40)\end{array}$ & $\begin{array}{c}0.28 \\
(0.45)\end{array}$ & $\begin{array}{c}0.23 \\
(0.42)\end{array}$ \\
\hline Risk & $\begin{array}{l}5.84 \\
(2.28)\end{array}$ & $\begin{array}{c}5.92 \\
(2.47)\end{array}$ & $\begin{array}{c}5.75 \\
(2.20)\end{array}$ & $\begin{array}{c}6.36 \\
(2.24)\end{array}$ & $\begin{array}{c}5.42 \\
(2.22)\end{array}$ & $\begin{array}{l}5.81 \\
(2.31)\end{array}$ \\
\hline Teamwork & $\begin{array}{l}5.58 \\
(2.34)\end{array}$ & $\begin{array}{c}5.31 \\
(2.51)\end{array}$ & $\begin{array}{c}5.31 \\
(2.24)\end{array}$ & $\begin{array}{c}6.14 \\
(2.79)\end{array}$ & $\begin{array}{c}5.44 \\
(1.87)\end{array}$ & $\begin{array}{c}5.75 \\
(2.26)\end{array}$ \\
\hline Teamsports & $\begin{array}{c}0.64 \\
(0.48)\end{array}$ & $\begin{array}{c}0.64 \\
(0.49)\end{array}$ & $\begin{array}{c}0.65 \\
(0.48)\end{array}$ & $\begin{array}{c}0.47 \\
(0.51)\end{array}$ & $\begin{array}{c}0.67 \\
(0.48)\end{array}$ & $\begin{array}{c}0.75 \\
(0.44)\end{array}$ \\
\hline Closeness & $\begin{array}{c}3.83 \\
(2.81)\end{array}$ & $\begin{array}{c}3.00 \\
(2.52)\end{array}$ & $\begin{array}{c}5.08 \\
(2.76)\end{array}$ & $\begin{array}{c}3.97 \\
(2.93)\end{array}$ & $\begin{array}{c}4.25 \\
(2.80)\end{array}$ & $\begin{array}{c}2.77 \\
(2.46)\end{array}$ \\
\hline $\mathrm{N}$ & 204 & 36 & 48 & 36 & 36 & 48 \\
\hline
\end{tabular}

Note: Mean with standard deviation in parenthesis. 


\section{C Contest Contributions and In-Out Difference}

It could be argued that the contest induces more In-Out difference because the subjects already committed resources to the conflict with the other group. This commitment to the conflict in combination with the sunk cost fallacy could than increase the behavioural difference between giving to the ingroup and giving to the outgroup. We would thus expect that higher contest contributions result in stronger discrimination between in- and outgroup. Regression (1) in Table 3.C.1 reports results from an OLS regression with the within-subject measure as dependent variables and the contest contributions as independent variable. Contest contributions have a negative coefficient and thus reduce the degree to which subjects discriminate between in- and outgroup. However, the coefficient is not significant which also does not change when we account for subjects' baseline social value orientation in regression (2). Thus the contest contributions of an individual do not seem to affect the degree to which it is willing to discriminate between in- and outgroup.

Table 3.C.1: OLS analysis of In-Out Difference

\begin{tabular}{lcc}
\hline \hline & \multicolumn{2}{c}{$\left(S V O_{i, \text { In }}-S V O_{i, \text { Out }}\right)$} \\
\cline { 2 - 3 } & $(1)$ & $(2)$ \\
\hline Contest Contribution & -0.058 & -0.098 \\
& $(0.072)$ & $(0.074)$ \\
Baseline-SVO & & -0.287 \\
& & $(0.170)$ \\
Constant & & \\
& $8.021^{* * *}$ & $15.410^{* * *}$ \\
$N$ & $(3.710)$ & $(5.675)$ \\
\hline \hline
\end{tabular}

Note: Within-subject. Standard errors clustered by group in parentheses. ${ }^{*} \mathrm{p}<0.10{ }^{* *} \mathrm{p}<0.05,{ }^{* * *} \mathrm{p}<0.01$. 


\section{D Order Effects by Treatment}

To break the order effect down by treatment, we compare the withinsubject measure (In-Out Difference) across treatments and order. Figure 3.D.1 shows the boxplots of the different In-Out differences for the different orders. When the first decision is an outgroup decisions as is the case in orders 3 and 4, the difference between ingroup and outgroup SVO has a median of 0 and a mean closer to zero than in the other possible orders. This is a consistent pattern across all treatments.

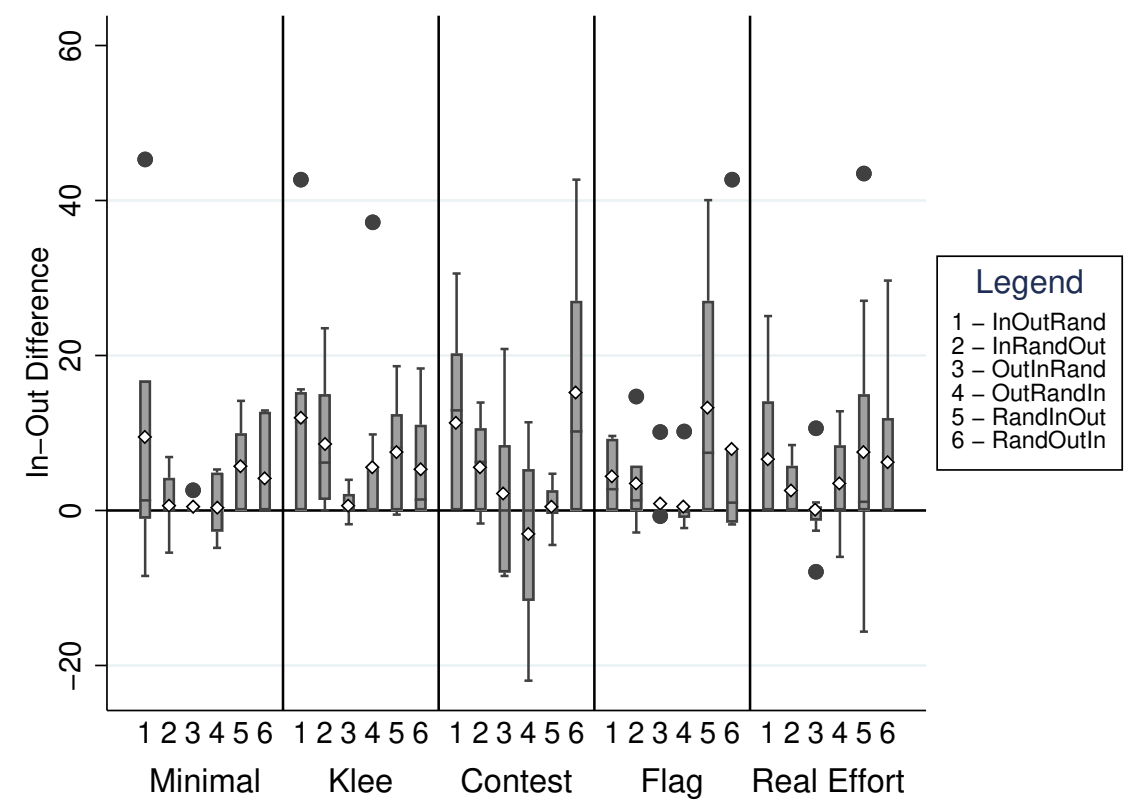

Figure 3.D.1: Within-subject In-Out Difference by Treatment and Order Note: Within-subject. Means are represented by white diamonds. 



\section{4 \\ Conflict and Migration}

Adapted from: Zaunbrecher, H. W., Heine, F., \& Riedl, A. (2021a). Conflict and migration: Mobility and social identity in group contests. Working Paper. 


\section{Abstract}

Group contests have been used to study conflict between countries, R\&D competitions, sports competition and lobbying. Usually, it is assumed that individuals belong to one group and that this group membership will remain unchanged. However, in practice, soldiers can defect, employees switch employers and athletes switch teams. In a lab experiment, we introduce intergroup mobility to a group contest and test how this affects contest contributions. We find that endogenous (voluntary) migration increases contest contributions, whereas exogenous migration (displacement) has a negative but only marginally significant effect relative to a baseline without intergroup mobility. Ingroup bias persists throughout the experiment in all treatments and does not decrease in the migration treatments. In the endogenous migration treatment, the decision to leave the own group is mainly driven by bad prospects of winning. 


\subsection{Introduction}

"Ita amicum habeas, posse ut facile fieri hunc inimicum putes."

Treat your friend as if he might become an enemy

$$
\text { - Publilius Syrus (1st century BC), Sententiae }
$$

"Ex inimico cogita fieri posse amicum"

Consider that you may make a friend of an enemy

- Seneca (1st century AD), Epistulae Morales ad Lucilium

The European nations have waged war against each other for most of history. However, recently the European Union won the Nobel Peace Prize for overcoming the division between East and West, and ethnically based national conflicts (The Norwegian Nobel Committee, 2016). Part of its non-negotiable fundamental principles are open borders and free movement (BBC, 2016) and some politicians credit freedom of movement with achieving this peace (Sodha, 2016). Umberto Eco states that the academic exchange program ERASMUS created the first generation of true European citizens and proposes to develop similar programs for all citizens to promote greater understanding amongst cultures (Riotta, 2012).

Studying the effect that migration and free movement have on conflict with field data is often difficult because dynamic interactions of migration and conflict are common, e.g. emigration caused by conflict. ${ }^{1}$ In the lab however, we can create a highly controlled environment in which we can exogenously vary migration and thus can study the causal link between migration and conflict directly. In this study, we ran a lab experiment in which two groups competed against each other for a prize in a group contest and varied the migration possibilities between groups.

\footnotetext{
${ }^{1}$ See e.g. Collier and Hoeffler, 2004 for a discussion of the link between diasporas/emigration and the risk of civil war.
} 
Economists have used group contests to model conflict between countries, R\&D competitions, sports competition and lobbying. In the contest game based on Tullock (1980) and Katz et al. (1990), groups compete against each other for a prize. In the Nash equilibrium, groups invest resources into the conflict to increase the winning probability even though the investment itself is lost and any positive investment reduces overall welfare. While the equilibrium contest investments are already wasteful in the theoretical model, participants in experiments usually spend even more resources on the conflict than what is expected from a rational individualistic agent (Dechenaux et al., 2015; Sheremeta, 2018). The explanations for this waste of resources include amongst others joy of winning, relative payoff maximisation, and impulsivity (Sheremeta, 2013). However, as these explanations apply to individual contests as well, they do not explain why contributions in group contests tend to be even higher than in individual contests (see e.g. Abbink et al., 2010).

An explanation for overbidding that is specific to group settings is social identity. Zaunbrecher and Riedl (2016) show that adopting the social identity model from Chen and Li (2009) and Chen and Chen (2011) to the group contest implies higher contest contributions for groups with a strong identity than for those without. Zaunbrecher et al. (2021b) show that the group contest setting itself already induces a strong group identity which would thus induce a higher waste of resources. Cason et al. (2012) find that communication results in higher contest contributions and suggest that this might be the result of communication strengthening group identity. Similarly, Chowdhury et al. (2016) have shown the escalating effect of primed natural identities on group contests.

Most of this research on group contests has been done with fixed groups. However, in naturally occurring group contests it often possible or even common to move between groups. For instance, employees change employer or teams within a firm, citizens emigrate to other countries, and athletes change clubs, all of which leads to less rigid group boundaries than are usually used in the lab. Tajfel and Turner (1979) suggest that having less rigid group boundaries could result in dissociation from the group and more selfish behaviour and Akerlof and Kranton (2000) stress the importance of exlcusion as a mechanism in social identifica- 
tion. Thus having more permeable boundaries could result in lower identification with the group.

Evidence from public good games suggests that changing group composition can lead to a decrease in cooperation (e.g. Grund et al., 2015, 2018). Conversely, the literature on endogenous groups suggests that letting participants choose the group they play with can lead to more efficient outcomes, especially if entry to the group can be restricted (e.g. Ahn et al., 2009; Charness \& Yang, 2014; Chen, 2017; Riedl et al., 2016). But to our knowledge there have been no studies that investigate the difference between fixed and changing teams in group contests. There is some theoretical and experimental literature on coalition formation and contests, where it has been shown that endogenous coalition formation can increase conflict (Bloch, 2012; Herbst et al., 2015; Smith et al., 2012), however the focus of those studies lies on the group formation process, coalition stability, and self selection into groups rather than migration between different groups and group conflict.

We run a lab experiment with three treatments in which eight participants repeatedly compete against each other in two groups to win a prize. In the control treatment, groups remain unchanged for the whole experiment. In the endogenous (voluntary) migration treatment, participants can decide to leave their group after each round. Per pair of competing groups two "stay or leave" decisions are randomly selected to be implemented. In the exogenous (displacement) treatment, we implement migration decisions from the endogenous treatment. This guarantees the same game paths in terms of group sizes in the endogenous and exogenous migration treatment. To shed light on the potential mechanisms at work, we measure social value orientation towards the ingroup and the outgroup before and after the contest. Furthermore, we elicit beliefs about the average individual contribution of the own group and the other group in each round. Because migration has the effect that the enemy of today can be a friend tomorrow and vice versa, we hypothesise that allowing migration weakens group identity. In terms of a social preferences model of social identity, this means that participants put less weight on the payoffs of their current group members which in turn decreases their contest contributions. Furthermore, migration between the groups could increase the weight participants 
put on the payoff of the opposing groups' players, treating enemies of today as potential friends of tomorrow which may also lead to a decrease in contributions.

However, in the endogenous treatment, migration decisions also contain a signalling value. While it is still true that there is uncertainty about the future composition of the own and other group which could decrease contributions, this might be counteracted by asymmetric social identity effects. A migration taking place signals to the group that receives a new member that they are more desirable than the opponent, potentially strengthening social identity and increasing contributions. To the group that lost a member it sends a signal that they are not desirable, potentially weakening social identity and decreasing contributions. The overall effect of the migrations could thus be ambiguous. The exogenous treatment allows us to abstract from these alternative explanations and allows us to isolate the effect of migration on contest contributions. We find that contest contributions are higher in the endogenous (voluntary) migration treatment than in the control treatment but this effect is only significant once we control for both group size and previous contributions. Comparing only the two migration treatments shows that contributions are significantly lower in the exogenous migration (displacement) treatment. When we consider actually implemented migrations, we find heterogeneous effects. Migrations in the exogenous treatment result in increasing contributions but the opposite happens in the treatment with endogenous migration. Despite the changing group compositions that the migrations engender, we do not observe that ingroup bias-as measured by social value orientationchanges between the start and end of the contest and does also not differ between treatments. An exploratory analysis of the migration decision in the endogenous treatment suggests that participants' prospects of winning are the strongest driver of the migration decision.

The implications of our findings depend on the context to which the model is applied. From the perspective of a social planner, the results suggest that migration does little to alleviate conflict between groups and endogenous migration might even further escalate conflict. For sports teams, companies, and perhaps even countries however, these results suggest that migration does not decrease identification with 
the own group and does not decrease the competitiveness of the own group.

The remainder of the chapter is structured as follows. First, we introduce our experimental design. Second, we discuss our predictions and hypotheses. Third, we present the empirical analysis of the experimental data. Fourth, we provide a discussion of our findings.

\subsection{Experimental Design}

The experiment has three stages. At the beginning of stage one, participants are randomly matched into groups of four and perform two social preference elicitations with respect to an ingroup and an outgroup member. In the second stage, they compete in a group contest for 15 rounds. Depending on the treatment, they are either in fixed groups, have the possibility to migrate, or might be forced to migrate during the contest. In the third stage, they perform two additional social preference elicitations with respect to an ingroup and an outgroup member and fill in a short questionnaire. In the following, we introduce the social value orientation test used to elicit social preferences and the structure of the contest game, before we elaborate on the different treatments and the procedures.

\subsubsection{Social Value Orientation}

Before and after the group contest, participants perform two social value orientation (SVO) tests, one with respect to an ingroup member and one with respect to an outgroup member. The SVO tests are based on the slider measure developed by Murphy et al. (2011) and are an efficient and parametric implementation of the SVO ring measure previously conceptualised by Griesinger and Livingston (1973) and Liebrand and McClintock (1988). The test itself consists of six modified dictator games in which participants divide money between themselves and another person. The six budget sets of the dictator games vary the cost of giving, such that giving money to the other participant is either costly, free, or profitable for the giver. Table 4.2.1 shows the 
end points of the budget sets and the associated relative price of giving. The end points represent pure altruistic, prosocial, individualistic, and competitive preferences, respectively.

Table 4.2.1: SVO Budget Sets

\begin{tabular}{cccc}
\hline $\begin{array}{c}\text { Budget } \\
\text { Set }\end{array}$ & $\begin{array}{c}\text { Option 1 } \\
\left(\pi_{\text {self }}, \pi_{\text {other }}\right)\end{array}$ & $\begin{array}{c}\text { Option 9 } \\
\left(\pi_{\text {self }}, \pi_{\text {other }}\right)\end{array}$ & $\begin{array}{c}\text { Relative price of giving } \\
-\left(\Delta \pi_{\text {self }} / \Delta \pi_{\text {other }}\right)\end{array}$ \\
\hline 1 & $(85,85)$ & $(85,15)$ & 0 \\
2 & $(85,15)$ & $(100,50)$ & -0.43 \\
3 & $(50,100)$ & $(85,85)$ & 2.33 \\
4 & $(50,100)$ & $(85,15)$ & 0.41 \\
5 & $(100,50)$ & $(50,100)$ & 1.00 \\
6 & $(100,50)$ & $(85,85)$ & 0.43 \\
\hline
\end{tabular}

Note: The budget sets represent the six items of the SVO slider measure. Option 1 and Option 9 represent the start and endpoint of a budget constraint in the selfother allocation space. Participants choose a point on the budget constraint that is a linear combination of Option 1 and 9 for each budget set. The relative price of giving represents the trade-off between own payoff and payoff of the other person for each of the budget sets. E.g. for budget set 3, increasing the payoff to the other by one unit decreases the own payoff by 2.33 units.

The allocation decisions are then aggregated into the social value orientation angle $S V O^{\circ}=\theta=\arctan \left(\frac{\left(\bar{A}_{o}-50\right)}{\left(\bar{A}_{s}-50\right)}\right)$, where $\bar{A}_{o}$ is the average allocation to the other person and $\bar{A}_{s}$ is the average allocation to the self. 50 is subtracted from both averages to center the angle within the SVO ring in the self-other allocation space. This provides us with a continuous measure of social preferences (Figure 4.2.1). From the difference between the own group and other group SVO we construct the ingroup bias which is our measure for the strength of social identity.

\subsubsection{Group contest}

The contest game between two groups $A$ and $B$ implemented in the experiment is structured in the following way: Each player receives an endowment of $e=120$ and decides independently and simultaneously 


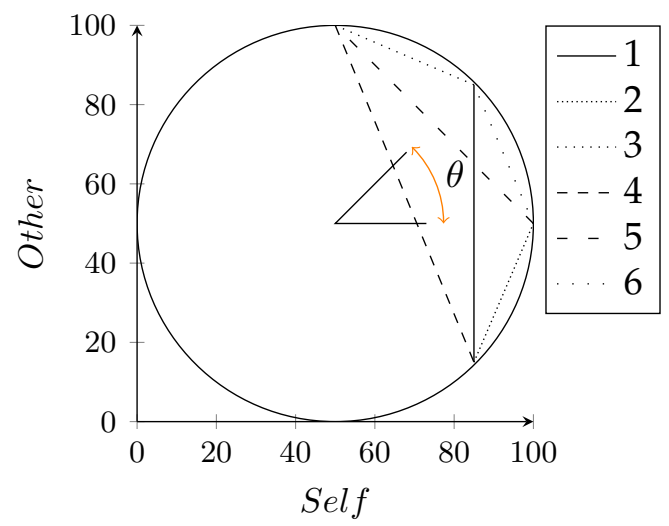

Note: The six budget constraints represent the six items of the SVO slider measure. The angle $\theta$ is the parameter that is calculated from the six points that players chose on the six budget constraints. The four points on the circle are the idealised allocation decisions that perfectly competitive, individualistic, prosocial or altruistic persons respectively would make. The theoretically possible SVO range resulting from the six budget sets is $-16.26^{\circ}$ to $61.39^{\circ}$.

Figure 4.2.1: SVO Budget Sets and SVO Angle in the Self-Other Payoff Space

with the other players how much of the endowment to invest in the contest game. Endowment that is not invested is added to the player's private account. Investments of members of group $A$ are labelled $a_{i}$ where $i \in A$, investments of group $B$ are defined analogously. Group sizes are labelled $N_{A}$ and $N_{B}$ and are equal to 4 for both groups in the Control but can vary in the migration treatments with the restriction that $N_{A}+N_{B}=8$. In the following we explain the game from the perspective of someone from group $A$, the expected payoff for someone from group $B$ can be derived analogously. For group $A$ the probability of winning the contest is given by the total investments of group $A$ divided by the sum of total investments of both groups:

$$
p_{A}\left(\sum_{i \in A} a_{i}, \sum_{j \in B} b_{j}\right)=\frac{\sum_{i \in A} a_{i}}{\sum_{i \in A} a_{i}+\sum_{j \in B} b_{j}} .
$$

If nobody invests, the probability of winning is $\frac{1}{2}$. Each unit of investment can be interpreted as a lottery ticket and after investments are 
made, one ticket is drawn from the investment pool of lottery tickets to decide which group wins the contest. Thus, the more investments are made by a group, the higher the chance to win the contest. The contest prize is $z=1,920$ and is equally split amongst all group members of the winning group. Thus, if Group $\mathrm{A}$ is the winning group, every group member in A gets an individual payoff of $z / N_{A}=1,920 / N_{A}$. The expected payoff of a player $g \in A$ who invests $a_{g}$ is thus the endowment plus the expected individual payoff of winning the contest minus the investments made by the individual group member $g$ :

$$
\pi_{g}\left(\sum_{i \in A} a_{i}, \sum_{j \in B} b_{j}\right)=120+\frac{a_{g}+\sum_{i \in A \backslash g} a_{i}}{a_{g}+\sum_{i \in A \backslash g} a_{i}+\sum_{j \in B} b_{j}} \cdot \frac{1,920}{N_{A}}-a_{g},
$$

The group contest game is repeated for 15 rounds. In addition to contribution decisions, we elicit players' expectations about the average contribution in their own group and in the other group after they made their contribution decision. At the beginning of each round, players receive information about their group composition. After each round, players are informed about their own contribution, which group won, how much their own and the other group invested, and what the probability of winning the contest was for their group.

\section{Control Treatment}

In the control treatment, group sizes are fixed at size 4 and the group composition stays unchanged throughout the experiment. Therefore, participants compete with the same group members in all 15 rounds of the contest.

\section{Endogenous Migration Treatment}

The endogenous migration treatment is identical to the control treatment except for that after each round, each player is presented with 
the choice to remain in their group or to move to the other group (i.e., to migrate). In each round, two of these decisions per group-pair are randomly chosen to be implemented.

If the player whose decision is selected, intends to migrate, this player will be transferred to the other group. If the player does not intend to migrate, she will remain in her group. Thus, at the end of a round, one of the following three situations could emerge: two migrations, one migration, or no migration.

To avoid confounds caused by group size effects, the probability for the own decision to be implemented is independent from the group size. Alternative setups would not guarantee this. For instance, one random decision per group instead of two random decisions per matched group-pair could be implemented. In that case, however, changes in group size would affect the probability that the own decision gets implemented. Similarly, we decided against randomly choosing two $\mathrm{mi}$ grations instead of migration decisions as the probability that the own decision is executed would then depend on other players' migration decisions. One could also implement all migration decisions but this could result in situations in which all players migrate and thus the groups just switch sides but still have the same teammates.

\section{Exogenous Migration Treatment}

If players can freely choose to migrate, the migration decision can be interpreted as a signal that one group is rated higher than another. This can potentially change the strength of social identity in both groups, weakening the identity in the group that is loosing a player and strengthening the group that receives an additional player. To disentangle if it is migration itself that drives behaviour or if it is the intention and signal value, we implement the migration decision exogenously in the exogenous migration treatment. Instead of letting players decide if they want to change groups or not, the migration pattern of each pair of groups from the Endogenous Migration treatment is implemented exogenously. This means that group sizes will develop in the same way as in the endogenous treatment, which creates a 
comparable path dependency as in the main migration treatment but without the potential selection effects.

\subsubsection{Payment and Procedures}

At the end of the experiment, one of the 15 contest rounds is randomly selected and paid out. Additionally, participants receive a payment from the SVO tests as follows: Players are randomly matched with another player from their group-pair and it is determined if the SVO before or after the contest counts. One of the players in each match is chosen to be the dictator and the other one is the receiver. The matched players' group memberships will determine whether one of the dictator's ingroup or outgroup decisions will be paid out. Then, one of the six decisions of the dictator will be picked at random for payment. Players get the information which round was selected, how much they earned in that round, how much they earned from the social value orientation tests and how much they will get paid out in total.

The experiment was conducted at the CentERlab of Tilburg University in September and November 2017 and took about 90 minutes. ${ }^{2}$ There were a total of 15 sessions, and treatments were partly randomised within session. ${ }^{3}$ The tokens earned in the experiment were exchanged at a rate of 20 tokens $=1$ Euro. In total we recruited 240 participants, 80 per treatment, who earned an average of 17.43 Euro (20.54 Dollars at 28th September exchange rate). This resulted in 10 group-pairs per treatment, our independent unit of observation. The experiment was programmed in zTree (Fischbacher, 2007).

\footnotetext{
${ }^{2}$ Instructions can be found in Appendix 4.A.

${ }^{3}$ Because of varying show-up rates and the exogenous treatment requiring data from previous endogenous migration sessions, most sessions were run with two of the three treatments. See Appendix 4.B for an overview of the different sessions.
} 


\subsection{Theoretical Framework, Equilibrium Benchmark, and Predictions}

Assuming risk-neutral preferences and common knowledge of rationality, the contest game has multiple equilibria at the individual player level, but a unique equilibrium at the group level. In line with the literature (see e.g. Konrad, 2009) we focus on the group level equilibrium. We use the equilibrium predictions from Zaunbrecher and Riedl (2016) which are $\sum_{i \in A} a_{i}=\frac{N_{B} \cdot z}{\left(N_{A}+N_{B}\right)^{2}}$ for contributions of group $A$ and $\sum_{j \in B} b_{j}=\frac{N_{A} \cdot z}{\left(N_{A}+N_{B}\right)^{2}}$ for contributions of group $B$ where $N_{A}$ and $N_{B}$ are the group sizes of groups $\mathrm{A}$ and $\mathrm{B}$. As the number of players in our game is 8 and thus $N_{B}=8-N_{A}$ and $z=1,920$ this results in $\sum_{i \in A} a_{i}=N_{B} \cdot 30$ and $\sum_{j \in B} b_{j}=N_{A} \cdot 30$. Table 4.3.1 shows the equilibrium benchmarks for each possible group size in the experiment.

Table 4.3.1: Individual Prize, Equilibrium Contribution, and Expected Payoffs by Group Size

\begin{tabular}{ccccc}
\hline $\begin{array}{c}\text { Group } \\
\text { Size }\end{array}$ & $\begin{array}{c}\text { Individual } \\
\text { Prize }\end{array}$ & $\begin{array}{c}\text { Equilibrium Group } \\
\text { Contribution }\end{array}$ & $\begin{array}{c}\text { Expected } \\
\text { Group Payoff }\end{array}$ & $\begin{array}{c}\text { Expected } \\
\text { Individual Payoff }\end{array}$ \\
\hline 1 & 1920 & 120 & 1270 & 1270 \\
2 & 960 & 180 & 1500 & 750 \\
3 & 640 & 150 & 1410 & 470 \\
4 & 480 & 120 & 1320 & 330 \\
5 & 384 & 90 & 1230 & 246 \\
6 & 320 & 60 & 1140 & 190 \\
7 & 274 & 61 & 1429 & 204 \\
8 & 240 & 1 & 2879 & 360 \\
\hline
\end{tabular}

Note: Numbers are rounded to integers. For the equilibrium contributions and expected payoffs, the group size of the other group is always 8 minus group size, as the number of players in our experiment is fixed at 8 . Thus a group of 1 always competes against a group of 7 , and so forth.

The case in which both groups have a size of four is equivalent to the control treatment. The sum of equilibrium group contributions over both groups is 240 and the same for group sizes 2 to 6 . For a group size of 1 , the contribution is a corner solution as groups without an endowment constraint would invest 210 tokens. In this case, it is optimal to 
contribute the full endowment of 120, whereas the opposing group of size 7 best responds by contributing 61 tokens. ${ }^{4}$ For a group size of 8 , the other group is empty and a contribution of one guarantees winning the contest. If the group of 8 would not contribute at all, they only had a $50 \%$ chance of winning the prize as the prize could in principle still be assigned to the empty group. As the payoff structure incentivises migration towards the smaller group in all but the largest groups, it was unlikely that there would be many instances in which we observe groups of 7 or $8 .^{5}$

In order to account for social identity in the model, we follow Zaunbrecher and Riedl (2016) and adopt the utility function of the form: $u_{g}(a)=\alpha \cdot \pi_{g}+(1-\alpha) \cdot \bar{\pi}_{A \backslash g}$, where $\pi_{g}$ is the payoff of player $g, \bar{\pi}_{A \backslash g}$ is the average payoff of player $g^{\prime}$ s other group members and $\alpha$ is the weight on own payoffs that depends on the strength of social identity (in the utility function for a player from group $B$ it is $\beta$ ). When applied to the contest game, this translates into the following payoff function of a player $g$ in group $A$ :

$$
\begin{aligned}
& u_{g}\left(\sum_{i \in A} a_{i}, \sum_{j \in B} b_{j}\right)=\alpha \cdot\left(\frac{\sum_{i \in A} a_{i}}{\sum_{i \in A} a_{i}+\sum_{j \in B} b_{j}} \cdot \frac{z}{N_{A}}-a_{g}\right)+ \\
& (1-\alpha) \cdot\left(\frac{1}{N_{A}-1}\right)\left(\left(N_{A}-1\right) \cdot \frac{\sum_{i \in A} a_{i}}{\sum_{i \in A} a_{i}+\sum_{j \in B} b_{j}} \cdot \frac{z}{N_{A}}-\sum_{i \in A \backslash g} a_{i}\right)
\end{aligned}
$$

Zaunbrecher and Riedl (2016) show that in equilibrium, group contributions for players of Group A decrease in $\alpha$, the weight put on own payoffs. ${ }^{6}$ Figure 4.3 .1 illustrates the predictions of this model for different group sizes and social preference parameters. ${ }^{7}$ For $\alpha$ and $\beta$ equal

\footnotetext{
${ }^{4}$ While we could have increased the endowment to avoid this corner solution, we decided against this, as doing so would have made the contest prize much less important for the overall payoff.

${ }^{5}$ In fact, we hardly encounter any groups larger than 6 in the experiment. To address the issue of group size, we employ group size controls in our data analysis.

${ }^{6}$ See Appendix 4.C for the derivation of this result.

${ }^{7}$ Group sizes of 0 and 8 are not shown as there is no opposing group.
} 
to 1 , the predictions are exactly the same as in the previous table. However, with decreasing $\alpha$ and $\beta$, and thus increasing weight put on the payoffs of others in the own group, equilibrium group contributions increase for all group sizes except for the instances in which we have a corner solution. However, even in the cases where we have a corner solution, contributions on group-pair level increase. This is because the small group, whose contributions do not increase beyond their endowment with decreasing $\alpha$ and $\beta$, faces a larger group which can increase its contribution without the endowment becoming a binding constraint. For example, in the case where group $A$ with $\alpha=0.5$ and group size of 1 faces a group $B$ with $\beta=0.5$ and a group size of 7 , group $A$ will only contribute 120 as it is constraint by its endowment. However, group $B$, which would only contribute 61 if- it consisted of selfish individuals, will now best respond by contributing 136.57 . The only exception to this is a case in which a small group of participants with social preferencesan $\alpha$ or $\beta$ below 1 -faces a group of purely selfish players $-\alpha$ or $\beta$ equal to 1 . This also holds if one of the social preferences parameters is decreased while the other is kept constant. Put differently, the more an individual cares about the own group, the more she contributes to the contest. $^{8}$

Similar to Chen and Li (2009), Chen and Chen (2011), and Zaunbrecher and Riedl (2016) we associate changes in social identity with changes in $\alpha$. In social psychology (Wetherell, 1996) and identity economics (Akerlof \& Kranton, 2000), rigid group boundaries and exclusion are an important feature of a strong identity. Previous findings in economic experiments confirm this and find better performance in groups with stronger group cohesion (Chen et al., 2014; Eckel \& Grossman, 2005) and lower cooperation if an outsider joins the group (Grund et al., 2018),

\footnotetext{
${ }^{8} \mathrm{~A}$ more complex model of social identity and ingroup-outgroup behaviour, could include weights on the own payoff, the payoff of the own group, and the payoff of the other group. However, as the payoffs of the two groups are inversely linked through the contest success functions, putting more weight on the other group has the same effect as decreasing the weight on the own group's payoffs and vice versa. Appendix 4.D provides equilibrium predictions for such a model. As including an additional weight on the other group's payoff does make the model considerably less tractable and requires many additional assumptions, we chose to stick with the more parsimonious model presented here.
} 


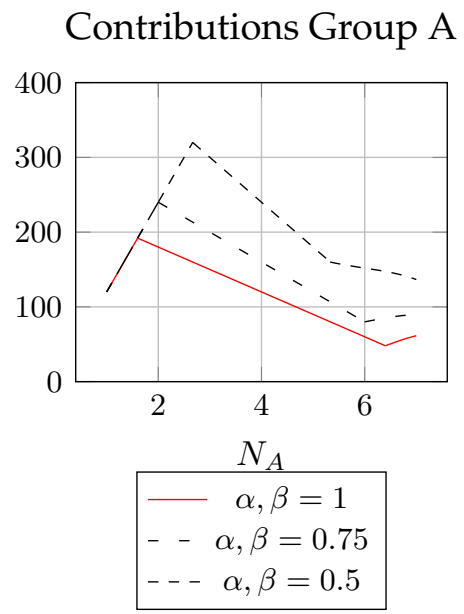

(a) Symmetric social preferences

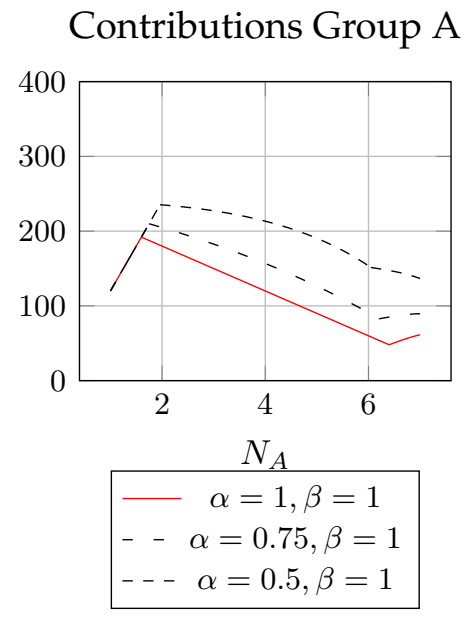

(b) Social preferences of group B fixed

Figure 4.3.1: Equilibrium predictions by group size

or if group entry is easily possible (Ahn et al., 2011). Introducing migration in a group contest setting should thus weaken identification with the own group. In our model, this would imply that relative to fixed groups, $\alpha$-the weight on the own payoff-increases while equilibrium contributions go down. Thus we hypothesise that introducing migration into the group contest decreases group contributions.

Main Hypothesis. The average group contribution in the migration treatments is lower than in the control treatment.

Furthermore, we have multiple sub-hypotheses regarding the channels through which we expect a decrease in contributions. The existence of migration could lead to less identification with the own group as the 'friend' of today can be the 'enemy' of tomorrow and vice versa. Thus, players should have a weaker social identity and be less prosocial towards their own group. As a consequence of the lower identification with the own group, group contribution would thus also be lower. As this is a result of the possibility to migrate, lower ingroup bias, lower prosociality towards the ingroup, and lower group contributions should already be observable in the first round. 
Sub-Hypothesis 1. Ingroup bias, SVO towards ingroup, and group contributions are lower at the beginning of the migration treatments than at the beginning of the control treatment.

Moreover, in treatments with the possibility of migration, we expect the ingroup bias, prosociality towards the own group, and consequently the contest investment to further decrease between the start and the end of the experiment due to group boundaries being fluid and initial social identity being eroded through group member turnover. Thus, we should see a decline in ingroup bias and SVO towards the ingroup between the beginning and end of the migration treatments and a corresponding decrease in contributions throughout the experiment.

Sub-Hypothesis 2. Ingroup bias, SVO towards ingroup, and group contributions are higher at the beginning of the migration treatments than at the end and the change is significantly different from the control treatment.

The mechanism we hypothesize is independent of the actual decision to migrate, so we would expect it to affect participants in the exogenous and endogenous migration treatment in a similar fashion. However, there are many reasons why behaviour in the Migration treatment with endogenous migration decision could be different. Players could sort into high and low contributing groups based on their own contribution preference, migration decisions could be interpreted as a signal about the status of the groups, or players are unsatisfied with their group and migrate to be able to 'punish' them. Thus, the Exogenous Migration treatment allows us to cleanly identify the effect of migration, independent of potential confounds that more natural endogenous decisions do introduce.

\subsection{Results}

We first provide descriptive statistics and analyse the group-pair level data for which we derive the main hypothesis. In the subsequent analysis we investigate the role of ingroup bias and SVO, and drivers of the decision to migrate. 


\subsubsection{Descriptive Statistics and Non-Parametric Analysis}

Figure 4.4.1 presents the average group contributions over time per treatment together with the average group contributions predicted by the risk-neutral Nash equilibrium without social preferences. ${ }^{9}$ There is considerable overcontribution in all treatments and none of the treatments converges towards the Nash Equilibrium. Contributions start off at a similar level but diverge around period 3. The contributions in the Exogenous Migration treatment drop below the contributions in the Control treatment whereas the contributions in the Endogenous Migration treatment rise above it. If we only consider independent observations-average contributions over time and group-pair-we observe that mean group contributions are higher in the endogenous (Mean $=221.08$; Std. $=50.69 ; \mathrm{N}=10$ ) and lower in the exogenous migration (Mean $=181.27 ;$ Std. $=63.86 ; \mathrm{N}=10$ ) than in the control treatment (Mean $=198.60 ;$ Std. $=33.15 ; \mathrm{N}=10)$. Comparing the contributions in the different treatments does not reveal significant differences between the treatments ( $p=0.33$, Kruskal-Wallis test). Contributions in the first round also do not differ significantly ( $p=0.875$, Kruskal-Wallis test).

Result 1: There is no significant difference in average group contributions across the three treatments

One possible explanation for this result could be a lack of migrations. By contrast, Figure 4.4.2 shows that this is unlikely to be the case. All groups start as groups of four but already in period three, only a minority of groups are groups of four. Given the strong incentives to migrate to smaller groups, it is not surprising that only a few groups of size six and larger (and 2 or lower) are observed. In total, $36.9 \%$ of group-pairs in the migration treatments are groups of $4,43.6 \%$ are groups of 5 and $3,14.1 \%$ are groups of 6 and $2,4.7 \%$ are groups of 1 and 7 , and $0.7 \%$ are groups of 8 . Even though these differences in group sizes should not affect the average equilibrium group contributions in a group-pair according to the risk-neutral theoretical benchmark, the coincidence of

\footnotetext{
${ }^{9}$ This Nash equilibrium holds for groups of size 2-6. For the other group sizes, predicted average group contributions would actually be lower because of corner solutions (see Section 4.3).
} 


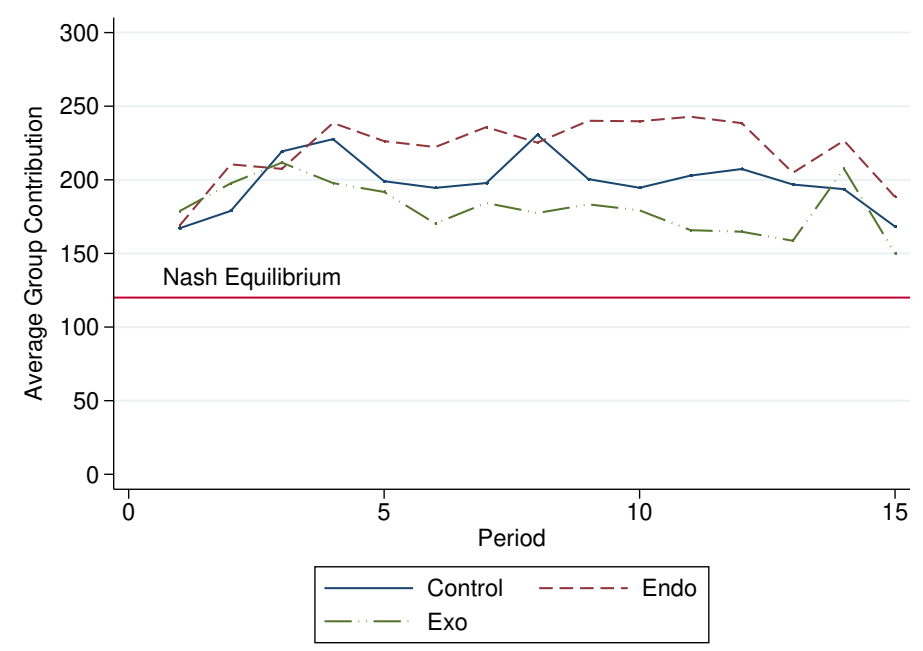

Figure 4.4.1: Development of group contributions over time and by treatment

diverging group sizes and diverging contributions after period 3 suggests that this could still be an important factor. ${ }^{10}$ As averaging over time and group-pair reduces the statistical power considerably, we also conduct regression analysis in which we can control for different group sizes and time-serial dependency.

\subsubsection{Treatment Comparison - Group-pair Regression with Controls}

Table 4.4.1 reports the results of random-effects regressions in which we cluster the standard errors on group-pair level (30 clusters) and use the average group contributions in a group-pair in each period as dependent variable. The control treatment without migrations is always the reference group.

\footnotetext{
${ }^{10}$ As described in the discussion of the theoretical predictions, with group sizes of 1-7 and $0-8$, we would actually expect lower contributions. However, these only make up a very small number of observations.
} 

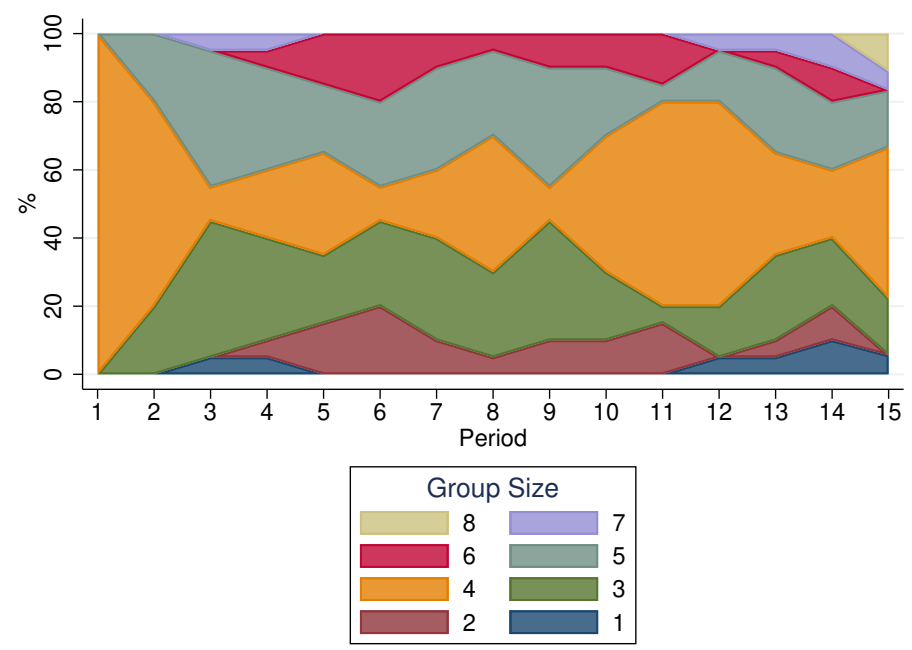

Figure 4.4.2: Development of group size over time

Table 4.4.1: Random-effects regressions of average group contributions averaged at group-pair level

\begin{tabular}{|c|c|c|c|c|c|c|}
\hline & $\begin{array}{c}\text { (1) } \\
\text { Avg.Group }_{\text {contribution }}\end{array}$ & $\begin{array}{c}(2) \\
\text { Avg.Group } \\
\text { contribution }_{t}\end{array}$ & $\begin{array}{c}\text { (3) } \\
\text { Avg.Group } \\
\text { contribution }_{t}\end{array}$ & $\begin{array}{c}(4) \\
\text { Avg.Group } \\
\text { contribution }_{t}\end{array}$ & $\begin{array}{c}\text { (5) } \\
\text { Avg.Group } \\
\text { contribution }_{t}\end{array}$ & $\begin{array}{c}\text { (6) } \\
\text { Avg.Group } \\
\text { contribution }_{t}\end{array}$ \\
\hline Endo & $\begin{array}{c}22.48 \\
(18.52)\end{array}$ & $\begin{array}{c}25.94 \\
(19.81)\end{array}$ & $\begin{array}{c}7.47 \\
(5.99)\end{array}$ & $\begin{array}{l}13.52^{*} \\
(7.36)\end{array}$ & $\begin{array}{l}20.88^{* * *} \\
(8.01)\end{array}$ & $\begin{array}{l}18.46^{* *} \\
(7.33)\end{array}$ \\
\hline Exo & $\begin{array}{c}-17.33 \\
(22.00)\end{array}$ & $\begin{array}{r}-13.87 \\
(21.33)\end{array}$ & $\begin{array}{r}-6.84 \\
(6.61)\end{array}$ & $\begin{array}{r}-1.07 \\
(7.26)\end{array}$ & $\begin{array}{r}-11.17^{*} \\
(6.65)\end{array}$ & $\begin{array}{c}-12.92^{* *} \\
(5.99)\end{array}$ \\
\hline Avggroupcontributions $_{t-1}$ & & & $\begin{array}{l}0.73^{* * *} \\
(0.04)\end{array}$ & $\begin{array}{l}0.72^{* * *} \\
(0.05)\end{array}$ & $\begin{array}{l}0.71^{* * *} \\
(0.04)\end{array}$ & $\begin{array}{l}0.72^{* * *} \\
(0.04)\end{array}$ \\
\hline \#Migrations $s_{t}$ & & & & & $\begin{array}{l}17.60^{* *} \\
(7.54)\end{array}$ & $\begin{array}{c}9.64 \\
(7.95)\end{array}$ \\
\hline$\#$ Migrations ${ }_{t} \times$ Endo & & & & & $\begin{array}{c}-27.50^{* * * *} \\
(8.56)\end{array}$ & $\begin{array}{c}-27.18^{* * *} \\
(10.50)\end{array}$ \\
\hline Constant & $\begin{array}{l}198.6^{* * *} \\
(10.14)\end{array}$ & $\begin{array}{l}198.6^{* * *} \\
(10.18)\end{array}$ & $\begin{array}{l}54.78^{* * * *} \\
(8.84)\end{array}$ & $\begin{array}{l}56.13^{* * *} \\
(9.39)\end{array}$ & $\begin{array}{l}59.02^{* * *} \\
(8.78)\end{array}$ & $\begin{array}{l}56.64^{* * *} \\
(8.36)\end{array}$ \\
\hline Group size controls & No & Yes & No & Yes & Yes & No \\
\hline$N$ & 450 & 420 & 450 & 420 & 420 & 420 \\
\hline Overall $R$ - squared & 0.056 & 0.121 & 0.538 & 0.604 & 0.615 & 0.549 \\
\hline
\end{tabular}

Standard errors clustered by group pair in parentheses, ${ }^{*} \mathrm{p}<0.10,{ }^{* *} \mathrm{p}<0.05,{ }^{* * *} \mathrm{p}<0.01$

Using only the migration treatment dummies Endo and Exo as inde- 
pendent variables in Regression (1) does neither show significant differences between the migration treatments and the control $(p$-value $=$ 0.225 for the Endogenous treatment and $p$-value $=0.431$ for the Exogenous treatment), nor significant differences between the migration treatments. ${ }^{11}$ Reducing the noise by including group size controls in Regression (2) and accounting for potential dynamics captured by adding lagged group-pair contributions (Avggroupcontributions $s_{t-1}$ ) in Regression (3) separately also does not improve the significance levels of the treatment dummies. Accounting for both, dynamics and group size differences, in Regression (4), the difference between the endogenous migration treatment and the control treatment as well as the difference between the migration treatments becomes significant at $10 \%$ level $(p$-value $=0.066$, F-test with Exo $=$ Endo $p$-value $=0.059)$.

While this effect could be due to the migrations themselves, controlling

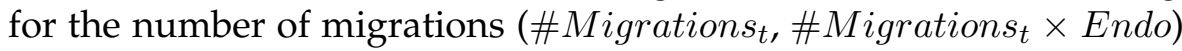
that occurred between period $t-1$ and $t$ in the exogenous and the endogenous migration treatments actually increases the treatment effects and turns the negative coefficient of the Exogenous Migration treatment dummy significant at the $10 \%$ level and the positive difference of the Endogenous Migration treatment significant at 5\% level (Regression (5)). ${ }^{12}$ The number of migrations has a positive effect in the exogenous treatment ( $p$-value $=0.02)$ but a negative effect on contributions in the Endogenous Migration treatment ( $p$-value $<0.001)$. This partly mitigates the respective positive and negative effects of the treatments themselves. ${ }^{13}$ A possible interpretation of these seemingly contradicting findings relates to the change in the reference group here. By adding the number of migrations in the migration treatments as variables, the coefficients of the treatment dummies for the Endogenous and Exogenous Migration treatment now only refer to the effects of the treatments in the case where no migrations take place. If no migrations take place

\footnotetext{
${ }^{11} p$-value $=0.11, F$-test with restriction Exo $=$ Endo

${ }^{12}$ The average number of migrations in the migration treatments is 0.57 per round or 1 migration every 1.75 periods. Migrations have a subscript $t$ here, because while the migrations decisions are made in $\mathrm{t}-1$, the actual migrations only take place at the start of the new period $t$.

${ }^{13} \mathrm{~A}$ graphical representation of this interaction effect can be found in Appendix 4.E.
} 
in the Endogenous Migration treatment, it could be an indicator that participants were satisfied with their group contributions and had intention to leave. As higher contributions result in higher chances of winning, this is more likely to occur when contributions are high. On the other hand, if participants decide to migrate, this might be an indicator that participants are not satisfied with the (low) contributions of their group and are thus more willing to leave. This effect is in line with our Sub-Hypothesis 2. In the Exogenous Migration treatment, participants cannot decide to migrate but are exogenously displaced. Here, the threat of potential migration could suppress contributions, which was the hypothesised mechanism for Sub-Hypothesis 1 . However, if contributions are low, the exogenous shock to the group composition caused by the displacement could be seen as possibility to restart cooperation within the group, and thus increase contributions. ${ }^{14}$

To account for potential endogeneity issues resulting from including both the number of migrations and group size changes that are a direct result of these migrations, we also run this regression without group size dummies (Regression (6)). In this specification, the number of migrations has no significant effect on contributions anymore in the exogenous treatment but the other results are robust. ${ }^{15}$ Although our hypotheses are about group-level contribution, we can also run these regressions on individual contributions and control for additional factors such as beliefs, individual migration decisions, or demographics. This replicates our findings on group-pair level with the exception that the exogenous migration treatment dummy is not marginally significant anymore. This is probably caused by the individual migration decision and group size changes picking up some of the negative treatment effect in the exogenous migration treatment (see Regression (16a) in Appendix 4.I). ${ }^{16}$

\footnotetext{
${ }^{14}$ Such an effect can be observed in public good games (Andreoni, 1988; Brandts et al., 2016; Croson, 1996).

${ }^{15}$ In Appendix 4.F we also ran the regressions without the control treatment, only comparing the migration treatments. Similarly to the results reported here, contribution levels are significantly higher in the Endogenous Migration treatment in the regressions with controls.

${ }^{16}$ An additional exploratory analysis of beliefs can be found in Appendix 4.H.
} 
Result 2: (a)When controlling for group size and lagged contributions, average group contributions in the Endogenous Migration treatment are significantly higher than in the Control treatment and marginally significantly lower in the Exogenous Migration treatment. (Supports Hypothesis 1 for the Exogenous treatment)

(b) Implemented migrations have a heterogeneous effect on contributions: They increase contributions in the Exogenous Migration treatment, whereas they decrease contributions in the Endogenous Migration treatment relative to groups without migrations (supports SubHypothesis 2 for the Endogenous treatment).

\subsubsection{The Role of SVO and Ingroup Bias}

Figure 4.4.3 shows the ingroup bias-the difference between ingroup and outgroup $\mathrm{SVO}$ - and the social value orientations towards ingroup and outgroup at the start and the end of the experiment. As predicted by Sub-Hypothesis 1 and shown in Figure 4.4.3a, ingroup bias is lower in the migration treatments at the start of the experiment. However, this difference is only marginally significant ( $p$-value $=0.097$, KruskalWallis test, $\mathrm{N}=240$ ). The ingroup bias stays relatively stable and only decreases slightly for the participants in the Control treatment. There are also no significant differences in ingroup bias between the different treatments at the end of the experiment ( $p$-value $=0.287$, KruskalWallis Test, $\mathrm{N}=26)^{17}$. Comparing the change in ingroup bias between the treatments also does not yield significant results $(p$-value $=0.987$, Kruskal-Wallis Test, $\mathrm{N}=26$ ).

Result 3: At the start of the experiment, ingroup bias is lower in the migration treatments than in the control treatment (supports Sub-Hypothesis

\footnotetext{
${ }^{17}$ The difference in number of observations between the ingroup bias at the start and the end has two reasons. First, while there was no interaction between players at the start of the experiment and thus their SVO choices can be treated as independent, this is not the case anymore at the end of the experiment. Therefore, we average the ingroup bias at the end of the experiment over the players in a group-pair. Furthermore, the differences in group sizes resulted in some cases in which players did not make an ingroup decisions-because they were the only player left in the group - and other cases in which there was no outgroup left and thus no outgroup SVO decision.
} 
1). However, this difference is only marginally significant and the bias does not change over the course of the experiment (does not support Sub-Hypothesis 2).
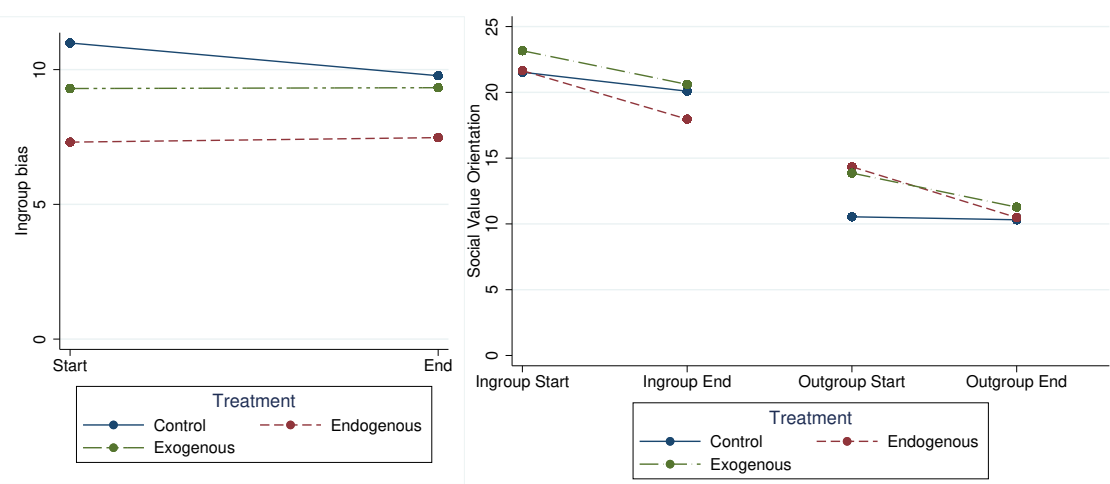

(a) Ingroup Bias before and after(b) SVOs before and after contest, by treatment contest, by treatment

Figure 4.4.3: Development of social preferences

Figure 4.4.3b shows that social value orientation towards the ingroup hardly differs between treatments at the start of the experiment ( $p$-value $=0.847$, Kruskal-Wallis Test, $\mathrm{N}=240)$. Social value orientation towards the outgroup is higher in the migration treatments than in the control treatment at the start of the experiment, but this difference is not statistically significant ( $p$-value $=0.164$, Kruskal-Wallis Test, $\mathrm{N}=240$ ). Over the course of the experiment, social value orientation towards both in- and outgroup decreases in the migration treatments. For the endogenous treatment, only the drop in outgroup SVO is significant at $5 \%$ level ( $p$-value $=0.035$, Sign test, $N=8$ ). For the exogenous treatment neither of the two decreases in social value orientation is statistically significant ( $p$-value $=0.144$ and $p$-value $=0.363$, Sign test, $\mathrm{N}=8$ ). In the control treatment, social value orientation towards the outgroup stays constant but social value orientation towards the ingroup drops between the start and end of the contest. However, this drop in social value orientation towards the ingroup is not significant ( $p$-value $=0.109$, Sign test, $\mathrm{N}=8$ ). Comparing the social value orientation changes across treatments does not show significant 
differences (Ingroup: $p$-value $=0.346, \mathrm{Kruskal}-W a l l i s$ Test, $\mathrm{N}=26$; Outgroup: $p$-value $=0.294$, Kruskal-Wallis Test, $\mathrm{N}=26) .{ }^{18}$ Thus we find no support for our Sub-Hypothesis 2 that ingroup bias and social value orientation towards the ingroup would decrease over the course of the experiment.

Result 4: (a)Social value orientation towards the ingroup does not differ between treatments at the start of the experiment (does not support SubHypothesis 1) and does not decrease significantly over the course of the experiment (does not support Sub-Hypothesis 2). Differences between the treatments are not significant.

(b) Social value orientation towards the outgroup does not differ between treatments at the start of the experiment but does decrease significantly over the course of the experiment in the endogenous migration treatment. Differences between the treatments are not significant.

\subsubsection{What drives Migration Decisions}

In Table 4.4.2 we present the results of an analysis of the individual decision to leave in the Endogenous migration treatment. Players make this decision at the end of each period, after having received information about contributions and outcome of the contest. As the decision to leave is a binary variable, we use a Probit model and include factors that we suspect to correlate with the decision to leave. These are on the one hand variables that describe the relation between the groups such as absolute (Group contribute (excl.self) $)_{t}$, Other group contribute ${ }_{t}$ ) and relative contributions of the groups (Own group more than other group $t_{t}$ ), size of the own group (Group Size $1: 7_{t}$ ), group size changes (Group increase $_{t}$, Group decrease $)$, migrations that occurred at the start of the round (\#Migrations $s_{t}$ ), and winning the round $\left(\right.$ Win $\left._{t}\right)$. On the other hand there are also factors that describe the relationship of the individual player with their group such as ingroup bias (Ingroup Bias $\left._{\text {Start }}\right)$, own contributions (Contribute $\left.{ }_{t}\right)$, or contributing

\footnotetext{
${ }^{18}$ An additional analysis of factors influencing changes in ingroup bias is provided in Appendix 4.G. None of the independent variables reaches statistical significance at conventional levels.
} 
more than the group average (Self more than own group $)_{t}$ that could influence the decision to migrate. We find that participants' decision to migrate is mostly driven by the desire to win. While higher contributions of the own group than the other group $(-13.1 \%$, $p$-value $<0.001)$, and winning the contest $(-13.8 \%, p$-value $=0.001)$ all greatly reduce the probability that an individual decides to leave, contributions by the other group increase the probability $(0.1 \%$ per contributed token, $p$-value $<0.001)$. Own contributions also decrease the probability that a person decides to leave their group $(-0.1 \%$ per contributed token, $p$-value $=0.029$ ). This could be the result of the sunk cost fallacy-participants are staying in their group because they already invested a lot on its behalf. Thus, if participants contributed a lot, their group contributed more than the other group, and won the contest, they are very unlikely to leave. However, the more the other group contributes, the more likely it becomes that participants leave.

The breakdown of the group sizes reveals that the participants understood the incentives and generaly choose to leave larger groups. Being in a group of size six or seven increases the probability to leave by $19.3 \%$ and $28.5 \%$, respectively ( $p$-value $=0.01$ and $p$-value $<0.001$ ). However, groups of two also increased participants desire to leave by $21.8 \%$ ( $p$-value $=0.096)$. This last result is somewhat surprising, as expected payoffs are much higher for smaller groups. This might indicate an unwillingness to contribute a high proportion of one's own endowment to the contest as the equilibrium predictions suggest that a group of two should invest $75 \%$ of their total endowment into the contest. Recent changes in group size, implemented migration decisions, or initial ingroup bias all did not affect the propensity to leave the group. 
Table 4.4.2: Probit: Drivers of the decision to migrate in round $t$

\begin{tabular}{|c|c|}
\hline & $\begin{array}{l}\text { Marginal Effects } \\
\text { DecisiontoLeave }_{t}\end{array}$ \\
\hline Contribute $_{t}$ & $\begin{array}{r}-0.001^{*} \\
(0.001)\end{array}$ \\
\hline Group contribute $(\text { excl.self })_{t}$ & $\begin{array}{r}-0.001 \\
(0.001)\end{array}$ \\
\hline Other group contribute $_{t}$ & $\begin{array}{l}0.001^{* * *} \\
(0.001)\end{array}$ \\
\hline Self more than own groupt & $\begin{array}{c}-0.005 \\
(0.065)\end{array}$ \\
\hline Own group more than other group & $\begin{array}{c}-0.131^{* * *} \\
(0.034)\end{array}$ \\
\hline Group Size $1_{t}$ & $\begin{array}{c}-0.036 \\
(0.285)\end{array}$ \\
\hline Group Size $2_{t}$ & $\begin{array}{r}0.218^{*} \\
(0.121)\end{array}$ \\
\hline Group Size $3_{t}$ & $\begin{array}{c}0.032 \\
(0.048)\end{array}$ \\
\hline Group Size $5_{t}$ & $\begin{array}{c}0.069 \\
(0.067)\end{array}$ \\
\hline Group Size $6_{t}$ & $\begin{array}{l}0.193^{* *} \\
(0.078)\end{array}$ \\
\hline Group Size $7_{t}$ & $\begin{array}{l}0.285^{* * *} \\
(0.072)\end{array}$ \\
\hline Win $_{t}$ & $\begin{array}{c}-0.138^{* * *} \\
(0.036)\end{array}$ \\
\hline Ingroup Bias Start $_{\text {Int }}$ & $\begin{array}{c}0.001 \\
(0.001)\end{array}$ \\
\hline Group increase $_{t}$ & $\begin{array}{r}-0.033 \\
(0.066)\end{array}$ \\
\hline Group decrease $_{t}$ & $\begin{array}{r}-0.036 \\
(0.049)\end{array}$ \\
\hline \#Migrations $s_{t}$ & $\begin{array}{r}-0.001 \\
(0.041)\end{array}$ \\
\hline$N$ & 1120 \\
\hline
\end{tabular}

\subsection{Discussion and Conclusion}

In this study we present a lab experiment to identify if and how the possibility to migrate and actual migration between groups affects contest 
contributions in a group contest game. We hypothesised that migration would decrease contributions due to a decrease in identification with the own group as measured by social preferences. By contrast, we find that contributions increase if participants can freely choose between switching groups or staying, but only after controlling for group size differences and previous contributions. In another treatment with exogenously determined migration, contribution levels are marginally lower than in the control without migration. Social identification with the own group, as measured by the ingroup bias in the social preference tests, stays unchanged throughout the experiment in all of the treatments.

Our study adds to the literature on group contests as it is to our knowledge the first study that is not conducted with fixed groups. We find that allowing for migration between the groups does little in alleviating the rampant overcontribution that is typical for experimental contest games (Sheremeta, 2018). If anything, and in line with previous findings on endogenous groups and coalition formation in contests (Bloch, 2012; Herbst et al., 2015; Smith et al., 2012), we find that allowing free movement may aggravate the overcontribution. Interestingly, if migration does take place in the endogenous migration treatment, contributions decrease in the following round, suggesting that at least in the very short term, we observe the hypothesised decrease in contributions due to migration. Still, this effect is not large enough to offset overall higher contributions in the endogenous migration treatment and goes in the opposite direction for the exogenous treatment, which cannot be explained by our hypotheses. One possible interpretation is, that if groups are allowed to form endogenously, migrations are an indication that participants are unhappy in their group. The analysis of the decision to migrate suggests that participants mainly leave their group to improve chances of winning and thus if migrations take place, they are likely to coincide with low contribution levels. In this case, migrations could act as a disciplining device, ensuring higher contributions by acting as a looming threat that people might leave the group if contributions are not high enough. In the Exogenous Migration treatment, participants do not get a choice to migrate but might get exogenously moved to an other group. If contributions are low, this exogenous shock to the 
group composition could be seen as opportunity to restart cooperation within the group. In public good games, restarting has been shown to increase cooperation at least in the short term (Brandts et al., 2016), thus a similar effect could be occurring here.

Our study also adds to the literature on group identity. We observe that groups do not need to have rigid boundaries, to maintain a social identity, as we observe a persistent ingroup bias in all of the treatments. Even in cases in which the group composition got completely shuffled did the ingroup bias not change. Thus, the ingroup bias that relatively minimal groups produce, does not seem to be dependent on the specific composition of the group or the permanence of membership.

For a social planner who wants to minimise the wasteful rent-seeking between groups, our experiment has bad news. We find that migration does little to alleviate the waste of resources that is common in contest games and rent-seeking situations. In contrast, allowing contestants to freely migrate between groups does even seem to have an escalating effect. For countries, sports teams, or companies however, these result suggest that migration does not decrease competitiveness of the own group. Furthermore, the identification with the own team does not suffer from having turnover amongst the group members. Thus, sports fans and company managers should not be overly concerned with "Mercenary" employees that aim to maximise their own earnings and often switch jobs or teams, as, in our setting, we find no evidence that changing composition of the own team has detrimental effects on team performance.

A limitation of our study is that our setup only involves two groups and thus players can only migrate to the opposing team in the conflict. Extending this to a richer setting with more groups, of which not all are involved in the conflict could provide interesting insights into conflict investment and self selection in a more dynamic group conflict setting. Furthermore, the groups in the experiment are small and thus every single migration constitutes are large change in the size and composition of the group. Using larger groups would allow to make group size and composition changes more gradual. It would also be instructive to use an extensive social identity manipulation-or to use natural 
groups-in the group contest to start the contest with more meaningful groups and to investigate if the effect of migration is more pronounced if the social identities of the competing groups are initially stronger. 


\section{Appendices}

4.A Instructions 


\section{Experiment Instructions}

\section{General Instructions}

Welcome and thank you for participating in this decision-making experiment. Please read these instructions carefully. If you have any questions during the experiment, please raise your hand and one of the experimenters will come to you to answer your question in private.

In this experiment you can earn money. The amount of money you earn will depend upon the decisions you make, on the decisions other participants make and on random events. Your identity will never be revealed to anyone during or after the experiment. Nor will you receive any information about other participants' identity. Your name will never be associated with any of your decisions. In order to keep your decisions private, do not reveal your choices to any other participant during or after the experiment. You will be paid in private and in cash at the end of today's session.

This experiment consists of two parts and your total earnings will be the sum of your earnings in both parts.

Throughout the experiment, your earnings will be counted in tokens. At the end of the experiment you will be paid in cash using the exchange rate

\section{0 tokens $=€ 0.50$}

The experiment consists of a number of independent tasks, which are described in detail below. At the end of the experiment you will be asked to fill out a questionnaire.

In the experiment there are no right or wrong choices. We are solely interested in your decisions. 


\section{Groups}

For the duration of the experiment you will be matched with other participants into two groups. One group will be called the RED group and the other group will be called the BLUE group. At any point in time during the experiment you will be a member of either the RED group or the BLUE group.

You and the other participants you are matched with will be identified with unique anonymous symbols. The experiment consists of several rounds. The symbols will appear in an overview screen at the beginning of each round as seen in the example screen below:

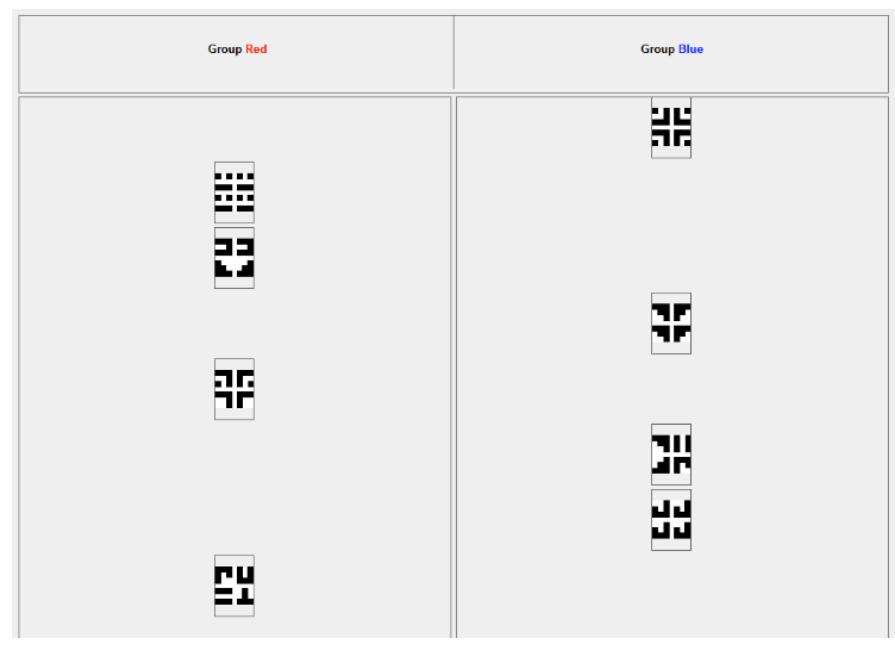

At the beginning of Part 1 of the experiment, you will get to know the group you are assigned to as well as the anonymous symbol that represents you.

\section{Part 1}

In this part you will be asked to make decisions in $\mathbf{2}$ rounds, and in each round you will face $\mathbf{6}$ decision situations. Your choices in these decision situations will affect the earnings of both you and another participant, whom we refer to as "the Other". All decisions will remain anonymous and confidential. You will not get to know the identity of the Other nor will the Other (or anybody else) get to know your identity. You will however, get information on the group membership of the Other.

- In the first round, the Other will be a member of your own group.

- In the second round, the Other will be a member of the other group. 
The order of the 6 decision situations within each round will be determined randomly by the computer.

At the end of the experiment there will be a part similar to this one.

\section{Decision Situations}

In each decision situation you will allocate tokens between you and the Other. Each decision situation will have 9 options. Here is an arbitrary example of a decision situation:

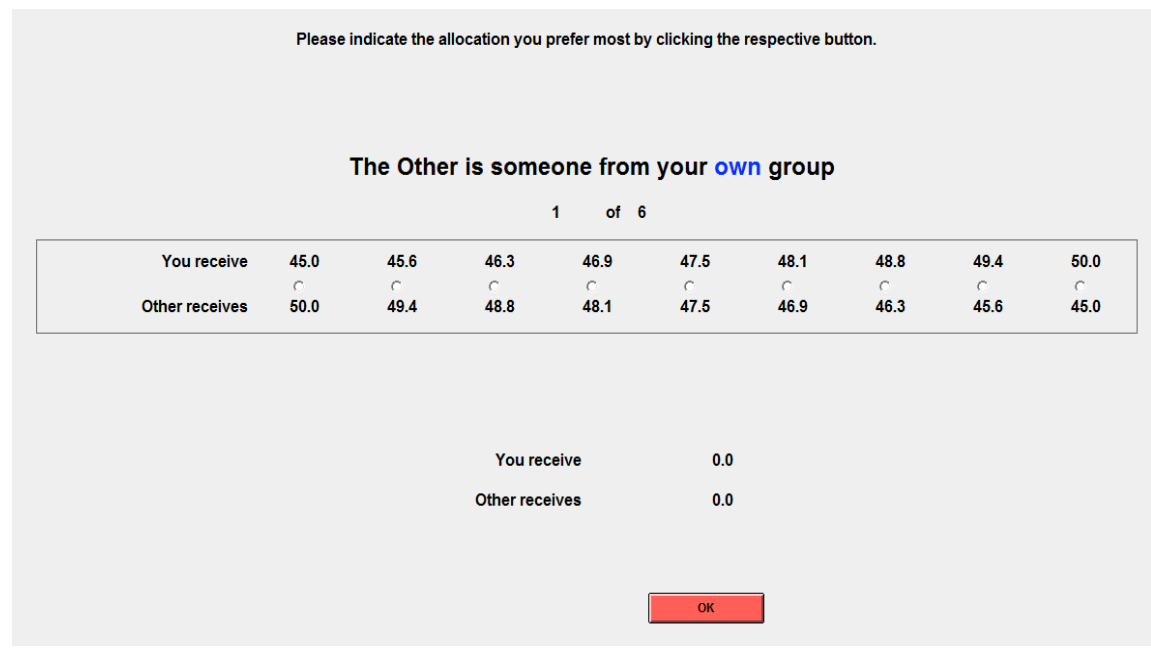

You should choose the allocation you prefer most. Each allocation may lead to different earnings for you and/or the Other. In the example above, you would be making allocation decisions between you and another member of your own group during this round. In this example the word "own" is in blue. In the actual decision situations, the colour of the word "own" will be the same as the colour of the group you belong to in this part.

In the example decision situation, if you would choose the leftmost allocation, you would earn 45 tokens and the Other would earn 50 tokens. If you would choose the rightmost allocation, you would earn 50 tokens and the Other would earn 45 tokens. The earnings for you and the Other from allocations in-between are derived similarly.

You select an allocation by clicking on the corresponding button with the mouse. After an allocation is selected, the earnings for you and the other will appear at the bottom of the screen 
When you are satisfied with your selected allocation you will need to confirm your choice by clicking on the "OK" button at the bottom of the screen.

\section{Payment Part 1}

After all participants have made all their decisions in the experiment, the computer will determine each participant's earnings in this part using the following procedure.

[Step 1] It is randomly determined if the decisions in this part or the decisions in a similar part taking place at the end of the experiment are paid out.

[Step 2] The computer will randomly assign half of the participants to be paid as "active" participant and the other half to be paid as "passive" participant.

[Step 3] Each active participant is paired with exactly one passive participant. Therefore, as active participant, you will be either paired with someone from your own group or someone from the other group. In the first case only decisions towards your own group will be relevant for your earnings. In the latter case only decisions towards the other group will be relevant for your earnings.

[Step 4] For each pair of active and passive participants, one of the active participant's six decisions will be randomly selected by the computer. The active participant receives the "You receive" amount of tokens and the passive participant receives the "Other receives" amount of tokens.

\section{Important!}

The used procedure guarantees that each active participant is paired with one - and only one - passive participant and vice versa.

When making your decision you will not know whether you will be an active or a passive participant in the earnings determination nor will you know the decision situation that counts for your and the Other's earnings. Therefore, you should view each decision situation as equally important and consider each of your choices as the one that determines your and the Other's earnings.

Your choice in one decision situation does not affect any other decision situation. Therefore, you should consider each decision situation independent of each other.

Nobody will be informed about your decisions. Likewise you will not receive any information of the decisions of other participants. 


\section{Comprehension Questions}

You will now be asked to answer some comprehension questions about how your decisions affect your earnings and earnings of others. After you have correctly answered the comprehension questions, please wait for the experiment to continue. 


\section{Part 2}

This part consists of 15 rounds. In each round the red and the blue group are competing for a prize in the following way: Each group member will be endowed with 120 tokens which are put in the member's private account. This will be called "Initial Endowment". Each member can use these tokens to buy lottery tickets for the own group. Each token buys one lottery ticket. Any token not used for buying lottery tickets will remain in the member's private account. Each member can buy tickets only for his or her own group. All decisions are made simultaneously and anonymously.

The lottery tickets purchasing decision screen is shown in the example below:

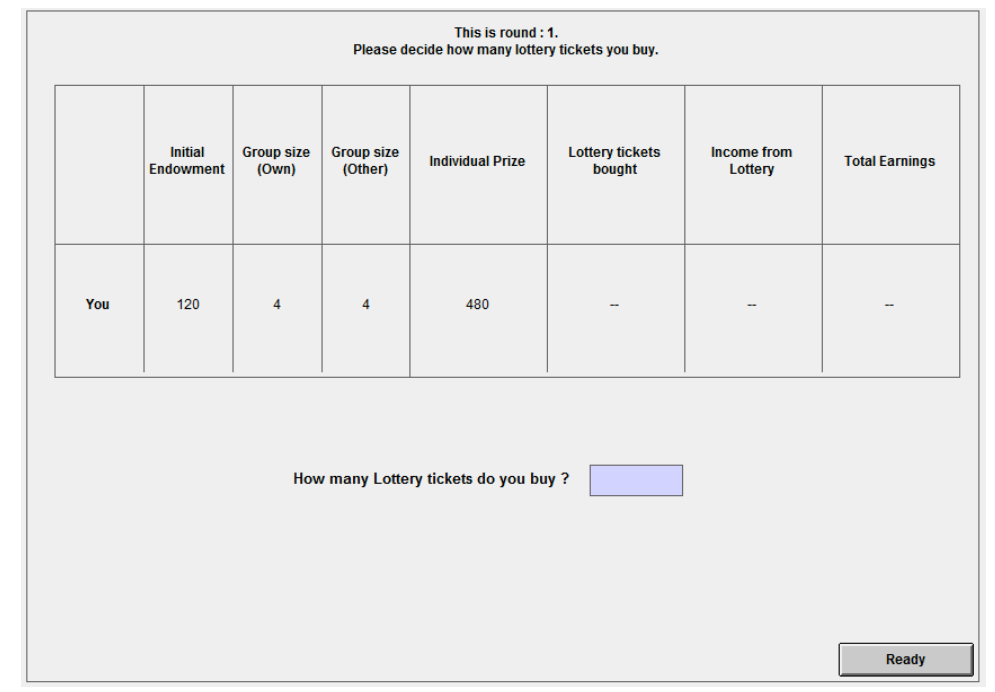

After you have decided how many tickets to buy, you will be asked for your best estimate of the average amount of tickets bought by the other group members of your own group and the average amount of tickets bought by the members of the other group.

After all members in both groups have made their decisions, a lottery will determine whether your group or the other group wins a prize of 1920 tokens. For this, all bought tickets are put in a "virtual" urn and one of these tickets will be randomly drawn as the winning ticket. If the ticket drawn is from a member of your own group your group will win the prize. If the ticket drawn is from a member of the other group the other group will win the prize. Each ticket in the urn has the same chance to be drawn.

In other words, if you and the other group members of your own group buy in total $X$ tickets, and the group members of the other group buy in total $Y$ tickets, then the chance that your group wins is given by $\frac{x}{x+y}$ and the chance that the other group wins is $\frac{r}{x+Y}$.

Hence, the group which buys more tickets has a higher chance of winning the prize than the group which buys less tickets. 
Note: If your group and the other group buy the same total amount of tickets, then the chance of winning the prize is 50:50. This is also the case if none of the groups buys any tickets. If your group buys K-times as many tickets as the other group, then also your group's chance is K-times as high as that of the other group. If only one of the groups buys tickets, then this group wins the prize with certainty.

After the winning group is determined, the prize of 1920 tokens is shared equally among the members of the winning group and added to the private accounts. For a group of 4 , this means that the individual prize for each member of the winning group is 480 tokens. The individual prize is displayed on the screen when you make your purchasing decision.

Thus, the earnings of a member of the winning and the losing group, respectively, are calculated as follows:

Earnings of a member of the winning group: 120 - bought lottery tickets +480

Earnings of a member of the losing group: 120 - bought lottery tickets

At the end of each round you get information about your earnings, your own group's total amount of tickets bought, the other group's total amount of tickets bought, the winning chances given these total amounts of tickets bought and which group won the prize.

The next screen shows an example of a screen at the end of a round for a member of the winning group (the screen for a member of the losing group looks similar):

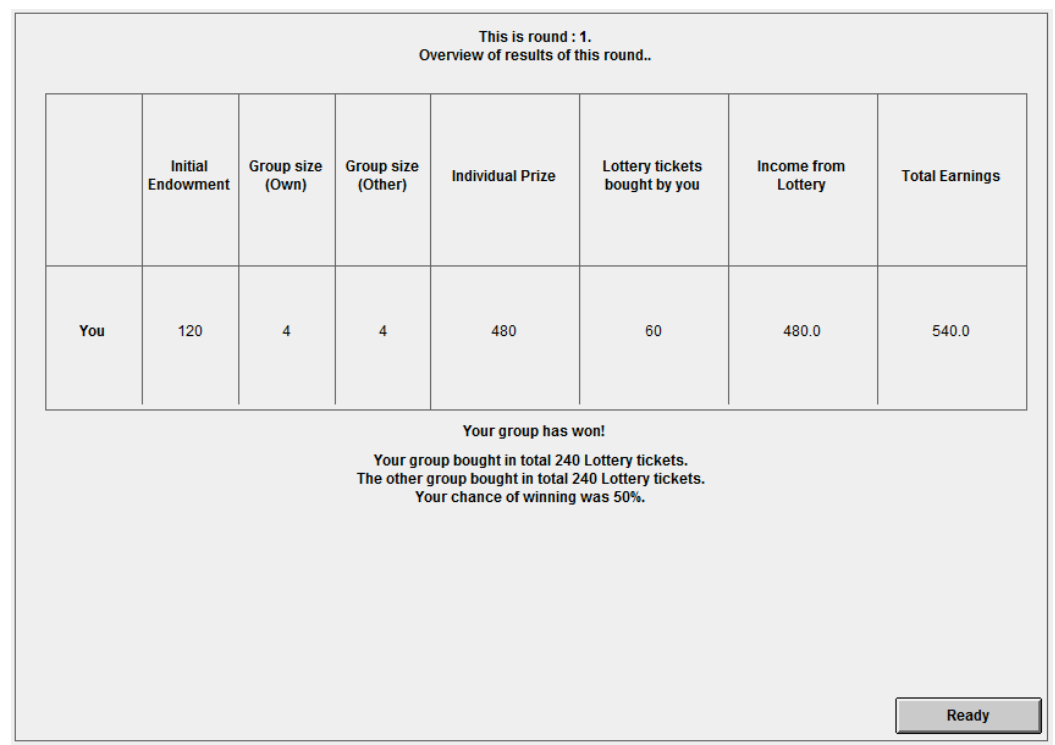

[Baseline: Your own group is the same as your own group in Part 1. Likewise, the other group is the same as the other group in Part 1. You and all other members of your group will remain members of your own group throughout all 15 rounds. The same holds for the members of the other group.] 
[Endogenous Migration: In Round 1 of this part your own group is the same as your own group in Part 1. Likewise, in Round 1 of this part the other group is the same as the other group in Part 1. At the end of Round 1 and each subsequent round (except for the last Round 15), you will have to decide if you want to stay in your current own group or want to switch to the other group as illustrated in the picture below:

\section{Please decide if you want to stay in your current own group or if you want to switch to the other group.}

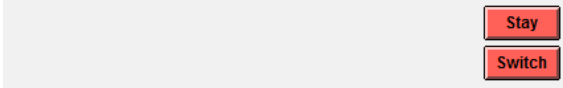

Each other group member of your current own group and each group member of the current other group also decides whether they want to stay in their respective current own groups or want switch to the other group.

After all 8 participants in your current own and other group have made their staying or switching decisions, the following procedure will determine which actual switches (if any) between groups will take place:

2 out of the in total 8 "stay" or "switch" decisions of all members of your and the other group are randomly selected and actually implemented. The other 6 not selected decisions will be counted as "stay" decisions. In each round, each of the 8 "stay" or "switch" decisions has equal chance to be one of the 2 actually implemented decisions.

As of Round 2, at the beginning of each round you will be informed about if you have stayed with your group or have switched to the group as well as your group membership (red or blue) in that round. Any group changes that took place will be visible in the overview screen. The symbols of the players that switched groups will have moved to their new group and an arrow will indicate the change.

Depending on the actually implemented "stay" and "switch" decisions, the group sizes (number of members in a group) of the two groups can change between rounds. The total prize the winning group receives stays the same irrespective of the size of the group. This means that individual earnings from winning the prize will change with the size of the group.

The table below shows what the individual share of the prize will be for each possible group size, in case this group wins the prize.

\begin{tabular}{|c|c|c|c|c|c|c|c|c|c|}
\hline $\begin{array}{c}\text { Group } \\
\text { Size }\end{array}$ & 0 & 1 & 2 & 3 & 4 & 5 & 6 & 7 & 8 \\
\hline $\begin{array}{c}\text { Individual } \\
\text { Prize }\end{array}$ & 0 & 1920 & 960 & 640 & 480 & 384 & 320 & 274.3 & 240 \\
\hline
\end{tabular}


Note: The group size is the number of all members; that is, if the size of your own group is 1 you would be the only member of this group.

The individual prize of a member in the losing group is 0 , irrespective of the group size.

Example: In Round 1 both groups have 4 members and the group size of each group is thus 4 . Therefore, each member of the winning group will earn 480 tokens. If after Round 1, for example, one person switches to the other group, one group will have 3 members and the other group will have 5 members. Each member of the group of 3 will receive 640 tokens in case this group wins, whereas each member of the group of 5 will receive 384 tokens if this group wins. Note that larger groups have more tokens in total and thus can potentially also buy more lottery tickets than smaller groups.]

[Exogenous Migration: In Round 1 of this part your own group is the same as your own group in Part 1. Likewise, in Round 1 of this part the other group is the same as the other group in Part 1. After Round 1 in each round the group membership of up to two participants may change. This happens independently of your or anyone else's decisions in this experiment.

As of Round 2, at the beginning of each round you will be informed about if you have stayed with your group or have switched to the other group as well as your group membership (red or blue) in that round. Any group changes that took place will be visible in the overview screen. The symbols of the players that switched groups will have moved to their new group and an arrow will indicate the change.

Depending on whether or not participants have switched groups, the group sizes (number of members in a group) of the two groups can change between rounds. The total prize the winning group receives stays the same irrespective of the size of the group. This means that individual earnings from winning the prize will change with the size of the group.

The table below shows what the individual share of the prize will be for each possible group size, in case this group wins the prize.

\begin{tabular}{|c|c|c|c|c|c|c|c|c|c|}
\hline $\begin{array}{c}\text { Group } \\
\text { Size }\end{array}$ & 0 & 1 & 2 & 3 & 4 & 5 & 6 & 7 & 8 \\
\hline $\begin{array}{c}\text { Individual } \\
\text { Prize }\end{array}$ & 0 & 1920 & 960 & 640 & 480 & 384 & 320 & 274.3 & 240 \\
\hline
\end{tabular}

Note: The group size is the number of all members; that is, if the size of your own group is 1 you would be the only member of this group.

The individual prize of a member in the losing group is 0 , irrespective of the group size.

Example: In Round 1 both groups have 4 members and the group size is thus 4 . Therefore, each member of the winning group will receive 480 tokens. If after Round 1, for example, one person switches to the other group, one group will have 3 members and the other group will have 5 members. Each member of the group of 3 will receive 640 tokens in case this group wins, whereas each member 
of the group of 5 will receive 384 tokens if this group wins. Note that larger groups have more tokens in total and thus can potentially also buy more lottery tickets than smaller groups.]

Your symbol and the overview screen, showing which symbols belong to each group, will be shown at the beginning of each round.

\section{Earnings in Part 2:}

This part has 15 rounds. At the end of the experiment one of these rounds will be randomly selected to be paid out. Each round is equally likely to be paid out. Therefore, when making your decisions, you should view each round as the one relevant for your earnings.

You will receive information on how much you earned at the end of the experiment.

\section{Comprehension Questions}

You will now be asked to answer some comprehension questions about Part 2. Tokens earned in these comprehension questions, will not be paid out. After you have correctly answered the comprehension questions, please wait for the experiment to continue with Part 1. 


\section{B Session overview}

Table 4.B.1: Independent observations (group-pairs) per session

\begin{tabular}{cccc}
\hline Session & Control & Endogenous & Exogenous \\
\hline 1 & 1 & 1 & 0 \\
2 & 0 & 2 & 0 \\
3 & 2 & 1 & 0 \\
4 & 0 & 2 & 0 \\
5 & 0 & 0 & 1 \\
6 & 0 & 1 & 0 \\
7 & 0 & 2 & 1 \\
8 & 0 & 1 & 1 \\
9 & 1 & 0 & 1 \\
10 & 1 & 0 & 1 \\
11 & 1 & 0 & 2 \\
12 & 0 & 0 & 1 \\
13 & 1 & 0 & 1 \\
14 & 0 & 0 & 1 \\
15 & 3 & 0 & 0 \\
\hline
\end{tabular}

Note: As the exogenous migration treatment required data from previous endogenous migration treatments, we only started running sessions with the exogenous treatment on the second day of experiments.

\section{C Equilibrium Strategies and Social Identity}

The following sections present theoretical predictions and equilibrium strategies. The game is first analyzed without considering social preferences. Then an extension to incorporate social identity and comparative statics are provided. 


\section{C.1 Equilibrium Strategy without social preferences}

To derive the Nash equilibrium for group contributions, the first order condition of the payoff functions of individual $g$ of group A is considered.

$$
\max _{a_{g}} \pi_{g}\left(\sum_{i \in A} a_{i}, \sum_{j \in B} b_{j}\right)=e+\frac{\sum_{i \in A} i_{a}}{\sum_{i \in A} a_{i}+\sum_{j \in B} b_{j}} \cdot \frac{z}{N_{A}}-a_{g}
$$

Taking the derivative with respect to $i_{g}$ delivers the first order condition:

$$
\frac{\partial \pi_{g}\left(\sum_{i \in A} a_{i}, \sum_{j \in B} b_{j}\right)}{\partial\left(a_{g}\right)}=0 \Rightarrow \frac{\sum_{j \in B} b_{j}}{\left(\sum_{i \in A} a_{i}+\sum_{j \in B} b_{i}\right)^{2}} \cdot \frac{z}{N_{A}}-1=0
$$

To assure that this is a maximum, the second derivative is considered:

$$
\left.\left.\frac{\partial^{2} \pi_{g}\left(\sum_{i \in A} a_{i}, \sum_{j \in B} b_{j}\right)}{\partial^{2}\left(a_{g}\right)}=\frac{-2 z \sum_{i \in A} a_{i}}{N_{A}\left(\sum_{i \in A} a_{i}+\sum_{j \in B} b_{j}\right)^{3}}<0 \forall \sum_{i \in A} a_{i}, \sum_{j \in B} b_{j} \in\right] 0, N_{A} * 120\right]
$$

$N_{A}$ is strictly positive, the contributions of group $A$ are between 0 and $N_{A} * 120$, thus the function is concave and the extremum a maximum except for the case where both groups invest $0 .{ }^{19}$ It can easily be shown that $\sum_{i \in A} a_{i}+\sum_{j \in B} b_{j}=0$ cannot be a maximum as it is always optimal to at least invest the minimal positive amount possible when the other group plays 0 as this guarantees winning the prize.

\footnotetext{
${ }^{19}$ Every individual has an endowment of 120 and thus the maximum group $A$ can contribute is $N_{A} * 120$
} 
The first order condition can be solved for group contributions in group A: ${ }^{20}$

$$
\sum_{i \in A} a_{i}=\sqrt{\sum_{j \in B} b_{j} \cdot \frac{z}{N_{A}}}-\sum_{j \in B} b_{j}
$$

Best response for an individual $b_{j}$ in group $B$ :

$$
\frac{\sum_{i \in A} a_{i}}{\left(\sum_{i \in A} a_{i}+\sum_{j \in B} b_{j}\right)^{2}} \cdot \frac{z}{N_{B}}-1=0
$$

Substituting equation (4.1) into equation (4.2) gives:

$$
\begin{aligned}
& \frac{\sqrt{\sum_{j \in B} b_{j} \cdot \frac{z}{N_{A}}}-\sum_{j \in B} b_{j}}{\left(\sqrt{\sum_{j \in B} b_{j} \cdot \frac{z}{N_{A}}}-\sum_{j \in B} b_{j}+\sum_{j \in B} b_{j}\right)^{2}}=\frac{N_{B}}{z} \\
& \Leftrightarrow \sqrt{\sum_{j \in B} b_{j} \cdot \frac{z}{N_{A}}}-\sum_{j \in B} b_{j}=\frac{N_{B}}{N_{A}} \cdot \sum_{j \in B} b_{j} \\
& \Leftrightarrow \sum_{j \in B} b_{j} \cdot \frac{z}{N_{A}}=\left(1+\frac{N_{B}}{N_{A}}\right)^{2}\left(\sum_{j \in B} b_{j}\right)^{2} \\
& \Leftrightarrow \sum_{j \in B} b_{j}=\frac{z}{N_{A} \cdot\left(1+\frac{N_{B}}{N_{A}}\right)^{2}} \\
& \Leftrightarrow \sum_{j \in B} b_{j}=\frac{N_{A} \cdot z}{\left(N_{A}+N_{B}\right)^{2}}
\end{aligned}
$$

\footnotetext{
${ }^{20}$ This function actually has two solutions, but the second solution always implies a negative investment from player $\mathrm{g}$, violating the boundary conditions
} 
Substituting equation (4.3) into equation (4.1) gives:

$$
\begin{aligned}
\sum_{i \in A} a_{i} & =\sqrt{\frac{N_{A} \cdot z}{\left(N_{A}+N_{B}\right)^{2}} \cdot \frac{z}{N_{A}}}-\frac{N_{A} \cdot z}{\left(N_{A}+N_{B}\right)^{2}} \\
\Leftrightarrow \sum_{i \in A} a_{i} & =\frac{N_{A} \cdot z}{\left(N_{A}+N_{B}\right)}-\frac{N_{A} \cdot z}{\left(N_{A}+N_{B}\right)^{2}} \\
\Leftrightarrow \sum_{i \in A} a_{i} & =\frac{N_{B} \cdot z}{\left(N_{A}+N_{B}\right)^{2}}
\end{aligned}
$$

This result is based on the fact that the members of each team have identical valuations and constant marginal costs of investments and does not require further symmetry assumptions (Abbink et al., 2010; Konrad, 2009). Furthermore, this result does not imply a unique solution in individual contributions as there exist infinitely many equilibria in individual contributions such that they sum up to the expression on the right hand side.

However this model does not account for other regarding preferences and especially social identity.

\section{C.2 Equilibrium strategies with social preferences}

In order to account for social identity in the model we closely follow the work of Charness and Rabin (2002), Chen and Li (2009) and Chen and Chen (2011) who use a utility function that is a weighted average of own and others' payoffs. We adopt the utility function of the form: $u_{g}=\alpha \cdot \pi_{g}+(1-\alpha) \cdot \bar{\pi}_{A \backslash g}$, where $\pi_{g}$ is the payoff of player $g, \bar{\pi}_{A \backslash g}$ is the average payoff of player $g^{\prime}$ s other group members and $\alpha$ is the weight 
on own payoffs that depends on social identity. ${ }^{21}$

$$
\begin{aligned}
& u_{g}\left(\sum_{i \in A} a_{i}, \sum_{j \in B} b_{j}\right)=\alpha \cdot\left(e+\frac{\sum_{i \in A} a_{i}}{\sum_{i \in A} a_{i}+\sum_{j \in B} b_{j}} \cdot \frac{z}{N_{A}}-a_{g}\right)+ \\
& (1-\alpha) \cdot\left(\frac{1}{N_{A}-1}\right)\left(\left(N_{A}-1\right) \cdot\left(e+\frac{\sum_{i \in A} a_{i}}{\sum_{i \in A} a_{i}+\sum_{j \in B} b_{i}} \cdot \frac{z}{N_{A}}\right)-\sum_{i \in A \backslash g} a_{i}\right)
\end{aligned}
$$

Taking the derivative with respect to $a_{g}$ and setting to zero provides the individual best response function: ${ }^{22}$

$$
\begin{aligned}
\frac{\partial u_{g}\left(\sum_{i \in A} a_{i}, \sum_{j \in B} b_{j}\right)}{\partial\left(a_{g}\right)}=0 & \Rightarrow \frac{\sum_{j \in B} b_{j}}{\left(\sum_{i \in A} a_{i}+\sum_{j \in B} b_{j}\right)^{2}}=\frac{\alpha N_{A}}{z} \\
& \Leftrightarrow \sum_{i \in A} a_{i}=\sqrt{\sum_{j \in B} b_{j} \cdot \frac{z}{\alpha N_{A}}}-\sum_{j \in B} b_{j}
\end{aligned}
$$

The best response function for an individual of group $B$, where $\beta$ is the equivalent to $\alpha$ for group $B$ is:

$$
\frac{\sum_{i \in A} a_{i}}{\left(\sum_{i \in A} a_{i}+\sum_{j \in B} b_{j}\right)^{2}}=\frac{\beta N_{B}}{z}
$$

Assuming that $\alpha$ and $\beta$ are identical within the respective groups, sub-

\footnotetext{
${ }^{21}$ Assuming symmetry within the group would reduce the formula to the individual payoff maximization problem that was discussed in the previous subsection.

${ }^{22}$ Proof of concavity/maximum is omitted as it is analogous to equation (4.1) and $\alpha$ and $\beta$ are assumed to be strictly positive
} 
stituting equation (4.6) in equation (4.7) gives: ${ }^{23}$

$$
\sum_{j \in B} b_{j}=\frac{\alpha z N_{A}}{\left(\alpha N_{A}+\beta N_{B}\right)^{2}}
$$

Substituting equation (4.8) in equation (4.6) gives:

$$
\sum_{i \in A} a_{i}=\frac{\beta z N_{B}}{\left(\alpha N_{A}+\beta N_{B}\right)^{2}} .
$$

Same as in the model without social preferences, this does not imply a unique solution in individual contributions.

\section{D Equilibrium predictions with social preferences for ingroup and outgroup}

In this simple model that includes social preferences for outgroup and ingroup, participant utility is a weighted average of their own payoff, the payoff of the own group, and the payoff of the other group. We show the utility function and equilibrium contributions for someone from group $A$. $A$ denotes the contributions of group $A, B$ denotes the contributions of group $B . N_{A}$ and $N_{B}$ are the group sizes of groups $A$ and $B$ respectively. $a$ is the individual contribution for a player of group $A$. $\alpha$ is the weight on the payoff of the own group, $\beta$ is the weight on the payoff of the other group. $\gamma$ and $\delta$ are the equivalent weights for someone from group $B$. For legibility, subscripts are suppressed.

$$
\begin{aligned}
U= & (1-\alpha-\beta)\left(\frac{1,920 A}{N_{A}(A+B)}-a+120\right) \\
& +\alpha\left(\frac{1,920\left(N_{A}-1\right) A}{N_{A}(A+B)}-A+a+120\left(N_{A}-1\right)\right) \\
& +\beta\left(\frac{1,920 B N_{B}}{N_{B}(A+B)}-B+120 N_{B}\right)
\end{aligned}
$$

\footnotetext{
$\overline{{ }^{23} \text { Steps are identical to the model }}$ without social preferences
} 
First order conditions:

$A=\frac{8 \sqrt{30} \sqrt{-B N_{A}(\alpha+\beta-1)\left(\alpha\left(N_{A}-2\right)-\beta\left(N_{A}+1\right)+1\right)}-B N_{A}(\alpha+\beta-1)}{N_{A}(\alpha+\beta-1)}$

$B=\frac{8 \sqrt{30} \sqrt{-A N_{B}(\gamma+\delta-1)\left(\gamma\left(N_{B}-2\right)-\delta\left(N_{B}+1\right)+1\right)}-A N_{B}(\gamma+\delta-1)}{N_{B}(\gamma+\delta-1)}$

Equilibrium contributions for group $A$ :

$$
A=-\frac{1,920 f(\cdot)^{2} g(\cdot)}{\left(f(\cdot)+N_{A}(\alpha+\beta-1) g(\cdot)\right)^{2}}
$$

where

$$
\begin{aligned}
& f(\cdot)=\left(8-N_{A}\right)(\gamma+\delta-1)\left(\alpha\left(N_{A}-2\right)-\beta\left(N_{A}+1\right)+1\right) \\
& g(\cdot)=\gamma\left(6-N_{A}\right)-\delta\left(9-N_{A}\right)+1
\end{aligned}
$$


Conditions required for existence of internal solution $(\wedge$ for AND conditions and $\vee$ for OR conditions):

$$
\begin{aligned}
& \left(N_{A}>0\right. \\
& \wedge \\
& \left(\left(3 \alpha<1 \wedge\left(\alpha \geq \beta \vee\left(\alpha>0 \wedge\left(1+\left(-2+N_{A}\right) \alpha>\left(1+N_{A}\right) \beta \wedge 2 \alpha+\beta<1\right)\right.\right.\right.\right. \\
& \text { V } \\
& (\alpha+\beta>1 \wedge \beta<1)))) \\
& \text { V } \\
& (3 \alpha>1 \wedge(2 \alpha+\beta \leq 1 \vee(2 \alpha \leq 1 \wedge \beta<1 \wedge \alpha+\beta>1))) \\
& \text { V } \\
& \left(3 \alpha==1 \wedge\left(3 \beta<1 \vee \frac{2}{3}<\beta<1\right)\right) \\
& \text { V } \\
& \left(\beta<1 \wedge\left(\left(\alpha \leq 0 \wedge 1+\left(-2+N_{A}\right) \alpha>\left(1+N_{A}\right) \beta\right)\right.\right. \\
& \text { V } \\
& (\alpha \leq 1 \wedge 2 \alpha>1 \wedge \alpha \leq \beta) \vee(\alpha>1 \wedge \alpha+\beta>1 \\
& \wedge \\
& \left.\left.\left.(\alpha-\beta)\left(1+\left(-2+N_{A}\right) \alpha-\left(1+N_{A}\right) \beta\right)<0\right)\right)\right) \\
& \text { V } \\
& \left.\left.\left(\alpha \leq 1 \wedge 2 \alpha>1 \wedge \alpha>\beta \wedge \alpha+\beta>1 \wedge 1+\left(-2+N_{A}\right) \alpha<\left(1+N_{A}\right) \beta\right)\right)\right) \\
& \text { V } \\
& (2 \alpha+\beta>1 \wedge((2 \alpha>1 \wedge \alpha+\beta<1 \\
& \wedge \\
& \left.(\alpha-\beta)\left(1+\left(-2+N_{A}\right) \alpha-\left(1+N_{A}\right) \beta\right)>0\right) \\
& \text { V } \\
& \left.\left.\left(2 \alpha \leq 1 \wedge 3 \alpha>1 \wedge \alpha>\beta \wedge 1+\left(-2+N_{A}\right) \alpha>\left(1+N_{A}\right) \beta\right)\right)\right)
\end{aligned}
$$


The following two figures illustrate the comparative statics of the model for the simplest case in which we vary one social preference parameter for group $A$, keeping the other constant, and group $B$ consists of selfish individuals. Furthermore, we do not impose the budget constraint, thus contributions are allowed to exceed the endowment. With increasing weight on the payoffs of the own group $(\alpha)$, group contributions increase for all groups larger than one. For increasing weight on the other group's payoffs $(\beta)$, group contributions decrease. The same pattern persists when we allow both parameters to vary and also when the other group has social preferences, but corner solutions become more common.

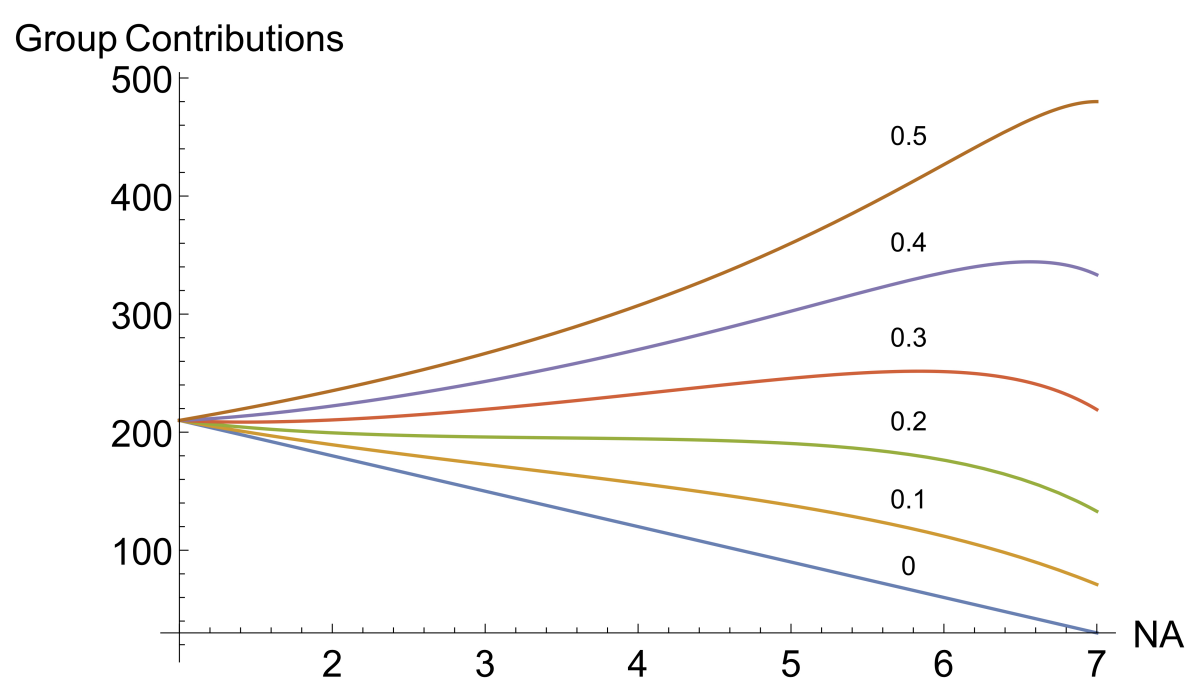

Figure 4.D.1: Group contributions with varying $\alpha(\beta=0)$ 


\section{Group Contributions}

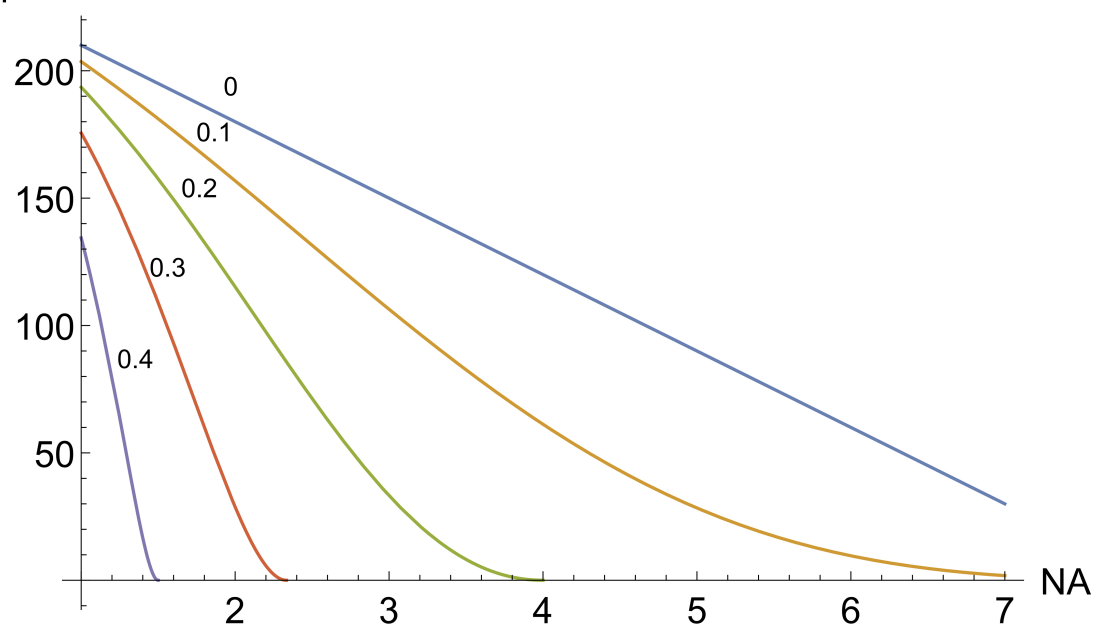

Figure 4.D.2: Group contributions with varying $\beta(\alpha=0)$ 


\section{E Marginal effect of migration treatments at different levels of migration}

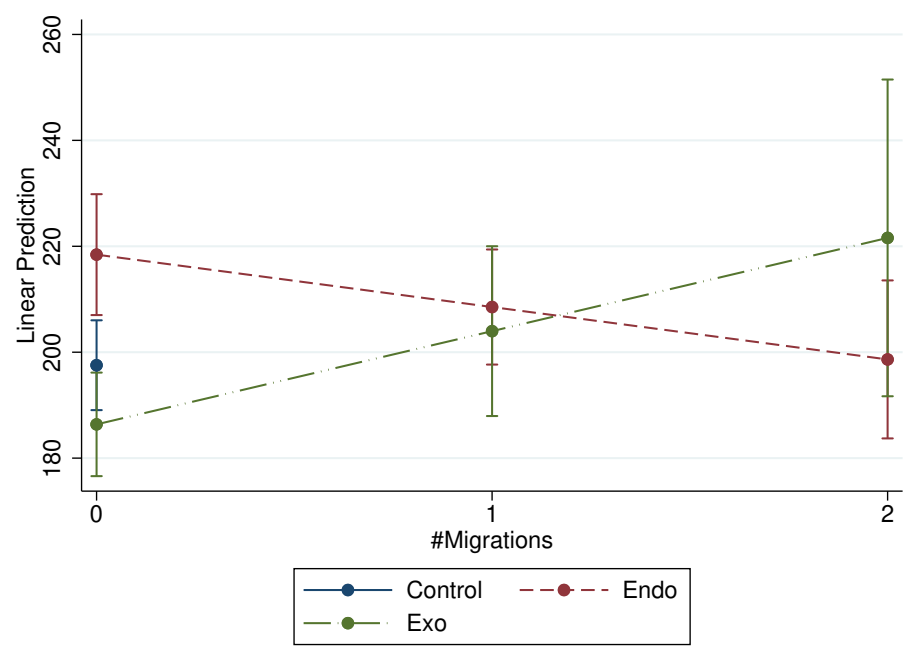

Figure 4.E.1: Marginal effect of the migration treatments at different levels of migration with $95 \% \mathrm{CI}$ 


\section{F Comparing only the migration treatments}

Table 4.F.1: Comparing Exogenous and Endogenous Migration at group-pair level

\begin{tabular}{|c|c|c|c|c|c|c|}
\hline & $\begin{array}{c}\text { (1a) } \\
\text { Group } \\
\text { contribution }\end{array}$ & $\begin{array}{c}(2 \mathrm{a}) \\
\text { Group } \\
\text { contribution }\end{array}$ & $\begin{array}{c}\text { (3a) } \\
\text { Group } \\
\text { contribution }\end{array}$ & $\begin{array}{c}(4 a) \\
\text { Group } \\
\text { contribution }\end{array}$ & $\begin{array}{c}(5 \mathrm{a}) \\
\text { Group } \\
\text { contribution }\end{array}$ & $\begin{array}{c}\text { (6a) } \\
\text { Group } \\
\text { contribution }\end{array}$ \\
\hline Endo & $\begin{array}{c}39.81 \\
(25.14)\end{array}$ & $\begin{array}{c}39.81 \\
(24.95)\end{array}$ & $\begin{array}{l}13.03^{*} \\
(7.55)\end{array}$ & $\begin{array}{l}13.35^{*} \\
(7.15)\end{array}$ & $\begin{array}{l}30.53^{* * *} \\
(7.02)\end{array}$ & $\begin{array}{l}29.70^{* * *} \\
(8.54)\end{array}$ \\
\hline Avggroupcontributions $_{t-1}$ & & & $\begin{array}{l}0.76^{* * *} \\
(0.05)\end{array}$ & $\begin{array}{l}0.75^{* * *} \\
(0.05)\end{array}$ & $\begin{array}{l}0.73^{* * *} \\
(0.05)\end{array}$ & $\begin{array}{l}0.75^{* * *} \\
(0.04)\end{array}$ \\
\hline \#Migrations $s_{t}$ & & & & & $\begin{array}{l}16.92^{* *} \\
(7.57)\end{array}$ & $\begin{array}{c}9.00 \\
(7.93)\end{array}$ \\
\hline$\#$ Migrations $\times$ Endot $_{t}$ & & & & & $\begin{array}{c}-26.77^{* * *} \\
(8.64)\end{array}$ & $\begin{array}{c}-26.38^{* *} \\
(10.63)\end{array}$ \\
\hline Constant & $\begin{array}{l}181.3^{* * *} \\
(19.69)\end{array}$ & $\begin{array}{l}184.6^{* * *} \\
(18.94)\end{array}$ & $\begin{array}{l}42.04^{* * *} \\
(10.49)\end{array}$ & $\begin{array}{l}48.91^{* * *} \\
(13.46)\end{array}$ & $\begin{array}{l}42.85^{* * *} \\
(12.81)\end{array}$ & $\begin{array}{l}38.64^{* * *} \\
(10.13)\end{array}$ \\
\hline Group size controls & No & Yes & No & Yes & Yes & No \\
\hline$N$ & 300 & 300 & 280 & 280 & 280 & 280 \\
\hline
\end{tabular}




\section{G What explains change in ingroup bias?}

Table 4.G.1: What explains changes in ingroup bias ?

Change in ingroup bias

\begin{tabular}{lc}
\hline Endo & 7.905 \\
& $(5.214)$ \\
Exo & 7.156 \\
& $(5.824)$ \\
\#Migrations & -0.600 \\
& $(0.538)$
\end{tabular}

$\begin{array}{lr}\text { \#Wins } & 0.416 \\ & (0.489) \\ \text { \#OwnMigrations } & -0.722 \\ & (1.306)\end{array}$

$\begin{array}{lc}\text { Average own contributions } & -0.003 \\ & (0.003) \\ \text { Average contributions of own groups } & 0.010^{*} \\ & (0.005)\end{array}$

Constant r $\begin{array}{r}6.264 \\ \end{array}$

Survey Controls Yes

$N \quad 206$

Note: Standard errors clustered by group pair in parentheses. Adding additional interactions of treatment and independent variables did not improve model performance (as judged by Akaike's and Bayesian information criteria). ${ }^{*} p<0.10,{ }^{* *} p<0.05,{ }^{* * *} p<0.01$ 


\section{H The Role of Beliefs}

Average beliefs about the contributions of the own and the other group do not differ significantly between treatments ( $p$-value $=0.545$ for the beliefs about the own group, $p$-value $=0.237$ for beliefs about the other group, Kruskal-Wallis test). However, on an individual level, there exist some interesting dynamics.

Table 4.H.1 shows that participants seem to have a good understanding of the effect that group size has on the optimal level of contributions, as they expect smaller groups-GroupSize $1: 3_{t}$ for beliefs about the own group and GroupSize5: $7_{t}$ for beliefs about the other group-to contribute more and larger groups to contribute less for both the own as well as the opposing group. ${ }^{24}$ The effect of ingroup bias (Ingroup Bias Start $_{\text {) }}$ on beliefs about the contributions of the other group is weakly significant and positive ( $p$-value $=0.05)$ suggesting that more ingroup biased participants expect higher contributions from the opposing group. However, in absolute terms this effect is not very large as the mean ingroup bias across all treatments is only 9.2 resulting in a increase in beliefs about the other groups contribution by $\sim 0.8$. Beliefs about own and other group contributions are also strongly positively affected by how much the participant (contribute $_{t-1}$ ), his group (owngroupcontribute ${ }_{t-1}$ ), and the other group (othergroupcontribute ${ }_{t-1}$ ) contributed in the preceding period (all significant at $0.01 \%$ level). Interestingly, a decrease or increase of the group (Group decrease $\times$ Endo $_{t}$, Group increase $\times$ Endo $_{t}$ ), compared to last round, does not have an additional effect for the beliefs about the contributions of the own group, but strongly decreases beliefs about the contributions of the other group in the endogenous migration treatment (Joint significance test $p$-value $<0.01$ ). If the own group size decreases and the change is exogenously caused $\left(\right.$ Group decrease $\left._{t}\right)$, participants expect the other group to contribute 10.45 tokens more. However, if the own group size decreased because someone decided to leave, this effect disappears (Group decrease $t_{t}$ + Group decrease $\times$ Endot $\left._{t}=-0,79\right)$. If the participant decided

\footnotetext{
${ }^{24}$ Note that having a group size of two when stating your beliefs about the other group means that the other group has a group size of six.
} 
to leave the group in the previous period (Leavedecision L $_{t-1}$ ), but was not allowed to leave, she expects the average contributions of the own group to be lower by about 4.90 tokens and the other groups' contributions to be higher by 3.63 tokens. However, if the decision to leave is in fact implemented, this effect disappears as the combined effects of migrating 4.77 (Migration $(S e l f)_{t-1}$ ) and 0.73 (Migration $(S e l f) \times E_{\text {Endo }}$ ( $)$ offset the negative effect of choosing to leave -4.90 (Joint significance test $p$-value $<0.01$ ). Being forced to leave the own group in the exogenous treatment $\left(\operatorname{Migration}(\mathrm{Self})_{t-1}\right)$ increases beliefs about the average contributions of the own group by 4.77 tokens. There is no effect for the number of migrations itself.

Overall, beliefs about the contributions of the own group do not vary between treatments but beliefs about the contributions of the other group are heterogeneous as individuals react differently to group size changes depending on the treatment they are in. 
Table 4.H.1: Determinants of beliefs about own and other group contributions in period $t$

(8a) (9a)

Beliefs about the contribution Beliefs about the contribution of the own Group of the other Group

\begin{tabular}{|c|c|c|}
\hline Endo & 1.672 & 1.352 \\
\hline Exo & -2.790 & 0.289 \\
\hline Ingroup Bias Start & 0.0744 & $0.086^{*}$ \\
\hline 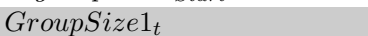 & & 2.164 \\
\hline${\text { GroupSize } 2_{t}}$ & $12.85 *$ & $-15.28^{* * *}$ \\
\hline GroupSize $_{t}$ & $9.410^{* * *}$ & $-6.108^{* * *}$ \\
\hline GroupSize5 $_{t}$ & $-5.436^{* * *}$ & $7.983^{* * *}$ \\
\hline GroupSize6 $_{t}$ & $-10.24^{* * *}$ & $20.97^{* * *}$ \\
\hline GroupSize $7_{t}$ & $-13.37^{* * *}$ & $39.27^{* * *}$ \\
\hline GroupSize ${ }_{t}$ & $-45.57^{* * *}$ & \\
\hline contribute $_{t-1}$ & $0.111^{* * *}$ & $0.053^{* * *}$ \\
\hline owngroupcontribute $_{t-1}$ & $0.082^{* * *}$ & $0.032^{* * *}$ \\
\hline othergroupcontribute $_{t-1}$ & $0.025^{* * *}$ & $0.080^{* * *}$ \\
\hline Group increase $_{t}$ & 2.180 & 0.921 \\
\hline Group increase $\times$ Endo $_{t}$ & -4.094 & $-8.855^{* *}$ \\
\hline Group decrease $_{t}$ & 0.067 & $10.45^{* *}$ \\
\hline Group decrease $\times$ Endo $_{t}$ & 2.243 & $-11.24^{* *}$ \\
\hline Leavedecision $_{t-1}$ & $-4.897^{* *}$ & $3.628^{* * *}$ \\
\hline $\operatorname{Migration}(\text { Self })_{t-1}$ & $4.769^{* * *}$ & -2.152 \\
\hline Migration $($ Self $) \times E_{n d o}-1$ & 0.726 & -2.199 \\
\hline \#Migrations Mi-1 $_{t}$ & -0.595 & -4.577 \\
\hline$\#$ Migrations $\times$ Endo $t-1$ & -0.041 & 6.238 \\
\hline Constant & $31.99^{* * *}$ & $17.27 *$ \\
\hline$N$ & 3346 & 3328 \\
\hline
\end{tabular}

Standard errors clustered by group pair and suppressed for legibility.

${ }^{*} \mathrm{p}<0.10,{ }^{* *} \mathrm{p}<0.05,{ }^{* * *} \mathrm{p}<0.01$ 


\section{I Individual Regressions - Drivers of the Contribution Decision}

Using the data on individual level, Table 4.I.1 presents the estimates of the treatment effects and migration dynamics on individual contributions. This analysis replicates the previous findings from the group-pair regressions, that the treatment effects of the migration treatments on their own (10a) or with group size dummies (11a) are not significant. While adding ingroup bias (Ingroup Bias Start $_{\text {) }}$ ) does not change the significance (12a), controlling for differences in group size, winning the previous round ( $\left.w i n_{t-1}\right)$, and initial contribution levels (contribute t-1 $_{t}$, owngroupcontribute ${ }_{t-1}$, othergroupcontribute $_{t-1}$ ), similar to the group-pair regressions, turns the Endogenous treatment dummy positive and significant (13a). 
Table 4.I.1: Individual contribution decision

\begin{tabular}{|c|c|c|c|c|c|c|c|}
\hline & $\begin{array}{c}\text { (10a) } \\
\text { contribute }\end{array}$ & $\begin{array}{c}\text { (11a) } \\
\text { contribute }\end{array}$ & $\begin{array}{c}(12 a) \\
\text { contribute }\end{array}$ & $\begin{array}{c}\text { (13a) } \\
\text { contribute }\end{array}$ & $\begin{array}{c}(14 a) \\
\text { contribute }\end{array}$ & $\begin{array}{c}(15 a) \\
\text { contribute }\end{array}$ & $\begin{array}{c}\text { (16a) } \\
\text { contribute }\end{array}$ \\
\hline Endo & $\begin{array}{c}4.20 \\
(4.79)\end{array}$ & $\begin{array}{c}6.61 \\
(4.96)\end{array}$ & $\begin{array}{c}7.17 \\
(5.09)\end{array}$ & $\begin{array}{l}4.38^{* *} \\
(2.00)\end{array}$ & $\begin{array}{l}4.58^{* *} \\
(2.33)\end{array}$ & $\begin{array}{l}4.44^{* *} \\
(2.24)\end{array}$ & $\begin{array}{l}5.02^{* *} \\
(2.34)\end{array}$ \\
\hline Exo & $\begin{array}{c}-5.50 \\
(5.17)\end{array}$ & $\begin{array}{r}-3.09 \\
(5.14)\end{array}$ & $\begin{array}{c}-2.83 \\
(5.06)\end{array}$ & $\begin{array}{c}0.37 \\
(1.93)\end{array}$ & $\begin{array}{c}1.30 \\
(2.01)\end{array}$ & $\begin{array}{r}-0.83 \\
(1.89)\end{array}$ & $\begin{array}{r}-0.50 \\
(1.90)\end{array}$ \\
\hline Ingroup Bias $_{\text {Start }}$ & & & $\begin{array}{c}0.15 \\
(0.10)\end{array}$ & $\begin{array}{l}0.09^{* * *} \\
(0.04)\end{array}$ & $\begin{array}{c}0.03 \\
(0.05)\end{array}$ & $\begin{array}{c}0.02 \\
(0.05)\end{array}$ & $\begin{array}{c}0.01 \\
(0.05)\end{array}$ \\
\hline contribute $_{t-1}$ & & & & $\begin{array}{l}0.58^{* * *} \\
(0.04)\end{array}$ & $\begin{array}{l}0.44^{* * *} \\
(0.05)\end{array}$ & $\begin{array}{l}0.45^{* * *} \\
(0.05)\end{array}$ & $\begin{array}{l}0.43^{* * *} \\
(0.04)\end{array}$ \\
\hline owngroupcontribute $_{t-1}$ & & & & $\begin{array}{c}0.01 \\
(0.02)\end{array}$ & $\begin{array}{l}-0.05^{* * *} \\
(0.01)\end{array}$ & $\begin{array}{l}-0.06^{* * * *} \\
(0.01)\end{array}$ & $\begin{array}{l}-0.06^{* * * *} \\
(0.01)\end{array}$ \\
\hline othergroupcontribute $_{t-1}$ & & & & $\begin{array}{l}0.02^{* *} \\
(0.01)\end{array}$ & $\begin{array}{c}0.01 \\
(0.01)\end{array}$ & $\begin{array}{r}0.02^{*} \\
(0.01)\end{array}$ & $\begin{array}{c}0.01 \\
(0.01)\end{array}$ \\
\hline win $_{t-1}$ & & & & $\begin{array}{c}0.65 \\
(0.96)\end{array}$ & $\begin{array}{c}0.15 \\
(0.74)\end{array}$ & $\begin{array}{c}0.27 \\
(0.85)\end{array}$ & $\begin{array}{c}0.19 \\
(0.87)\end{array}$ \\
\hline Beliefgroupcontribution $_{t}$ & & & & & $\begin{array}{l}0.57^{* * *} \\
(0.04)\end{array}$ & $\begin{array}{l}0.57^{* * *} \\
(0.04)\end{array}$ & $\begin{array}{l}0.58^{* * *} \\
(0.04)\end{array}$ \\
\hline Belie fothergroupcontribution $_{t}$ & & & & & $\begin{array}{c}0.01 \\
(0.03)\end{array}$ & $\begin{array}{c}-0.01 \\
(0.03)\end{array}$ & $\begin{array}{c}0.01 \\
(0.03)\end{array}$ \\
\hline Group increase $_{t}$ & & & & & & $\begin{array}{c}-6.20^{* * * *} \\
(2.40)\end{array}$ & $\begin{array}{c}-6.19^{* * * *} \\
(2.34)\end{array}$ \\
\hline Group increase $\times$ Endo $t$ & & & & & & $\begin{array}{c}3.90 \\
(4.10)\end{array}$ & $\begin{array}{c}3.77 \\
(4.02)\end{array}$ \\
\hline Group decrease $_{t}$ & & & & & & $\begin{array}{l}4.74^{* *} \\
(2.34)\end{array}$ & $\begin{array}{r}4.36^{*} \\
(2.23)\end{array}$ \\
\hline Group decrease $\times$ Endo $_{t}$ & & & & & & $\begin{array}{l}8.25^{* * *} \\
(3.20)\end{array}$ & $\begin{array}{l}8.44^{* * *} \\
(3.22)\end{array}$ \\
\hline Leavedecision $_{t-1}$ & & & & & & $\begin{array}{r}-0.97 \\
(2.04)\end{array}$ & $\begin{array}{r}-0.50 \\
(1.96)\end{array}$ \\
\hline Migration $(\text { Self })_{t-1}$ & & & & & & $\begin{array}{r}-3.50 \\
(3.36)\end{array}$ & $\begin{array}{r}-3.99 \\
(3.55)\end{array}$ \\
\hline Migration $($ Self $) \times$ Endo $_{t-1}$ & & & & & & $\begin{array}{c}6.90 \\
(4.43)\end{array}$ & $\begin{array}{c}7.10 \\
(4.55)\end{array}$ \\
\hline \#Migrations M $-1_{1}$ & & & & & & $\begin{array}{c}3.54^{*} \\
(1.93)\end{array}$ & $\begin{array}{c}3.86^{*} \\
(1.98)\end{array}$ \\
\hline$\#$ Migrations $\times$ Endo $_{t-1}$ & & & & & & $\begin{array}{c}-8.71^{* * *} \\
(2.77)\end{array}$ & $\begin{array}{c}-8.83^{* * * *} \\
(2.82)\end{array}$ \\
\hline Constant & $\begin{array}{l}49.65^{* * * *} \\
(2.53)\end{array}$ & $\begin{array}{l}49.65^{* * *} \\
(2.53)\end{array}$ & $\begin{array}{l}48.00^{* * * *} \\
(2.93)\end{array}$ & $\begin{array}{l}14.01^{* * *} \\
(2.12)\end{array}$ & $\begin{array}{c}3.03 \\
(2.15)\end{array}$ & $\begin{array}{c}3.01 \\
(2.05)\end{array}$ & $\begin{array}{c}8.58 \\
(7.48)\end{array}$ \\
\hline Group Size Controls & No & Yes & Yes & Yes & Yes & Yes & Yes \\
\hline Survey Controls & No & No & No & No & No & No & Yes \\
\hline$N$ & 3600 & 3600 & 3600 & 3360 & 3360 & 3360 & 3360 \\
\hline Overall $R$ - squared & 0.010 & 0.077 & 0.080 & 0.422 & 0.525 & 0.534 & 0.544 \\
\hline
\end{tabular}

Standard errors clustered by group pair in parentheses

${ }^{*} \mathrm{p}<0.10,{ }^{* *} \mathrm{p}<0.05,{ }^{* * *} \mathrm{p}<0.01$ 
Moreover, analysing the individual level contributions also allows us to explore the influence of group composition changes, individual migration decision, initial ingroup bias, and beliefs on the contribution decision.

The initial ingroup bias (Ingroup Bias Start $_{\text {I }}$ ) does not influence consecutive contribution decisions except in a specification in which we do not account for participants' beliefs about the contribution of others, migration dynamics, and survey measures (13a). Winning in the previous period does not affect the contributions in the following round. Beliefs about the contributions of the own group (Belief groupcontribution ) $^{\text {) }}$ have a strong positive effect and are significant in all specifications ( $p$-value $<0.01)$ whereas beliefs about the contributions of the other group (Beliefothergroupcontribution ${ }_{t}$ ) do not seem to affect the contribution decision. ${ }^{25}$ There are no notable differences between the specification with (16a) and without survey controls (15a). In the full specification (16a), we find that while being in a group that increased in size compared to the previous round (Group increase ${ }_{t}$ ) does decrease contributions by $\sim 6.19$ tokens, this effect is partly mitigated when the group increase is caused by someone who intentionally joins the group in the endogenous migration treatment (Group increase $\times E^{2}$ ido $_{t}$ ) and reduces to $-6.19+3.77=-2.42$. Being in a group that shrunk does also make a difference. While a decrease already leads to a $\sim 4.36$ token increase in the Exogenous treatment (Group decrease $t_{t}$ ), this is further amplified in the endogenous treatment (Group decrease $\times$ Endo $t$ ) where the overall effect is $4.36+8.44=12.8$ (The interactions are jointly significant with $\mathrm{p}<0.01)$. Both of these effects are in addition to the effect that being in a small or large group has on contributions, as we already control for the different group sizes. Players who indicate they would like to leave their group (Leavedecision ${ }_{t-1}$ ), and those who are made to migrate in the exogenous treatment (Migration $(S e l f)_{t-1}$ ) reduce their contributions by 0.50 and 3.99 tokens in the following round, but players who wanted to migrate and got chosen to do so (Migration $($ Self $\left.) \times E_{n d o} o_{t-1}\right)$ increase their contributions by $-0.50-3.99+7.10=2.61$ tokens (the coefficients are jointly significant $\mathrm{p}<0.01$ ). Looking at the pure effect of a migration happening, assuming that group sizes stayed constant

\footnotetext{
${ }^{25}$ For a more detailed analysis of the role of beliefs, see Appendix 4.H.
} 
and the individual did not decide to leave or migrate previous round, we find that migrations have a weakly significant positive effect in the Exogenous treatment (\#Migrations ( $_{t-1}$ ) and increase contributions by 3.86 tokens, but have a net negative effect in the Endogenous treatment (\#Migrations $\times$ Endo $o_{t-1}$ ) and decrease contributions by $3.86-8.83=$ -4.4 tokens. Comparing (15a) and (16a) shows that the inclusion of the demographic variables from the post-experiment survey is inconsequential for the analysis. As a robustness check, we also ran this regression analysis separately for each treatment to see if the independent variables affect contributions in the different treatments in a different way (Table 4.I.2). However, besides the already discussed differences in reactions to group composition changes and migrations, we find no especially notable differences. 
Table 4.I.2: Pooled and Un-pooled Treatment Analysis

\begin{tabular}{|c|c|c|c|c|}
\hline & $\begin{array}{c}(17 a) \\
\text { Pooled }\end{array}$ & $\begin{array}{c}(18 \mathrm{a}) \\
\text { Control }\end{array}$ & $\begin{array}{l}\text { (19a) } \\
\text { Endo }\end{array}$ & $\begin{array}{c}(20 a) \\
\text { Exo }\end{array}$ \\
\hline Endo & $5.024^{* *}$ & & & \\
\hline Exo & -0.500 & & & \\
\hline GroupSize $1_{t}$ & $50.61^{* * *}$ & & $62.81^{* * *}$ & $54.00^{* *}$ \\
\hline GroupSize $2_{t}$ & $-7.588^{* * *}$ & & -7.809 & -5.662 \\
\hline GroupSize $3_{t}$ & $3.350^{*}$ & & 2.573 & 3.652 \\
\hline GroupSize $5_{t}$ & -1.038 & & -0.529 & -1.782 \\
\hline GroupSize6 $_{t}$ & $-3.369^{* *}$ & & $-4.155^{* *}$ & $-3.928^{* *}$ \\
\hline GroupSize $7_{t}$ & -1.323 & & -0.313 & $-5.596^{*}$ \\
\hline GroupSize $_{t}$ & $-8.371^{* * *}$ & & -2.473 & -5.967 \\
\hline contribute $_{t-1}$ & $0.432^{* * *}$ & $0.507^{* * *}$ & $0.304^{* * *}$ & $0.409^{* * *}$ \\
\hline owngroupcontribute $_{t-1}$ & $-0.059^{* * *}$ & $-0.068^{* *}$ & $-0.050^{* * *}$ & $-0.075^{* * *}$ \\
\hline othergroupcontribute $_{t-1}$ & 0.012 & $0.032^{* *}$ & 0.001 & -0.009 \\
\hline Beliefgroupcontribution $_{t}$ & $0.578^{* * *}$ & $0.447^{* * *}$ & $0.750^{* * *}$ & $0.630^{* * *}$ \\
\hline Belief othergroupcontribution $_{t}$ & 0.001 & -0.068 & $0.021^{* *}$ & 0.041 \\
\hline win $_{t-1}$ & 0.194 & 0.335 & -2.008 & $2.932^{*}$ \\
\hline Ingroup Bias Start & 0.011 & 0.074 & 0.061 & -0.042 \\
\hline Group increase $_{t}$ & $-6.185^{* * *}$ & & $-4.981^{* *}$ & -2.287 \\
\hline Group increase $\times$ Endot & 3.769 & & & \\
\hline Group decrease $_{t}$ & $4.361^{*}$ & & $2.988^{*}$ & $12.49^{* * *}$ \\
\hline Group decrease $\times$ Endot & $8.438^{* * *}$ & & & \\
\hline Leavedecision $_{t-1}$ & -0.497 & & & 0.181 \\
\hline Migration $(\text { Self })_{t-1}$ & -3.991 & & -3.932 & 3.589 \\
\hline $\operatorname{Migration}($ Self $) \times$ Endot-1 $_{t}$ & 7.102 & & & \\
\hline$\#$ Migrations $s_{t-1}$ & $3.863^{*}$ & & $3.681^{*}$ & $-4.956^{* *}$ \\
\hline$\#$ Migrations $\times$ Endot-1 $_{t}$ & $-8.826^{* * *}$ & & & \\
\hline Age & -0.293 & 0.251 & $-0.510^{*}$ & -0.440 \\
\hline Female & $-2.599^{*}$ & -2.777 & $-4.313^{*}$ & -3.536 \\
\hline OtherEurope & 2.430 & -0.276 & 1.703 & $6.499^{* *}$ \\
\hline Asian & -0.178 & 2.767 & -0.832 & -2.622 \\
\hline Othercountries & $4.529^{*}$ & 0.964 & $5.577^{* *}$ & 5.971 \\
\hline Econ & $-3.959^{* *}$ & -2.540 & $-5.731^{*}$ & -6.433 \\
\hline Siblings & -0.338 & -1.495 & -0.867 & -0.163 \\
\hline Teamsports & -1.357 & -1.884 & -1.082 & -1.885 \\
\hline Instructions & -0.083 & 0.995 & -0.627 & -0.023 \\
\hline RiskSeeking & $1.150^{* * *}$ & $1.357^{* *}$ & 0.701 & $1.208^{* *}$ \\
\hline Teamwork & 0.102 & -0.348 & -0.011 & 0.523 \\
\hline Constant & 8.577 & -6.425 & 21.92 & 17.44 \\
\hline$N$ & 3,360 & 1,120 & 1,120 & 1,120 \\
\hline
\end{tabular}

Standard errors suppressed for legibility.

${ }^{*} \mathrm{p}<0.10,{ }^{* *} \mathrm{p}<0.05,{ }^{* * *} \mathrm{p}<0.01$ 


\section{5 \\ General Discussion}

This thesis has explored how social identity, inequality, and migration interact with how scarce resources are distributed or fought over. We observe in Chapter 2 that experiencing a wage decrease (even if it is only a relative one) results in more selfish choices when it comes to the distribution of resources. As the resources distributed are not Manna from heaven but tax income that was previously taken from the earnings of the participants, very selfish choices imply a willingness to compensate oneself for the wage decrease at the cost of the other participant. This effect can even be observed when a person with an absolute higher income experiences no decrease in wage but observes that a poorer person experiences a wage increase.

Chapter 3 suggests that conflict over resources can strengthen social identity and lead to more ingroup bias. Alternative methods to induce social identity in the lab were only effective when administered in combination with an within-subject measurement of the strength of social identity. This in turn suggests that within-subject measures of social identity potentially interact with the social identity induction itself, raising concerns over the use of such designs in lab experiments that study social identity. 
The theory underlying Chapter 4 suggests that such an increase in ingroup bias results in more wasteful conflict over resources. When we try to mitigate this by allowing people to migrate between groups, and thus allowing enemies to become allies and allies enemies, this ingroup bias and overcontribution does not diminish. On the opposite: If anything, the empirical results suggest that allowing people to migrate between groups increases the amount of resources wasted on the conflict and does not change the bias in favor of the ingroup. However, we also find some encouraging effects: Even though the presence of the opportunity to migrate increases wasteful conflict expenditure, actual migrations do decrease the contributions to the conflict.

Linking the different results suggests that decreasing absolute or relative wages can be dangerous for a society as they result in more contested redistribution decisions. Olson (1982) identified that rent-seeking efforts can result in inefficiencies if coalitions form that primarily try to enhance the position of their own group members. In chapter 3 and 4 , we have seen that this in turn has the potential to strengthen group identities and fuel further wasteful conflict over resources, ultimately lowering social welfare. For policymakers this suggests that it is not sufficient to fix income inequalities through redistribution but that more attention should be spent on achieving equitable growth.

More research is needed to investigate how to reduce wasteful rentseeking. Promising approaches that are close to our attempt of making group boundaries permeable but in more cooperative settings were pursued by Chen et al. (2014) and Xu et al. (2020). Chen et al. (2014) found that priming a common group identity can lead to joint payoff maximization in coordination games whereas having salient different identities does not result in efficient coordination. Xu et al. (2020) show that having cooperative experience with an outgroup member before making an allocation decision can mitigate ingroup bias. If these approaches would work in a contest setting has not been investigated yet. The results from chapter 3 suggest that the competition over resources could induce a ingroup bias that could override a primed common identity or the effect of previous cooperative interactions. Future research should try address this and look into alternative ways to mitigate the overcontribution prevalent in group contests. 


\section{Bibliography}

Aaldering, H., Greer, L. L., Van Kleef, G. A., \& De Dreu, C. K. (2013). Interest (mis) alignments in representative negotiations: Do prosocial agents fuel or reduce inter-group conflict? Organizational Behavior and Human Decision Processes, 120(2), 240-250.

Abbink, K., Brandts, J., Herrmann, B., \& Orzen, H. (2010). Intergroup conflict and intra-group punishment in an experimental contest game. American Economic Review, 100(1), 420-447.

Abeler, J., Falk, A., Goette, L., \& Huffman, D. (2011). Reference points and effort provision. American Economic Review, 101(2), 470-92.

Ahn, T., Isaac, R. M., \& Salmon, T. C. (2011). Rent seeking in groups. International Journal of Industrial Organization, 29(1), 116-125.

Ahn, T.-K., Isaac, R. M., \& Salmon, T. C. (2009). Coming and going: Experiments on endogenous group sizes for excludable public goods. Journal of Public Economics, 93(1-2), 336-351.

Akerlof, G. A., \& Kranton, R. E. (2000). Economics and identity. Quarterly Journal of Economics, 115(3), 715-753.

Aksoy, B., \& Palma, M. A. (2019). The effects of scarcity on cheating and in-group favoritism. Journal of Economic Behavior \& Organization, $165,100-117$.

Alesina, A. F., \& Giuliano, P. (2009). Preferences for redistribution (tech. rep.). National Bureau of Economic Research.

Alesina, A., \& La Ferrara, E. (2005). Preferences for redistribution in the land of opportunities. Journal of Public Economics, 89(5-6), 897931.

Alm, J., Bloomquist, K. M., \& McKee, M. (2015). On the external validity of laboratory tax compliance experiments. Economic Inquiry, 53(2), 1170-1186.

Almås, I., Cappelen, A. W., \& Tungodden, B. (2020). Cutthroat capitalism versus cuddly socialism: Are americans more meritocratic and efficiency-seeking than scandinavians? Journal of Political Economy, 128(5), 1753-1788.

Alvaredo, F., Chancel, L., Piketty, T., Saez, E., \& Zucman, G. (2017). World inequality report 2018. World Inequality Lab. 
Andreoni, J. (1988). Why free ride?: Strategies and learning in public goods experiments. Journal of Public Economics, 37(3), 291-304.

Andreoni, J., \& Miller, J. (2002). Giving according to garp: An experimental test of the consistency of preferences for altruism. Econometrica, 70(2), 737-753.

Andreoni, J., Rao, J. M., \& Trachtman, H. (2017). Avoiding the ask: A field experiment on altruism, empathy, and charitable giving. Journal of Political Economy, 125(3), 625-653.

Armantier, O., \& Boly, A. (2013). Comparing corruption in the laboratory and in the field in burkina faso and in canada. The Economic Journal, 123(573), 1168-1187.

Bacine, N., \& Eckel, C. (2020). Trust and Betrayal: An Investigation into the Influence of Identity. Working Paper.

Baker, A., Larcker, D. F., \& Wang, C. C. Y. (2021). How much should we trust staggered difference-in-differences estimates? Available at SSRN 3794018.

Banuri, S., Eckel, C. C., \& Wilson, R. K. (2012). Deconstructing nepotism. Available at SSRN 2248187.

Baran, N. M., Sapienza, P., \& Zingales, L. (2010). Can we infer social preferences from the lab? Evidence from the Trust Game. NBER Working Paper No. 15654.

Bayer, P., \& Charles, K. K. (2018). Divergent paths: A new perspective on earnings differences between black and white men since 1940. Quarterly Journal of Economics, 133(3), 1459-1501.

BBC. (2016). Brexit: EU says no compromise on freedom of movement [http: / / www.bbc.com / news / world-europe-36659900 [Accessed: 30.11.2016]].

Bellemare, C., Bissonnette, L., \& Kröger, S. (2016). Simulating power of economic experiments: The powerBBK package. Journal of the Economic Science Association, 2(2), 157-168.

Bellemare, C., Kröger, S., \& Van Soest, A. (2008). Measuring inequity aversion in a heterogeneous population using experimental decisions and subjective probabilities. Econometrica, 76(4), 815-839.

Bénabou, R., \& Ok, E. A. (2001). Social mobility and the demand for redistribution: The POUM hypothesis. Quarterly Journal of Economics, 116(2), 447-487. 
Benjamin, D., Choi, J. Et al. (2010). Social identity and preferences. American Economic Review, 100(4), 1913-28.

Benz, M., \& Meier, S. (2008). Do people behave in experiments as in the field?-evidence from donations. Experimental Economics, 11(3), 268-281.

Blau, F. D., \& Kahn, L. M. (2017). The gender wage gap: Extent, trends, and explanations. Journal of Economic Literature, 55(3), 789-865.

Bloch, F. (2012). Endogenous formation of alliances in conflicts (M. R. Garfinkel \& S. Skaperdas, Eds.). In M. R. Garfinkel \& S. Skaperdas (Eds.), Oxford handbook of the economics of peace and conflict.

Bolton, G. E., \& Ockenfels, A. (2000). ERC: A theory of equity, reciprocity, and competition. American Economic Review, 90(1), 166193.

Brandts, J., Rott, C., \& Solà, C. (2016). Not just like starting overleadership and revivification of cooperation in groups. Experimental Economics, 19(4), 792-818.

Breza, E., Kaur, S., \& Shamdasani, Y. (2017). The morale effects of pay inequality. Quarterly Journal of Economics, 133(2), 611-663.

Cacault, M. P., \& Grieder, M. (2019). How group identification distorts beliefs. Journal of Economic Behavior \& Organization, 164, 63-76.

Camerer, C. (2015). The promise and success of lab-field generalizability in experimental economics: A critical reply to levitt and list (G. R. Fŕechette \& A. Schotter, Eds.). In G. R. Fŕechette \& A. Schotter (Eds.), The handbook for experimental economic methodology. Oxford, Oxford University Press.

Camerer, C., Babcock, L., Loewenstein, G., \& Thaler, R. (1997). Labor supply of New York City cabdrivers: One day at a time. Quarterly Journal of Economics, 112(2), 407-441.

Camerer, C., Dreber, A., Forsell, E., Ho, T.-H., Huber, J., Johannesson, M., Kirchler, M., Almenberg, J., Altmejd, A., Chan, T., Heikensten, E., Holzmeister, F., Imai, T., Isaksson, S., Nave, G., Pfeiffer, T., Razen, M., \& Wu, H. (2016). Evaluating replicability of laboratory experiments in economics. Science.

Cameron, A. C., \& Miller, D. L. (2015). A practitioner's guide to clusterrobust inference. Journal of Human Resources, 50(2), 317-372. 
Card, D., Mas, A., Moretti, E., \& Saez, E. (2012). Inequality at work: The effect of peer salaries on job satisfaction. American Economic Review, 102(6), 2981-3003.

Cason, T. N., Sheremeta, R. M., \& Zhang, J. (2012). Communication and efficiency in competitive coordination games. Games and Economic Behavior, 76(1), 26-43.

Chakravarty, S., Fonseca, M. A., Ghosh, S., \& Marjit, S. (2016). Religious fragmentation, social identity and conflict: Evidence from an artefactual field experiment in india. PloS one, 11(10), e0164708.

Chapman, G. B. (1996). Expectations and preferences for sequences of health and money. Organizational Behavior and Human Decision Processes, 67(1), 59-75.

Charness, G., \& Chen, Y. (2020). Social identity, group behavior, and teams. Annual Review of Economics, 12(1), 691-713.

Charness, G., \& Rabin, M. (2002). Understanding social preferences with simple tests. Quarterly Journal of Economics, 817-869.

Charness, G., Rigotti, L., \& Rustichini, A. (2007). Individual behavior and group membership. American Economic Review, 97(4), 13401352.

Charness, G., \& Yang, C.-L. (2014). Starting small toward voluntary formation of efficient large groups in public goods provision. Journal of Economic Behavior E Organization, 102, 119-132.

Chen, R. (2017). Coordination with endogenous groups. Journal of Economic Behavior \& Organization, 141, 177-187.

Chen, R., \& Chen, Y. (2011). The potential of social identity for equilibrium selection. American Economic Review, 101, 2562-2589.

Chen, R., Chen, Y., Riyanto, Y. E., Et al. (2020). Best practices in replication: A case study of common information in coordination games. Experimental Economics, 1-29.

Chen, Y., \& Li, S. X. (2009). Group identity and social preferences. American Economic Review, 99(1), 431-457.

Chen, Y., Li, S. X., Liu, T. X., \& Shih, M. (2014). Which hat to wear? impact of natural identities on coordination and cooperation. Games and Economic Behavior, 84, 58-86.

Chowdhury, S. M., Jeon, J. Y., \& Ramalingam, A. (2016). Identity and group conflict. European Economic Review, 90, 107-121. 
Clark, A. E., Frijters, P., \& Shields, M. A. (2008). Relative income, happiness, and utility: An explanation for the easterlin paradox and other puzzles. Journal of Economic Literature, 46(1), 95-144.

Clark, A. E., \& Oswald, A. J. (1996). Satisfaction and comparison income. Journal of Public Economics, 61(3), 359-381.

Cohn, A., Fehr, E., \& Goette, L. (2015). Fair wages and effort provision: Combining evidence from a choice experiment and a field experiment. Management Science, 61(8), 1777-1794.

Cohn, A., Fehr, E., Herrmann, B., \& Schneider, F. (2014). Social comparison and effort provision: Evidence from a field experiment. Journal of the European Economic Association, 12(4), 877-898.

Collier, P., \& Hoeffler, A. (2004). Greed and grievance in civil war. $O x$ ford Economic Papers, 56(4), 563-595.

Crawford, V. P., \& Meng, J. (2011). New York City cab drivers' labor supply revisited: Reference-dependent preferences with rational expectations targets for hours and income. American Economic Review, 101(5), 1912-1932.

Crosetto, P., Weisel, O., \& Winter, F. (2012). A flexible z-tree implementation of the social value orientation slider measure (murphy et al. 2011)—manual. Jena Economic Research Papers, 2012.

Croson, R. T. (1996). Partners and strangers revisited. Economics Letters, 53(1), 25-32.

Dana, J., Weber, R. A., \& Kuang, J. X. (2007). Exploiting moral wiggle room: Experiments demonstrating an illusory preference for fairness. Economic Theory, 33(1), 67-80.

Dechenaux, E., Kovenock, D., \& Sheremeta, R. M. (2015). A survey of experimental research on contests, all-pay auctions and tournaments. Experimental Economics, 18(4), 609-669.

DellaVigna, S., Lindner, A., Reizer, B., \& Schmieder, J. F. (2017). Reference-dependent job search: Evidence from Hungary. Quarterly Journal of Economics, 132(4), 1969-2018.

Dohmen, T., Falk, A., Huffman, D., Sunde, U., Schupp, J., \& Wagner, G. G. (2011). Individual risk attitudes: Measurement, determinants, and behavioral consequences. Journal of the European Economic Association, 9(3), 522-550. 
Dube, A., Giuliano, L., \& Leonard, J. (2019). Fairness and frictions: The impact of unequal raises on quit behavior. American Economic Review, 109(2), 620-63.

Eckel, C. C., \& Grossman, P. J. (2005). Managing diversity by creating team identity. Journal of Economic Behavior \& Organization, 58(3), 371-392.

Engel, C. (2011). Dictator games: A meta study. Experimental Economics, 14(4), 583-610.

Epper, T., Fehr, E., \& Senn, J. (2020). Other-regarding preferences and redistributive politics. University of Zurich, Department of Economics, Working Paper, (339).

Falk, A., \& Heckman, J. J. (2009). Lab experiments are a major source of knowledge in the social sciences. science, 326(5952), 535-538.

Fehr, E., \& Schmidt, K. M. (1999). A theory of fairness, competition, and cooperation. Quarterly Journal of Economics, 114(3), 817-868.

Fischbacher, U. (2007). Z-tree: Zurich toolbox for ready-made economic experiments. Experimental Economics, 10(2), 171-178.

Fisman, R., Jakiela, P., \& Kariv, S. (2017). Distributional preferences and political behavior. Journal of Public Economics, 155, 1-10.

Franzen, A., \& Pointner, S. (2013). The external validity of giving in the dictator game. Experimental Economics, 16(2), 155-169.

Gächter, S., Starmer, C., \& Tufano, F. (2015). Measuring the closeness of relationships: A comprehensive evaluation of the'inclusion of the other in the self'scale. PloS one, 10(6), e0129478.

Genesove, D., \& Mayer, C. (2001). Loss aversion and seller behavior: Evidence from the housing market. Quarterly Journal of Economics, 116(4), 1233-1260.

Goette, L., Huffman, D., \& Meier, S. (2006). The impact of group membership on cooperation and norm enforcement: Evidence using random assignment to real social groups. American Economic Review, 96(2), 212-216.

Goldin, C., \& Katz, L. F. (2007). Long-run changes in the wage structure: Narrowing, widening, polarizing. Brookings Papers on Economic Activity, (2), 135-168.

Goodman-Bacon, A. (2021). Difference-in-differences with variation in treatment timing. Journal of Econometrics. 
Greiner, B. (2015). Subject pool recruitment procedures: Organizing experiments with orsee. Journal of the Economic Science Association, 1(1), 114-125.

Griesinger, D. W., \& Livingston, J. W. (1973). Toward a model of interpersonal motivation in experimental games. Systems Research and Behavioral Science, 18(3), 173-188.

Grossman, Z., \& Van Der Weele, J. J. (2017). Self-image and willful ignorance in social decisions. Journal of the European Economic Association, 15(1), 173-217.

Grund, C., Harbring, C., \& Thommes, K. (2015). Public good provision in blended groups of partners and strangers. Economics Letters, $134,41-44$.

Grund, C., Harbring, C., \& Thommes, K. (2018). Group (re-) formation in public good games: The tale of the bad apple? Journal of Economic Behavior \& Organization, 145, 306-319.

Guala, F., \& Filippin, A. (2016). The effect of group identity on distributive choice: Social preference or heuristic? The Economic Journal.

Guyse, J. L., Keller, L. R., \& Eppel, T. (2002). Valuing environmental outcomes: Preferences for constant or improving sequences. Organizational Behavior and Human Decision Processes, 87(2), 253277.

Hartley, D. (2013). Urban decline in Rust-Belt cities. Federal Reserve Bank of Cleveland Economic Commentary, 2013-06.

Haslam, S. (2004). Psychology in organizations. SAGE Publications.

Herbst, D., \& Mas, A. (2015). Peer effects on worker output in the laboratory generalize to the field. Science, 350(6260), 545-549.

Herbst, L., Konrad, K. A., \& Morath, F. (2015). Endogenous group formation in experimental contests. European Economic Review, 74, 163-189.

Iriberri, N., \& Rey-Biel, P. (2011). The role of role uncertainty in modified dictator games. Experimental Economics, 14(2), 160-180.

Iriberri, N., \& Rey-Biel, P. (2013). Elicited beliefs and social information in modified dictator games: What do dictators believe other dictators do? Quantitative Economics, 4(3), 515-547.

Kahneman, D., \& Tversky, A. (1979). Prospect theory: An analysis of decision under risk. Econometrica, 47(2), 263-292. 
Karlan, D. S. (2005). Using experimental economics to measure social capital and predict financial decisions. American Economic Review, 95(5), 1688-1699.

Katz, E., Nitzan, S., \& Rosenberg, J. (1990). Rent-seeking for pure public goods. Public Choice, 65(1), 49-60.

Kerschbamer, R., \& Müller, D. (2020). Social preferences and political attitudes: An online experiment on a large heterogeneous sample. Journal of Public Economics, 182, 104076.

Kessler, J., \& Vesterlund, L. (2015). Handbook of experimental economic methodology (G. Fréchette \& A. Schotter, Eds.). In G. Fréchette \& A. Schotter (Eds.). Oxford University Press.

Klor, E. F., \& Shayo, M. (2010). Social identity and preferences over redistribution. Journal of Public Economics, 94(3), 269-278.

Konrad, K. A. (2009). Strategy and dynamics in contests. Oxford University Press.

Kőszegi, B., \& Rabin, M. (2006). A model of reference-dependent preferences. Quarterly Journal of Economics, 121(4), 1133-1165.

Kranton, R., Pease, M., Sanders, S., \& Huettel, S. (2020). Deconstructing bias in social preferences reveals groupy and not-groupy behavior. Proceedings of the National Academy of Sciences, 117(35), 21185-21193.

Krueger, A. O. (1974). The political economy of the rent-seeking society. American Economic Review, 64(3), 291-303.

Kuhn, P., Kooreman, P., Soetevent, A., \& Kapteyn, A. (2011). The effects of lottery prizes on winners and their neighbors: Evidence from the Dutch postcode lottery. American Economic Review, 101(5), 2226-47.

Lane, T. (2016). Discrimination in the laboratory: A meta-analysis of economics experiments. European Economic Review, 90, 375-402.

Levitt, S. D., \& List, J. A. (2007a). On the generalizability of lab behaviour to the field. Canadian Journal of Economics/Revue canadienne d'économique, 40(2), 347-370.

Levitt, S. D., \& List, J. A. (2007b). What do laboratory experiments measuring social preferences reveal about the real world? Journal of Economic Perspectives, 21(2), 153-174.

Levitt, S. D., \& List, J. A. (2008). Economics. homo economicus evolves. Science (New York, NY), 319(5865), 909-910. 
Liebrand, W. B., \& McClintock, C. G. (1988). The ring measure of social values: A computerized procedure for assessing individual differences in information processing and social value orientation. European journal of personality, 2(3), 217-230.

Loewenstein, G., \& Sicherman, N. (1991). Do workers prefer increasing wage profiles? Journal of Labor Economics, 9(1), 67-84.

Luttmer, E. F. (2005). Neighbors as negatives: Relative earnings and well-being. Quarterly Journal of Economics, 120(3), 963-1002.

Mago, S. D., Samak, A. C., \& Sheremeta, R. M. (2016). Facing your opponents: Social identification and information feedback in contests. Journal of Conflict Resolution, 60(3), 459-481.

Mas, A. (2006). Pay, reference points, and police performance. Quarterly Journal of Economics, 121(3), 783-821.

Milanovic, B. (2016). Global inequality: A new approach for the age of globalization. Cambridge, MA, Harvard University Press.

Müller, D. (2019). The anatomy of distributional preferences with group identity. Journal of Economic Behavior E Organization, 166, 785807.

Murphy, R. O., \& Ackermann, K. A. (2014). Social value orientation: Theoretical and measurement issues in the study of social preferences. Personality and Social Psychology Review, 18(1), 13-41.

Murphy, R. O., Ackermann, K. A., \& Handgraaf, M. (2011). Measuring social value orientation. Judgment and Decision Making, 6(8), 771781.

Ockenfels, A., \& Werner, P. (2014). Beliefs and ingroup favoritism. Journal of Economic Behavior E Organization, 108, 453-462.

Olson, M. (1982). The rise and decline of nations: Economic growth, stagflation, and social rigidities. Yale University Press.

Page, E. B. (1963). Ordered hypotheses for multiple treatments: A significance test for linear ranks. Journal of the American Statistical Association, 58(301), 216-230.

Pedroni, A., Frey, R., Bruhin, A., Dutilh, G., Hertwig, R., \& Rieskamp, J. (2017). The risk elicitation puzzle. Nature Human Behaviour.

Piketty, T. (2014). Capital in the twenty-first century century. Cambridge, MA, Harvard University Press. 
Piketty, T., Saez, E., \& Zucman, G. (2018). Distributional national accounts: Methods and estimates for the United States. Quarterly Journal of Economics, 133(2), 553-609.

Potters, J., \& Stoop, J. (2016). Do cheaters in the lab also cheat in the field? European Economic Review, 87, 26-33.

Qualtrics. (2005). Qualtrics survey software. Available from: www.qualtrics.com.

Riedl, A., Rohde, I. M., \& Strobel, M. (2016). Efficient coordination in weakest-link games. The Review of Economic Studies, 83(2), 737767.

Riedl, A., \& Smeets, P. (2017). Why do investors hold socially responsible mutual funds? Journal of Finance, 72(6), 2505-2550.

Riotta, G. (2012). Umberto eco: 'it's culture, not war, that cements european identity'. The Guardian. https: / www.theguardian.com/ world/2012/jan/26/umberto-eco-culture-war-europa

Rizzo, J. A., \& Zeckhauser, R. J. (2003). Reference incomes, loss aversion, and physician behavior. Review of Economics and Statistics, 85(4), 909-922.

Ross, W. T., \& Simonson, I. (1991). Evaluations of pairs of experiences: A preference for happy endings. Journal of Behavioral Decision Making, 4(4), 273-282.

Senik, C. (2009). Direct evidence on income comparisons and their welfare effects. Journal of Economic Behavior \& Organization, 72(1), 408-424.

Sheremeta, R. M. (2013). Overbidding and heterogeneous behavior in contest experiments. Journal of Economic Surveys, 27(3), 491-514.

Sheremeta, R. M. (2018). Behavior in group contests: A review of experimental research. Journal of Economic Surveys, 32(3), 683-704.

Sherif, M., Harvey, O. J., White, B. J., Hood, W. R., Sherif, C. W., Et al. (1961). Intergroup conflict and cooperation: The robbers cave experiment (Vol. 10). University Book Exchange Norman, OK.

Smith, A. C., Skarbek, D. B., \& Wilson, B. J. (2012). Anarchy, groups, and conflict: An experiment on the emergence of protective associations. Social Choice and Welfare, 38(2), 325-353.

Snowberg, E., \& Yariv, L. (2021). Testing the waters: Behavior across participant pools. American Economic Review, 111(2), 687-719. 
Sodha, S. (2016). Why is EU free movement so important? [https: / / www.bbc.com / news / world-europe-33655318 [Accessed: 27.08.2019]]. BBC.

Solnick, S. J., \& Hemenway, D. (1998). Is more always better?: A survey on positional concerns. Journal of Economic Behavior \& Organization, 37(3), 373-383.

Tajfel, H., \& Turner, J. (1985). The social identity theory of intergroup behaviour (S. Worchel \& W. Austin, Eds.). In S. Worchel \& W. Austin (Eds.), Psychology of intergroup relations. Chicago, Nelson Hall.

Tajfel, H. (1970). Experiments in intergroup discrimination. Scientific American, 223(5), 96-102.

Tajfel, H., \& Turner, J. C. (1979). An integrative theory of intergroup conflict. The Social Psychology of Intergroup Relations, 33(47), 74.

The Norwegian Nobel Committee. (2016). The Nobel Peace Prize 2012 to the European Union [http:/ /www.nobelprize.org/nobel_prizes/ peace/laureates/2012/press.html [Accessed: 30.11.2016]].

Tullock, G. (1967). The welfare costs of tariffs, monopolies, and theft. Economic Inquiry, 5(3), 224-232.

Tullock, G. (1980). Efficient rent seeking, In Toward a theory of the rentseeking society. Texas A \& M University Press.

Tversky, A., \& Kahneman, D. (1991). Loss aversion in riskless choice: A reference-dependent model. Quarterly Journal of Economics, 106(4), 1039-1061.

Wetherell, M. (1996). Group conflict and the social psychology of racism. Identities, Groups and Social issues, 175-238.

Wichman, C. J., \& Ferraro, P. J. (2017). A cautionary tale on using panel data estimators to measure program impacts. Economics Letters, 151, 82-90.

Xu, X., Potters, J., \& Suetens, S. (2020). Cooperative versus competitive interactions and in-group bias. Journal of Economic Behavior $\mathcal{E}$ Organization, 179, 69-79.

Young, A. (2019). Consistency without inference: Instrumental variables in practical application. Working Paper.

Zaunbrecher, H. W., \& Gagnon, N. (2020). Declining wages increase selfish redistribution in an environment with fixed income inequality. GSBE Research Memoranda, (023). 
Zaunbrecher, H. W., Heine, F., \& Riedl, A. (2021a). Conflict and migration: Mobility and social identity in group contests. Working Paper.

Zaunbrecher, H. W., \& Riedl, A. (2016). Social identity and group contests. Working Paper, (024).

Zaunbrecher, H. W., Williams, T., \& Riedl, A. (2021b). Social identity in the lab: A horse race between methods. Working Paper.

Zhang, L., \& Ortmann, A. (2014). The effects of the take-option in dictator-game experiments: A comment on engel's (2011) metastudy. Experimental Economics, 17(3), 414-420. 


\section{Impact Paragraph}

This thesis contributes to the understanding of social identity, group contests, inequality, and redistributive preferences. Chapter 3 advances the understanding of social identity and minimal groups by showing that the most consistent method to create an ingroup bias is to pit a people against an opponent. In our experiment, it is sufficient to explain participants that they compete against another group and to let them decide how hard they want to compete to trigger this ingroup bias. However, we can also show that how we measure this ingroup bias might have an effect on what we measure. As this can confound studies of social identity, researchers should carefully consider how their measurement method interacts with their treatment effects. Another contribution to the social identity literature comes from chapter 4 . We show that groups that compete against each other have a persistent ingroup bias in social preferences, even when the group composition changes and allies of today can be enemies of tomorrow. This suggests that the important factor for a strong social identity is not so much who my allies are or who the enemy is, but just that there is a common enemy. Recently, this was observable in protests against COVID regulations in Germany. While usually these groups have very little in common, the COVID regulations brought Hippies, Anti-Vaccers, and Neo-Nazis together to protest shoulder to shoulder against mask requirements and other restrictions that were passed by the German government.

We also contribute to the literature on overcontribution in contests. The literature generally shows that individuals contribute more than the amount that would maximise their expected profit in contests. This is even more pronounced in group contests. However, most studies use fixed groups that repeatedly compete against each other which is not always the case in the field. Employees change employers, football players change teams, and soldiers can defect to the enemy. We hypothesised that if the enemy of today can be a friend tomorrow and vice versa, individuals would contribute less to a group contest than if groups are fixed and the allies of today are also the allies of tomorrow. 
We show that people hardly decrease their competitive efforts when the group composition changes. When we switch group members with their opposition, the contest contributions only decrease slightly. When we let group members decide for themselves if they want to go to the opposing group, contest contributions actually increase.

Chapter 2 provides additional insights into drivers of social preferences. While it is well established that income inequality can explain preferences for redistribution, less is known about the effect of income changes on redistributive preferences. We investigate how wage decreases both in absolute terms and relative to the wage development of another person affect redistributive preferences. We find that decreasing absolute and relative wages result in more selfish redistribution choices. This effect is particularly pronounced for individuals who have a higher income than the person they are matched with and even holds when their own wage is stable and the low earner has a wage increase that puts them on an equal footing. As the pool of resources that the participants redistribute is actually generated by taxing their wages in a task that takes some effort to accomplish, the high earners effectively appropriate resources from the low earners to compensate themselves for the relative wage decrease. In practice this means that policies that aim to close earnings gaps between groups-such as between minorities and whites, and men and women-are likely to be met with resistance by members of the traditionally better off group who are averse to income trends inequality. Similarly, the decrease in generosity when faced with an absolute wage decrease can increase the rich's opposition to fiscal stimuli with redistributive aspects during economic downturns. As economic downturns usually have a particularly strong effects on the lower percentiles of the income distributions-and thus require even more redistribution than in normal times-this should be of special concern to policymakers. 


\section{Summary}

This thesis explores how social preferences affect individuals' behavior in situations in which people fight over, or have to propose how to distribute resources. Chapter 2 investigates the causal impact of income decreases on redistribution decisions, in an environment where the income inequality that may be created with wage changes is kept fixed. We both look at absolute decreases in wage and relative decreases compared to another person. We hypothesize that intra-personal and inter-personal decreases create dissatisfaction for an individual, and causes them to support redistribution policies that compensate them for the situation at the cost of others. We find evidence that people indeed propose more selfish distributions of income when they experience decreasing wages, even in cases in which the other person has actually earned overall less income then them.

Chapter 3 explores how to study social identity in the lab. Studying causal effects of social identity in a field setting is often not possible because it is usually not possible to directly manipulate or observe social identity in a natural settings. This is why both in economics and in social psychology, lab experiments have been used to create and study social identities in a controlled environment. We propose to use social value orientation tests as manipulation checks for social identity experiments and consider two additional aspect: We compare alternative methods to induce social identity and explore different ways to econometrically measure the strength of social identity. A one-shot group contest game is the only method to induce social identity no matter which measurement design is chosen. We also find that any social identity induction method successfully generates ingroup bias in a within-subject design which seem to be driven by salience effects.

Group contests, social identity, and migration are the topic of Chapter 4. In studies researching collective rent-seeking, group conflict, and group contests it is usually assumed that individuals belong to one group and that this group membership will remain unchanged. In the field, group 
boundaries are not as strict. Combatants switch sides and employees change employers. We introduce migration to a group contest experiment in the lab and investigate how it affects contest contributions and social identity. When we provide participants with a choice to stay or leave their group, we observe an increase in contest contributions. Making the choice to stay or leave exogenous leads to decrease in contributions, however this decrease is less pronounced. Ingroup bias in the migration treatments is only marginally lower than in the Control treatment at the start of the experiment but these treatment differences do not persist throughout the experiment. When people decide to switch groups, they mostly leave because of bad prospects of winning. 


\section{About the author}

Henrik W. Zaunbrecher was born in Aachen on March 19, 1990. He received his Bachelor of Science in Economics and Business Economics at Maastricht University in 2012. During the Bachelor program, he also spent a semester at the University of Glasgow. After internships at Deutsche Bank Private Equity and PricewaterhouseCoopers, which saw him complete projects in Germany, the United Kingdom, and Italy, he returned to Maastricht to pursue the Research Master in Economic and Financial Research. During

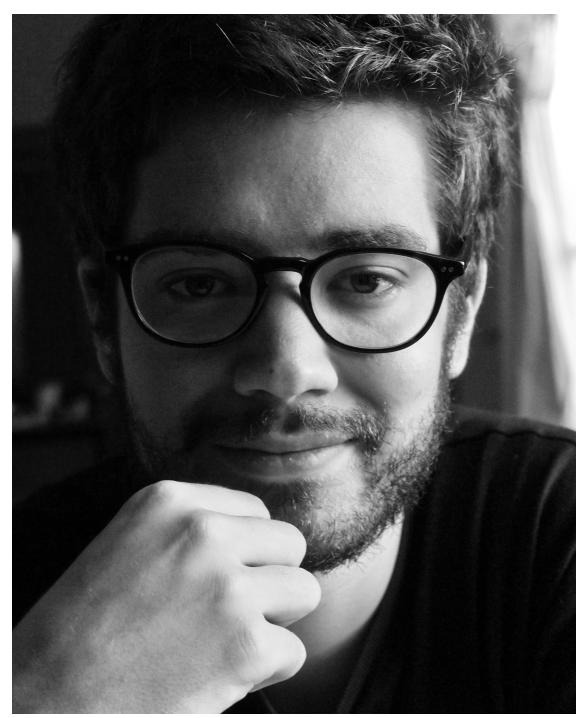
the research master he worked as research assistant for Arno Riedl on multiple projects in the field of behavioural economics and taught courses in Microeconomics. He successfully defended his Master thesis on "Social Identity and Conflict" in 2015 and subsequently started a PhD in Economics at the Department of Economics at Maastricht University. In 2018 he spent a trisemester as Visiting PhD at the Department of Economics at Oxford University. He also worked as a researcher for the Maastricht School of Governance from September 2019 till March 2020 to advise on experimental design and preference elicitation for a project in Kenya. 